DAC Guidelines and Reference Series

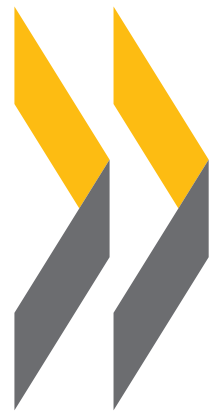

Accountability and Democratic Governance

ORIENTATIONS AND PRINCIPLES FOR DEVELOPMENT 



\title{
Accountability and Democratic Governance
}

\author{
ORIENTATIONS AND PRINCIPLES \\ FOR DEVELOPMENT
}

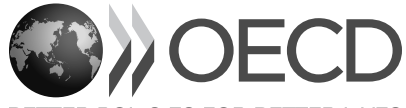


This work is published under the responsibility of the Secretary-General of the OECD. The opinions expressed and arguments employed herein do not necessarily reflect the official views of OECD member countries.

This document and any map included herein are without prejudice to the status of or sovereignty over any territory, to the delimitation of international frontiers and boundaries and to the name of any territory, city or area.

\section{Please cite this publication as:}

OECD (2014), Accountability and Democratic Governance: Orientations and Principles for

Development, DAC Guidelines and Reference Series, OECD Publishing.

http://dx.doi.org/10.1787/9789264183636-en

ISBN 978-92-64-18362-9 (print)

ISBN 978-92-64-18363-6 (PDF)

Series: DAC Guidelines and Reference Series

ISSN 1990-0996 (print)

ISSN 1990-0988 (online)

The statistical data for Israel are supplied by and under the responsibility of the relevant Israeli authorities. The use of such data by the OECD is without prejudice to the status of the Golan Heights, East Jerusalem and Israeli settlements in the West Bank under the terms of international law.

Photo credits: Cover @ Roman Dekan | Dreamstime.com.

Corrigenda to OECD publications may be found on line at: www.oecd.org/about/publishing/corrigenda.htm.

(c) OECD 2014

You can copy, download or print OECD content for your own use, and you can include excerpts from OECD publications, databases and multimedia products in your own documents, presentations, blogs, websites and teaching materials, provided that suitable acknowledgment of the source and copyright owner is given. All requests for public or commercial use and translation rights should be submitted to rights@oecd.org. Requests for permission to photocopy portions of this material for public or commercial use shall be addressed directly to the Copyright Clearance Center (CCC) at info@copyright.com or the Centre français d'exploitation du droit de copie (CFC) at contact@cfcopies.com. 


\section{Foreword}

Support for better governance and accountability has been a growing component of development co-operation in recent decades. The ways in which people hold their governments to account has been acknowledged and embedded in strong commitments agreed in the Paris Principles and the Busan Global Partnership for Effective Development Co-operation. There is growing recognition, too, that strengthening accountability is critical if we are to make women's rights and gender equality a reality. Research suggests that a lack of accountability can be more of an obstacle to progress in this area than, for instance, a lack of resources.

While this strengthened focus on supporting accountability is welcome, a new approach is needed. Donors have tended to replicate Western models, rather than going "with the grain" and tailoring their support to partner country settings. Development co-operation is inherently political. Outsiders cannot impose a one-size-fits-all global recipe for success in development. Only the people of a country can be the source of authority and legitimacy. What development co-operation can and should do is insist that governments help citizens participate in the development process, that fundamental rights be preserved, and that accountability mechanisms be in place through healthy institutions so that governments answer to the people and their representatives.

The merit of this study conducted by the DAC Network on Governance is its exploration of innovative ways to improve support to accountability in developing countries - while "doing no harm" and avoiding undermining inherently political processes. This study highlights the need for a more holistic, comprehensive approach to accountability support and more deference to partners as they evolve their systems, while external actors play the part of facilitators. It proposes a systems approach where all accountability actors take part in the country's own development script. Findings were based on analysis of accountability functions in processes such as service delivery in sectors and in public financial management. The report is grounded in evidence from in-depth case studies in Mali, Mozambique, Peru and Uganda. It also benefits from consultations with leading experts in the field. The result is an important set of findings for 
policy makers and programme managers, donors and partners from developing country accountability institutions who work every day to strengthen democratic governance.

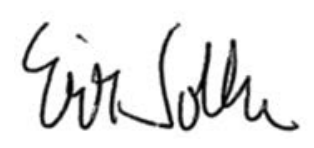

Erik Solheim

Chair

OECD Development Assistance Committee 


\section{Acknowledgements}

The OECD-DAC Governance Network (GOVNET) ran a collaborative programme on development co-operation and accountability with a range of leading donors, partner countries and experts on accountability. The aim was to take stock of experience, survey emerging trends, assess leading thinking and literature, and identify promising leads on how to better support accountability in developing countries - and to help avoid undermining or skewing local processes.

Part 1, the Orientations are based on a commissioned study written by Leni Wild from the UK Overseas Development Institute (ODI) with the support of Julie Leonard from the Pricewaterhouse Coopers (PWC). We would like to express our great appreciation to both authors for their excellent work. Particular thanks are due to Ben Dickinson and Alan Hudson who laid the foundations for a line of inquiry on how to improve support to accountability. We would also like to thank representatives of donor agencies, experts and DAC Secretariat staff who supported the development of this study and submitted written or oral comments on the manuscript. The GOVNET and the DAC Secretariat would like to gratefully acknowledge the support of the French Ministry of Foreign and European Affairs (Ministère des Affaires étrangères et européennes), the Swiss Agency for Development and Cooperation (SDC), the United States Agency for International Development (USAID), the United Kingdom (UK) Department for International Development (DFID) and IrishAid for their respective support for the case studies in Mali, Mozambique, Peru and Uganda. The GOVNET would like to also to acknowledge actors working on accountability issues in developing countries, individuals who engaged in the local consultations and donors in country offices for the time and energy spent facilitating research with local partners and/or country-level consultations in Mali (in particular the Alliance pour refonder la gouvernance en Afrique and the Secrétariat à l'harmonisation de l'aide SHA), Mozambique (in particular the Government of Mozambique), Peru (in particular the Agencia Peruana de Cooperación Internacional - APCI and Ciudadanos al dia), and Uganda (in particular the Government of Uganda). 
Part II, the Principles were developed through expert consultations to help identify emerging good practice for supporting elections, parliaments, political parties and media. We are especially grateful to Thomas Carothers (Carnegie Endowment for International Peace), Sina Odugbemi (World Bank, Communication for Governance and Accountability Programme), James Deane (BBC Media Action) and Greg Power (Global Partners and Associates) for their innovative inputs, leading thinking and knowledge in the development of these principles. We are thankful to the following organizations for their invaluable collaboration in jointly sponsoring expert consultations with the OECD DAC. For the seminar on electoral assistance, special thanks go to the United Nations Electoral Assistance Division, Department of Political Affairs (UN, DPA), the United Nations Development Programme (UNDP), UK DIFD, the European Commission (EC), and the European Commission - United Nations Development Programme Joint Task Force on Electoral Assistance (EC-UNDP JTF), for the seminar on political party assistance, International Institute for Democracy and Electoral Assistance (IDEA) should be thanked. The seminar on media assistance was held with the excellent engagement of the World Bank Institute, BBC Media Action and Internews.

The OECD-DAC Secretariat team was led by Lisa Williams with support from Ben Dickinson, Eduardo Gonzalez, Kjetil Hansen, Raundi Halvorson-Quevedo, Donna Muwonge and Deborah Alimi, under the supervision of Alexandra Trzeciak-Duval.

We thank them all. 


\section{Table of contents}

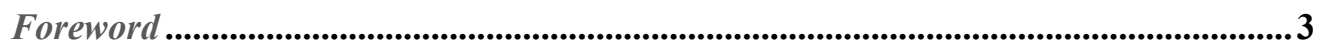

Acknowledgements...............................................................................................................................5

Acronyms and abbreviations ..................................................................................................... 11

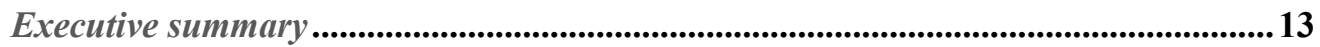

Part I Orientations on development co-operation, accountability and democratic governance.......................................................................................................... 17

Chapter 1 The role of accountability in promoting good governance.........................19

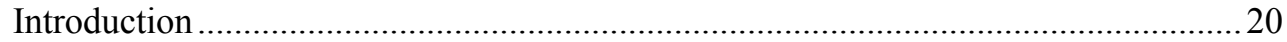

What is the role of development co-operation in domestic accountability?.................23

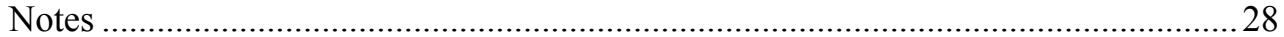

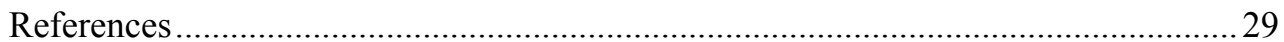

Chapter 2 Considering the political dimension, getting traction and achieving results.................................................................................................................31

Instruments and approaches to support domestic accountability: What can be

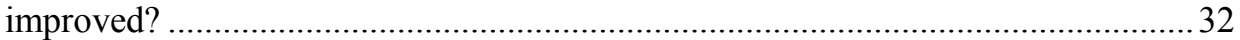

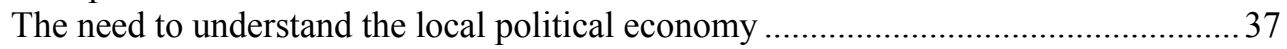

Imposing "best practices" on developing country contexts........................................... 40

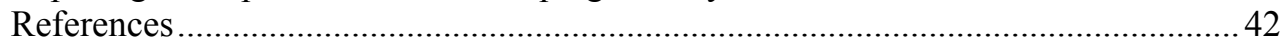

Chapter 3 Taking a systems-wide approach to accountability in developing

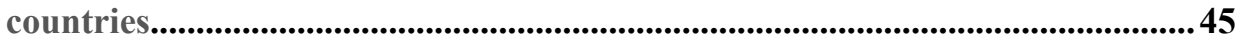

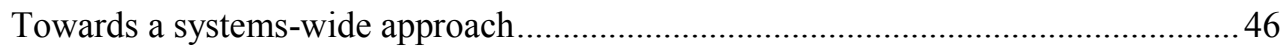

Implications of systems-wide approaches for policy and practice ………................... 48

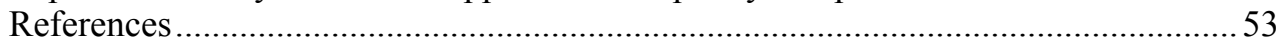

Chapter 4 Ensuring development co-operation helps rather than hinders

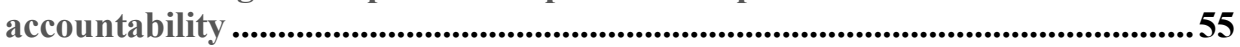

How to avoid skewing accountability in developing countries? .................................56

The links between aid and taxation in strengthening citizen-state relations .................56

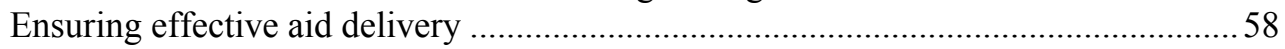

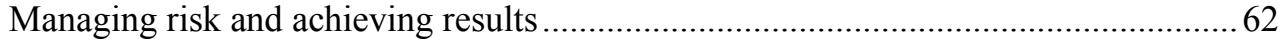

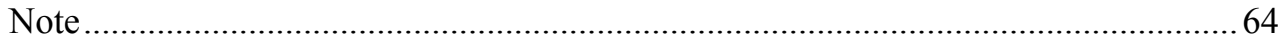

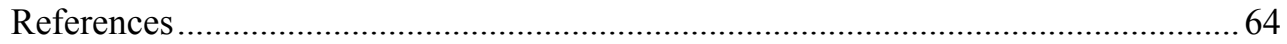

Chapter 5 Conclusions and strategic orientations to improve support to accountability ......................................................................................................................6 67 
Base support on realism and a political economy analysis ..........................................68

Take a systems approach to programme design ...........................................................6

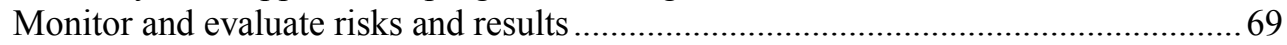

Part II Principles for assistance to accountability actors and institutions:

Elections, political parties, the media, parliament and revenue matters ...................71

Chapter 6 Introduction to principles for assistance to accountability .......................73

Chapter 7 Principles for international electoral assistance............................................. 79

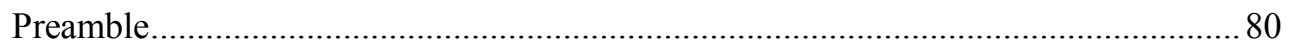

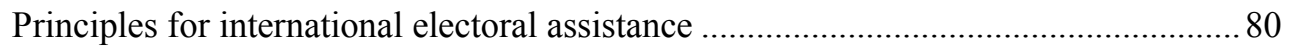

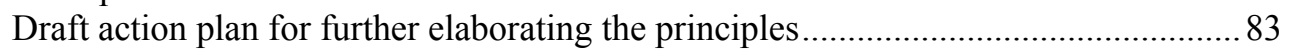

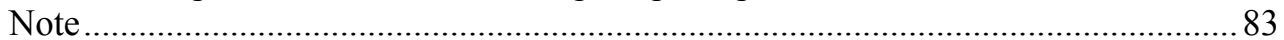

Chapter 8 Principles for political party assistance ....................................................85

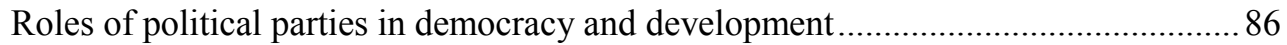

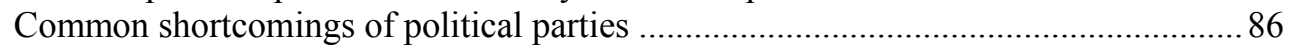

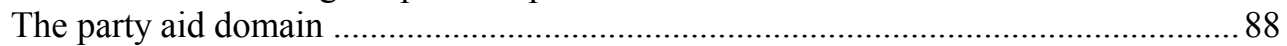

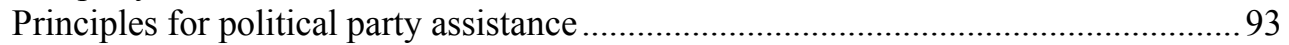

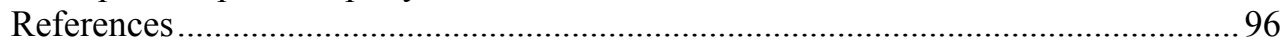

Chapter 9 Principles for media assistance...........................................................................97

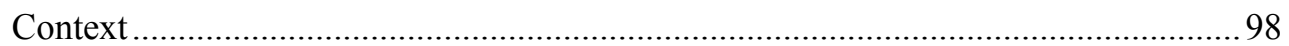

Media and accountability in the democratic public sphere .........................................99

The media, domestic accountability, and the role of development assistance ........... 100

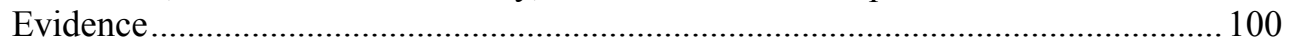

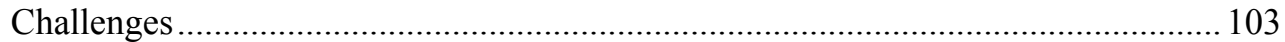

Strategic principles for media assistance............................................................... 104

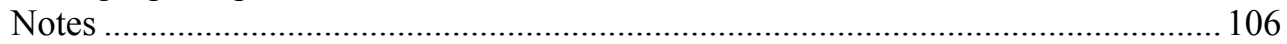

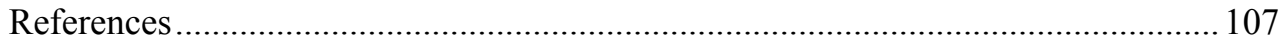

Chapter 10 Principles for parliamentary assistance...............................................111

Parliaments and domestic accountability ............................................................... 112

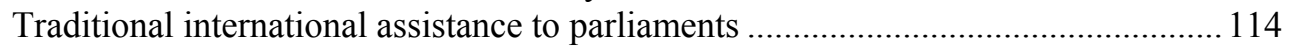

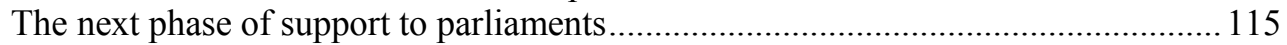

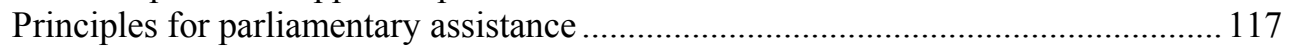

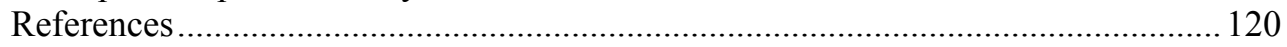

Chapter 11 Principles for supporting developing countries in revenue

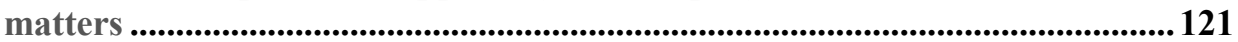

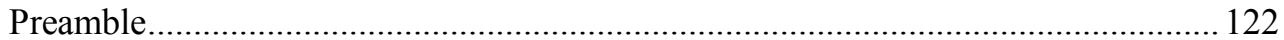

The principles for international engagement in revenue matters ............................ 123

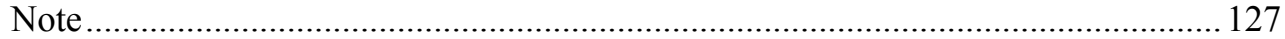


References

Annex A Recommendations from case studies in Mali, Mozambique, Peru and Uganda.....

Insights from Mali: Improving accountability support to education and decentralisation

Insights from Mozambique: Improving accountability support in budgeting and health.

Insights from Peru: Improving accountability support in budgeting and child nutrition.

Insights from Uganda: Improving accountability support in budget processes and service delivery

References 136

\section{Table}

Table 2.1. Examples of common methods and approaches to domestic accountability* 33

\section{Figures}

Figure 1.1. Development co-operation, domestic accountability and the wider

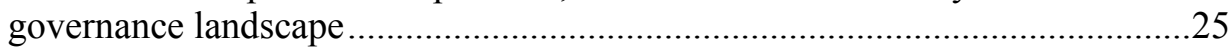

Figure 3.1. A model accountability system for budgeting

\section{Boxes}

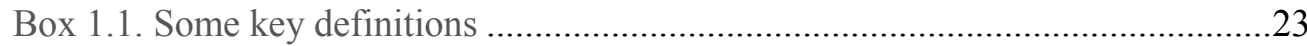

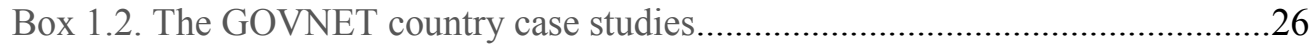

Box 2.1. Characteristics of consensual politics in Mali ..............................................35

Box2.2. The realities of citizen participation in Uganda's budget monitoring

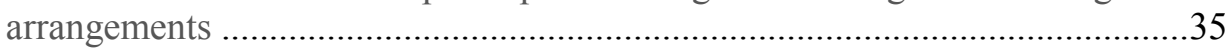

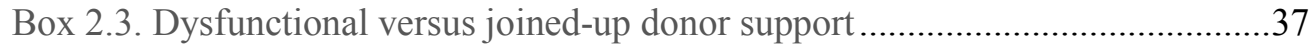

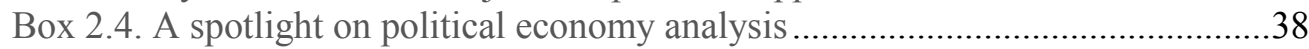

Box 2.5. Donors' work on political economy analysis: some examples ....................39

Box 2.6. Duplicating effort: misaligned donor support in Mali ...............................41

Box 3.1. The Poverty Observatory system in Mozambique.......................................48

Box 3.2. USAID support to political party platforms in Peru ...................................49

Box 3.3. The role of traditional chiefs in service delivery and taxation in Mali .......50

Box 3.4. Accountability support to multiple actors in Uganda and Mali .................52

Box 4.1. Promoting local awareness and support for taxation in Mali and Uganda 57

Box 4.2. Making information on aid more transparent: Some recent initiatives......60

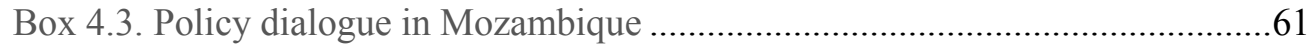


Box 4.4. Co-ordinated donor approaches for deepening democracy in Uganda ......63 Box 5.1. Core recommendations for programme design, implementation and

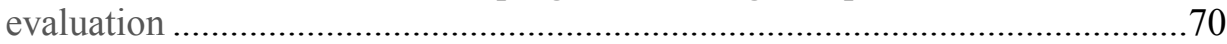

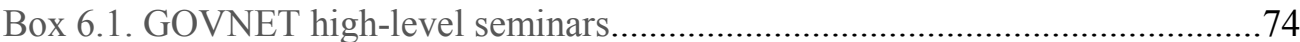

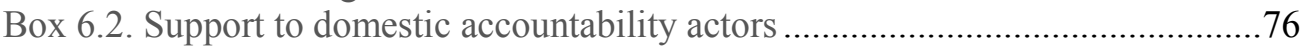

Box 9.1. Political accountability and information deficiencies...............................98

Box 9.2. Using the media to enhance accountability mechanisms............................99

Box 9.3. The power of the media as measured by the corrupt ..............................101

Box 9.4. When a radio programme turned the lights on in Angola..........................102 


\section{Acronyms and abbreviations}

CSO Civil society organisation

DAC Development Assistance Committee

DFID Department for International Development (United Kingdom)

GBS General budget support

GEO Global Electoral Organisation

GOVNET OECD-DAC Governance Network

IATI International Aid Transparency Initiative

ICT Information and communication technologies

IMF International Monetary Fund

MP Member of Parliament

NIMD Netherlands Institute for Multiparty Democracy

OAS Organization of American States

ODA Official development assistance

PFM Public financial management

Sida Swedish International Development Co-operation Agency

UNDP United Nations Development Program

USAID US Agency for International Development

USD United States dollar 



\section{Executive summary}

Development requires effective governance and institutions that can deliver. When institutions are held to account - whether by citizens or other state institutions - they deliver services better. Groundbreaking events like the 2011 Arab Spring attest to the importance of accountability in institutions for state-building and socio-political development. The development community will need to deepen its understanding of how it can best facilitate reform in line with societal demands and government capacity in the developing world.

Development assistance for accountability in developing countries has grown over the past decade in both diversity and volume. In this time various challenges have arisen:

- Developing countries' capacity has been strengthened - but unevenly.

- Information about government policy and actions is more readily available - but many people are still not sufficiently empowered or capable of acting on it.

- Citizens' voices have been amplified and, at times, have brought about change but they are still too often ignored, dispersed, or lost.

- Reforms have been agreed - but not always substantively implemented; transformational change remains the exception.

A new approach is needed. Donors have tended to replicate accountability models that have worked in their home country; but these may not work in developing countries. A tendency to focus on strengthening specific institutions has caused capacity imbalances, ignoring the potential for reform offered by broad-based local alliances. Donors also appear to have struggled to link support programmes to the realities of the wider political context or to the informal "rules of the game". And accountability may be undermined by too much aid: this can short-circuit the development of more legitimate, tax-based social and fiscal contracts between citizens and the state, encouraging stronger accountability to donors than to citizens.

There is growing recognition of the need for new approaches, but no broad agreement on what changed practice actually looks like. This orientations note therefore distils the findings of "work in progress" by the development co-operation and research 
communities to assess donor policy and practice in promoting accountability in developing countries.

\section{Strategic orientations}

\section{Understand the context}

The accountability picture is fundamentally shaped by local politics, power and incentives in both formal and informal spheres. Development co-operation activities should be based on an accurate reading of the political context of accountability institutions and processes. This means understanding the context before developing the most suitable programming options, rather than applying standardised "best practice". It also means building on institutions and processes that are already up and running effectively.

\section{Look at accountability systems as a whole}

Domestic accountability works as a system, involving a wide range of actors and institutions, information flows and patterns of influence and incentives. Balanced, targeted support depends on a fuller understanding of, and respect for, this accountability system. A "systems approach" can avoid supply-driven, top-down, blueprint assistance targeted only at formal accountability institutions. Instead, it can help donors to understand the specific country context and do much more to work "with the grain" of local institutions and reformers.

\section{Decide where to focus support}

Start with the core accountability problem to be addressed, then work back from it to the wider network of relevant actors and institutions. This reveals the stakeholders with whom to work, and means working with what is already in place, rather than supporting formal institutions which may not have adequate standing or influence. Develop creative approaches for supporting appropriate, "local" solutions.

\section{Ensure balanced support that works with the links in the system}

Working with wider accountability networks represents a significant shift for the development assistance community. Support broad-based alliances, where appropriate, which bring together a range of actors with common interests in reform. Provide support in ways that foster co-ordination and collaboration within specific communities. Carefully assess the causal factors and essential linkages that support reform. Clearly identify intra-dependencies and feedback loops among accountability actors that could be supported in the design phase.

\section{Manage risk and achieve results}

Strengthen the enabling environment to allow national ownership for domestic accountability to take root and flourish. Development assistance can facilitate information exchange and learning by bringing like-minded actors together. Realise the limits to the effectiveness of assistance on its own and accept that progress is likely to be 
non-linear and erratic. Develop more effective results frameworks to 1) identify realistic programme objectives at the outset; 2) correctly gauge and manage risks; and 3) understand better what works and why.

\section{Ensure development assistance does not undermine domestic accountability}

Be aware of the overall magnitude of development co-operation in a given country, and be attentive to dynamics that may subvert or undermine accountability relationships between governments and their citizens. Adhere to the Paris Principles on Aid Effectiveness. Be transparent about how much development co-operation is being given and what for; ensure that development assistance is fully integrated into public budget systems; and take a "portfolio" approach to development co-operation programming in specific countries, combining a range of different development co-operation approaches. Finally, use development co-operation instruments that improve donor co-ordination and collaboration, to divide labour across the local development assistance community.

\section{Conclusion}

These strategic actions will require some changes in donor approaches, including different roles, new forms of assistance, adjustments to funding modalities and new approaches to risk and results management. There will need to be wholesale shifts in behaviour by parts of the development assistance community, moving outside conventional comfort zones and changing reflexes towards new approaches to risk taking and political engagement. While this poses challenges which need to be understood, managed and implemented cautiously, the risks of not changing may be greater. 



\section{Part I}

\section{Orientations on development co-operation, accountability and democratic governance}





\section{Chapter 1}

\section{The role of accountability in promoting good governance}

This chapter introduces the objectives of the study. It reflects on how donors can improve their support to accountability in developing countries and on what needs to be done to change practice. It provides more clarity on the links and relationships among development co-operation and domestic accountability, presenting in a comprehensive way where donors stand in this area of development co-operation. 


\section{Introduction}

Strengthening domestic accountability has been a growing component of development assistance in recent decades. This is in line with the rising interest in improving governance - increasingly seen as the touchstone of successful development. The role of domestic accountability has been acknowledged in development co-operation effectiveness work and embedded in relevant commitments agreed at meetings in Paris, Accra and Busan. ${ }^{1}$ These trends underscore the widely-held view that efforts to address poverty and promote development are most effective when they are informed by a good understanding of the social, political and governance context in which they are implemented and where they support productive citizen-state relations. They build on calls from citizens, local organisations and accountability institutions in developing countries for greater voice and representation in development decision making and debates. They also build on longstanding efforts by the international community to support democracy.

However, domestic accountability support has not been as successful as hoped: while the capacity of accountability actors has been strengthened, important weaknesses and gaps have not been addressed. All too often this is due to inaccurate assumptions by donors about the nature of local democratic and institutional contexts and transitions. Inevitably, donors have tended to design programmes and projects that replicate institutions and processes characteristic of more developed countries, rather than provide support which builds on local realities to substantially improve accountability. ${ }^{2}$ This has resulted in too many examples of countries with all the trappings of accountability - but without most of its functionalities. ${ }^{3}$ As a consequence, accountability and governance support are now being challenged to "work with the grain" of societies and to develop country-specific strategies which represent the "best fit" rather than "best practice" (CFS, 2010).

While there is growing recognition of the need for new approaches, there is not yet broad agreement on what changed practice actually looks like. This orientations note therefore aims to provide more clarity, by focusing on three key themes:

1. The need for much more politically-informed, smarter development co-operation. The principles underpinning "best fit" rather than "best practice" approaches, and working with institutions as they are rather than as they should be, are broadly accepted. But actually putting this into policy and practice remains a challenge. This note looks at strategies for achieving more politically feasible 
and realistic approaches, including the implications for risk analysis and management.

2. A focus on the substantive functions or issues to address, not just the form, of domestic accountability. If support aims at strengthening accountability for budget processes, for example, it should start with the core accountability problem or function to be addressed and then develop creative approaches to work with rather than simply supporting formal institutions which may lack substantive influence. This means carefully analysing, and potentially re-considering, the use of different aid modalities overall and their interaction with domestic accountability.

3. An "accountability systems" approach, rooted in these core accountability functions. This emphasises the need to move beyond a narrow focus on supply-side versus demand-side accountability support, or a focus only on formal institutions, and instead to look more closely at the linkages among actors and how these can be strengthened over time. This programme has taken an important line of inquiry to unpack the hypothesis that donors tend to take a siloed approach and supply support to individual institutions of accountability - parliaments, the media and the like - without developing a greater understanding of how citizens interact in systems or processes of accountability, as noted below.

Changes in practice will require some changes in donor approaches, including different roles, new forms of assistance, adjustments to funding modalities and new approaches to risk and results management. It will involve wholesale shifts in behaviour by parts of the development assistance community, moving outside conventional comfort zones and reflexes towards new approaches to risk taking and political engagement. While this poses challenges which need to be understood, managed and implemented cautiously, the risks of not changing may be greater. Some agencies and organisations are already beginning to move in this direction, as suggested through case studies and research.

This note distils the findings of "work in progress" by the development co-operation and research communities to assess donor policy and practice in promoting domestic accountability. It is aimed at a range of practitioners, from those designing and implementing accountability programmes to those for whom accountability issues form a small part of their overall development assistance programming. It is also targeted at a wider interested audience, including civil society actors and citizens around the world who interact with donors working on accountability support. It represents a collective effort by the OECD-DAC Governance Network 
(GOVNET) in collaboration with partners in developing country accountability institutions - such as parliaments, civil society organisations, political parties, and the media - to explore citizen-state relations and to better understand the impact of development co-operation on domestic accountability.

The note has a particular focus on accountability for budget processes and service delivery. It is based on country case studies in Mali, Mozambique, Peru and Uganda (Annex A), a survey of leading analytical thinking and donor innovations in this field since mid-2009, and the findings of a series of special high-level international dialogues on how to best support domestic accountability institutions and processes. These led to the identification of key principles for supporting specific institutions that play critical roles in democratic governance, including elections, parliaments, the media, and political parties (Part II). ${ }^{4}$

At the same time, this note implicitly acknowledges that there is still much to learn about "good practice" in supporting domestic accountability. There is not much hard evidence about "what works and what doesn't work' on which to base definitive conclusions. Accordingly, this text does not provide the complete recipe for success - it is not a guidance note or a "how to" instruction manual - but rather reflects existing research and collective experience to offer some preliminary, yet promising, findings. It seeks to acquaint the reader with what a changed approach to domestic accountability support might look like, introducing some of the conceptual underpinnings, and making suggestions for specific implications for programming and implementation.

Part I begins with a brief overview of domestic accountability and related development assistance support, including a definition of the concept, historical trends and functional links between development cooperation, domestic accountability and the wider governance landscape. Chapter 2 then describes the important role that politics, incentives and informal institutions play in delivering functional accountability - and the concomitant need to integrate these factors into relevant development assistance efforts. Chapter 3 sets out the scope and method for moving towards a systems-wide approach to domestic accountability. The need for such an approach was a particularly promising finding from the GOVNET case studies, and is reinforced by emerging international research. The note then explores the "big picture" implications of development co-operation for domestic accountability processes and institutions (Chapter 4), and concludes with some core recommendations for the future (Chapter 5). Part II outlines specific principles for targeted, institution-specific support to key components of domestic accountability systems - electoral systems, parliamentary support, political party development and media assistance. 
Annex A provides short summaries of the findings of case studies in Mali, Mozambique, Peru and Uganda. The full case studies are available on the OECD website (www.oecd.org/dac/governance).

\section{What is the role of development co-operation in domestic accountability?}

At its core, accountability concerns the relationship between the rulers and the ruled (Schedler et al., 1999). As such, it is fundamentally about politics and power (Newell and Wheeler, 2006; Box 1.1).

\section{Box 1.1. Some key definitions}

Accountability - also referred to as "domestic" accountability for the purpose of this programme - involves three key concepts:

- Transparency: citizens have access to information about commitments that the state has made and whether it has met them.

- Answerability: citizens are able to demand that the state justifies its actions.

- Enforceability: citizens are able to sanction the state if it fails to meet certain standards.

Domestic accountability involves both a horizontal and a vertical dimension. The horizontal dimension is the system of checks and balances among the executive, the legislative and the judicial branches. Vertical accountability entails the relationships between citizens and decision makers, including the ability of citizens to influence political decision-making processes.

Domestic accountability therefore relates to the relationship between the state and its citizens, on whose behalf a state - particularly a state with aspirations of legitimacy - is expected to rule. This does not imply that these relationships are ever perfect - working to achieve domestic accountability and state legitimacy is a challenge for all countries. But how citizens relate to and perceive the state remains a crucial building block of state formation and development.

Source: Hudson and GOVNET (2009).

There is a growing body of knowledge on accountability and citizen-state relations in developing countries. In part, this stems from longstanding debate and interest in processes of democratisation and commitments to supporting governments to be more responsive to their citizens. In recent years, there has been growing recognition of the role that 
governance and accountability plays in development. Analytical inquiry and international discourse have focused on three core areas:

1. How to ensure transparency: long recognised as important both for efficient policy making and implementation (for example, ensuring accurate and verifiable budgeting) and for wider probity and legitimacy benefits;

2. How to encourage broad-based participation: strengthening the political involvement of citizens in decision-making processes and in mechanisms for legitimacy and control; and

3. How to improve the access and quality of public services to all citizens (World Bank, 2004).

These trends have contributed to a broad category of development cooperation aimed at strengthening accountability processes in developing countries. Such development co-operation generally involves support: 1) for the "supply side' of accountability (the state institutions such as audit institutions and parliaments - as well as broader governance reforms, for example to public procurement or financial management); or 2) for the "demand side' (i.e. to build citizen demand for more transparent, accountable government, often through strengthening civil society organisations or the media).

However, understanding of how development assistance can best be used to support domestic accountability institutions and processes remains limited. To shed light on these limitations, this note draws on four country case studies - Mali, Mozambique, Peru and Uganda (see Box 1.2 and Annex A). The case studies applied a schematic model of the key factors to be considered in understanding the complex relationship between development co-operation and domestic accountability (Figure 1.1; and see Hudson and GOVNET, 2009). 
Figure 1.1. Development co-operation, domestic accountability and the wider governance landscape

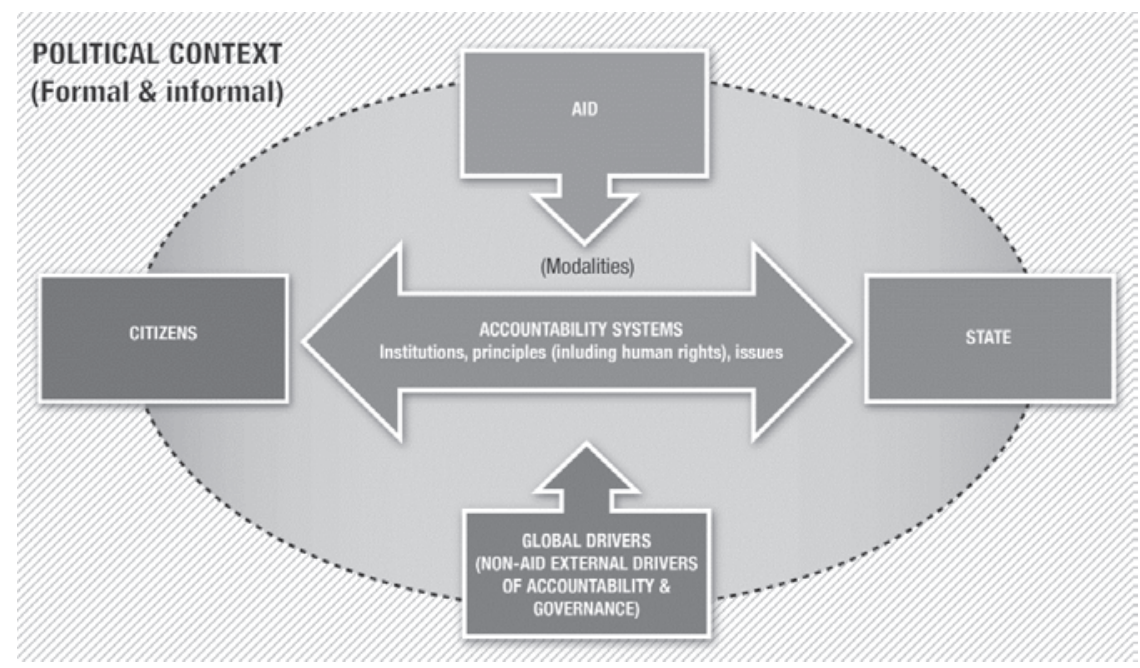

The model suggests that while development co-operation can and does shape the scope and capacity for domestic accountability, it is only one part of an accountability picture which is fundamentally shaped by politics, power and incentives - and that these operate across formal and informal spheres of activity.

The links and relationships among development co-operation and domestic accountability can be summarised as follows:

- Domestic accountability is about the relationship between the state and its citizens (people) and the extent to which the state is answerable for its actions.

- Domestic accountability is not led by any one actor, but rather brings together a variety of actors and institutions. For example, accountability for the oversight of public resources involves parliamentarians, national audit institutions, ministry of finance officials, and often monitoring by civil society groups and the media - it is not the responsibility of any one institution acting alone.

- Citizen-state relations are embedded in specific contexts, with their own political realities, incentive structures and configurations of formal and informal power.

- While there are many examples of development co-operation strengthening domestic accountability in positive ways, it can also 
undermine the development of more legitimate and sustainable taxbased social and fiscal contracts between citizens and the state (particularly where aid makes up an important share of government revenues).

- For a number of issues, there are several external global drivers of accountability and governance that affect accountability systems and which need to be taken into account when supporting accountability. These include regional or international agreements, standards and procedures (such as human rights frameworks or corruption instruments); and the activities of multinational firms whose actions are initiated and controlled, to varying degrees, beyond the borders of the country concerned.

Rather than seeing particular accountability actors (for instance, civil society, parliaments, or the media) as the entry point for the case studies, the model above prompted a focus on specific issues. This meant exploring the scope and dynamics of domestic accountability systems involving multiple stakeholders, and assessing how these systems worked to demand or deliver accountability in particular areas, such as in budget processes or service delivery. This approach helped to situate the analysis in a practical and concrete context (see Box 1.2).

\section{Box 1.2. The GOVNET country case studies}

GOVNET commissioned research into the realities of aid/development cooperation and domestic accountability through in-depth country case studies in Mali, Mozambique, Peru and Uganda, along with a series of multi-stakeholder dialogues. The countries' budget processes and service delivery (health and education) were selected as the two entry points for understanding domestic accountability systems in the case studies. Each study mapped existing accountability; held in-depth interviews with key actors from civil society, government and donor agencies; and conducted substantive background analysis of the impact of specific strategies and programmes. In parallel, GOVNET held a series of meetings and gathered expert advice in a multi-pronged effort to identify international good practice in supporting key domestic accountability institutions such as political parties, parliaments, civil society and the media. The case studies were led by individual GOVNET members, but designed to be as participatory as possible - a range of local stakeholders was involved in selecting the entry point issues and findings were validated through consultations and dialogue.

This series of case studies forms the evidence base for the broader reflection on how donors could better support accountability actors and institutions to improve citizen-states relations in partner countries. Each case study also represents a 
possible entry point for further work on implementing these orientations in-country and building up strong partnerships to move forward into the accountability and effective institutions agendas. The methodology may also be useful for analysing service delivery in sectors or budget processes in other countries.

Findings suggest that accountability does work as a system around several sectoral and organisational processes (budget processes, decentralisation, provision of health and education services, etc.) and donor support may be more strategic if it is designed for systemic approaches. The studies illustrate that donors supporting accountability in each of these contexts have tended to work in isolation and to target a single actor, risking unbalancing the system as a whole. Evidence thus shows that there is a need to go beyond traditional approaches to accountability assistance by building links between actors and constructing strong constituencies or coalitions of change that involve civil society, the media, parliaments, political parties and a range of other institutions. Hence the need for an "accountability systems approach" to allow for greater attention to these dynamics.

\section{Common themes}

While generalisations across the case studies are challenging, a number of common themes and actors emerged (see also Table 2.1) Budget processes can play an important role in strengthening domestic accountability, since citizens' views of the state and its legitimacy are shaped by the ways in which resources are spent, verified and evaluated. Most countries have a formal budget process through which the government creates and approves a budget. In practice it encompasses a cycle which can be broken down into four stages: formulation (usually led by the executive); approval (often via parliamentary debate and approval of budget); execution (implementation of policies within the budget, which can involve local government and non-state actors); and oversight (often by national audit institutions and parliaments).

Looking across the case studies, domestic accountability systems for budget processes involved a range of actors playing a variety of roles at different points in the cycle. They included: the government (political leaders, key ministries such as finance); parliament (often parliamentary committees such as the Public Accounts Committee and the Budget Committee); national audit institutions; civil society organisations (for example conducting budget monitoring); media; and local government. Most of the countries (e.g. Mali, Peru and Uganda) share a common focus on participatory budgeting processes. Moreover, strong emphasis was placed by donors and governments on improving budget transparency, as shown in an emphasis on comparative ratings surveys such as the Open Budget Index. The budget process has been a key area of focus for donor support to country systems and for reforms to the public sector. For instance, the Public Expenditure and Financial Accountability (PEFA) programme - widely supported by the donor community - has substantially progressed knowledge and understanding about. how to strengthen country public financial management (PFM) systems.

Service delivery also plays an important role in shaping citizen-state relations, as citizens come into contact with the state - especially in its local forms - most 
directly through their use of state-provided services (such as health and education) (Hudson and GOVNET 2009; Eldon and Gunby, 2009). In practice, service delivery chains can involve a range of providers and actors both inside and outside of government. The domestic accountability system for service delivery often includes: the government (political leadership, key ministries such as ministries of finance, as well as relevant line ministries in health, education and so on); parliament (including relevant committees); service providers (state providers, non-state providers, for-profit providers); CSOs (engaged in service delivery or monitoring), national audit institutions; and user groups or professional associations (e.g. doctors, teachers). Donor support in this area commonly focuses on strengthening either the supply side (i.e. state responsiveness to citizen public service needs and state capacity to plan and deliver key services) or the demand side (i.e. strengthening citizen demands on the state to improve service delivery).

The GOVNET case study assessments suggest that while there may have been some identifiable progress in terms of strengthened capacity and capabilities of some accountability actors around these issues - such as improvements to national audit institutions or to government transparency there remain a number of weaknesses, gaps and deficits that are not being addressed. A more informed, fuller understanding of the accountability system is essential in order to provide balanced, targeted support to improve institutional capacity and processes while still respecting the inherent dynamics of the system. At the same time, greater clarity is needed about the political economy drivers which shape the relationships among actors within those systems. These two issues are explored in greater depth in the following sections.

\section{Notes}

1. The Paris Declaration on Aid Effectiveness (OECD, 2005/2008) calls for “enhancing donors' and partner countries' respective accountability to their citizens and parliaments for their development policies, strategies and performance". The Accra Agenda for Action (OECD, 2005/2008) goes further, making specific reference to the role of parliaments, local authorities and civil society organisations in developing and monitoring development plans and objectives in developing countries. And most recently in the Busan Partnership for Effective Development Cooperation (Fourth High Level Forum on Aid Effectiveness, 2011), the international community agreed to accelerate and deepen implementation of their commitments to strengthen the capacity and accountability roles of parliaments and local governments.

2. This borrows from thinking in Pritchett et al. (2010), which examines administrative capabilities of the state. 
3. See for example CFS (2010); Booth (2011); Rocha Menocal and Sharme (2008); Pritchett et al. (2010).

4. GOVNET good practice notes for supporting civil society institutions and judicial systems are forthcoming.

\section{References}

Booth, D. (2011), "Governance for Development in Africa: Building on What Works", Policy Brief 1, Africa Power and Politics Programme, Overseas Development Institute, London, available at www.institutionsafrica.org/filestream/20110406-appp-policy-brief-01-governance-fordevelopment-in-africa-building-on-what-works-by-david-booth-april2011.

CFS (Centre for the Future State) (2010), An Upside Down View of Governance, Institute of Development Studies, University of Sussex, Brighton.

Fourth High Level Forum on Aid Effectiveness (2011), The Busan Partnership for Effective Development Co-operation. Outcome document of the Fourth High Level Forum on Aid Effectiveness, Busan, Korea, 29 Nov-1 Dec, available at www.aideffectiveness.org/busanhlf4/images/stories/hlf4/OUTCOME_D OCUMENT_-_FINAL_EN.pdf

Hudson, A. and GOVNET (2009), "Background Paper for the Launch of the Workstream on Aid and Domestic Accountability", OECD DAC GOVNET, OECD, Paris.

Newell, P. and J. Wheeler (2006), "Taking Accountability into Account", in Rights, Resources and the Politics of Accountability, Zed Books, London.

OECD (2005/2008), Paris Declaration on Aid Effectiveness and the Accra Agenda for Action, OECD Publishing, Paris.

Pritchett, L., M. Woolcock and A. Andrews (2010), "Capability Traps? The Mechanisms of Persistent Implementation Failure", Working Paper, $\mathrm{N}^{\circ} 234$, Centre for Global Development, Washington, DC.

Rocha Menocal, A. and B. Sharma (2008), Joint Evaluation of Citizen's Voice and Accountability: Synthesis Report, Department for International Development, London.

Schedler, A., L. Diamond et al (eds.) (1999), The Self-restraining State: Power and Accountability in New Democracies, Lynne Rienner, London. 
World Bank (2004), World Development Report: Services Work for Poor People, The World Bank, Washington, DC. 


\section{Chapter 2}

\section{Considering the political dimension, getting traction and achieving results}

Drawing on lessons from the case studies and emerging trends, this chapter puts the emphasis on the weaknesses and gaps of donors' current approaches to supporting accountability. It underlines the fundamental objective of development co-operation for accountability, which is to take a political economy analysis, do no harm and to strengthen not only the forms, but also the functions, of accountability. 
A growing body of analytical research and country experience highlights the importance of politically-informed, "smarter" development co-operation approaches. Paradoxically, standard donor approaches that replicate good practice and success stories generated elsewhere may more often than not result in bad practice. This is because without a nuanced understanding of the local context and realpolitik, technocratic solutions are likely to be inappropriate and/or ineffective. The emphasis instead should be on taking context as the starting point, and developing programming options which represent the best fit rather than standardised best practice. This is particularly important for support to domestic accountability, which inevitably involves interaction with political actors and processes. However, changing policy and practice remains a challenge. This section looks at some of the options for realising these changes, with a particular focus on embedding political economy analysis in programme design and working to support accountability functions - not just the particular forms it can take or the institutions it may involve.

\section{Instruments and approaches to support domestic accountability: What can be improved?}

Table 2.1 sets out a simplified overview of some of the common methods and approaches used to support domestic accountability across the four country cases - these are typical examples of the type of development assistance provided to this aspect of governance.

Support is commonly provided through different types of technical assistance and capacity development initiatives, often to specific actors or institutions such as civil society organisations or national audit institutions. This typically involves training, tailored advice from consultants or external experts, as well as support for specific activities (reporting, campaigning, etc.). In Peru and Uganda, some support is targeted at improving transparency and access to information; in Mali and Mozambique, there is a broader focus on community outreach and mobilisation to improve citizen demand. Institutional support is provided for national audit bodies, parliament and civil society organisations. Recent innovations involve support for policy dialogue, such as civil society forums or political party forums that bring different actors and organisations together; as well as forms of peer ranking, such as the use of score cards or ranking indices to compare accountability performance. 


\section{Table 2.1. Examples of common methods and approaches to domestic accountability*}

\begin{tabular}{|c|c|c|}
\hline Types of support & Targeted actors/institutions & Main activities \\
\hline Technical assistance & $\begin{array}{l}\text { Parliament, national audit } \\
\text { institutions, government ministries } \\
\text { and agencies }\end{array}$ & $\begin{array}{l}\text { Tailored analysis, use of } \\
\text { consultants/external experts as } \\
\text { advisers }\end{array}$ \\
\hline Capacity development & $\begin{array}{l}\text { CSOs, parliament, political } \\
\text { parties, national audit institutions }\end{array}$ & $\begin{array}{l}\text { Training, including workshops, action } \\
\text { training and training of trainers, } \\
\text { support for advocacy/campaigning, } \\
\text { support for specific activities } \\
\text { e.g. budget monitoring or analysis }\end{array}$ \\
\hline $\begin{array}{l}\text { Transparency and access } \\
\text { to information }\end{array}$ & $\begin{array}{l}\text { National audit institutions, CSOs, } \\
\text { media }\end{array}$ & $\begin{array}{l}\text { Support to improve reporting and } \\
\text { dissemination (e.g. audit reports), } \\
\text { support for "watchdog" efforts }\end{array}$ \\
\hline Community outreach & cSOs & $\begin{array}{l}\text { Community sensitisation, use of } \\
\text { plays/songs/campaigns }\end{array}$ \\
\hline Community monitoring & csOs & $\begin{array}{l}\text { Use of citizen scorecards, } \\
\text { community monitoring }\end{array}$ \\
\hline Policy dialogue & $\begin{array}{l}\text { CSOs, political parties, the } \\
\text { executive }\end{array}$ & Support for policy forums/meetings \\
\hline Institutional support & $\begin{array}{l}\text { CSOs, national audit bodies, } \\
\text { parliament }\end{array}$ & Core funding, provision of equipment \\
\hline Peer ranking & $\begin{array}{l}\text { Parliament, state accountability } \\
\text { institutions }\end{array}$ & Score cards, indices \\
\hline Peer support & $\begin{array}{l}\text { Political parties, executive and } \\
\text { government agencies }\end{array}$ & $\begin{array}{l}\text { Exchange visits, coaching, twinning } \\
\text { arrangements. }\end{array}$ \\
\hline
\end{tabular}

Note: *The case studies focused specifically on accountability in budget processes, service delivery and decentralisation: thus, the forms of accountability support discussed below are relevant to those issues only.

\section{The gap between theory and reality}

In the governance arena, development assistance is typically underpinned by a number of "theories of change" or assumptions about how reform will happen. This was very much in evidence in the GOVNET case studies. Programme implementation necessarily involved a theory about "what might cause change", even though that theory may not have been explicit (Pawson and Tilley, 1997). This provided the hypothesis for how, and for whom, a given programme might "work" - thus providing a legitimate basis or rationale for carrying out the planned assistance.

While the case studies all represented very different contexts, many of the key objectives and theories about how change was to happen - as a result of donor support - were quite consistent. For example, the rationale for support to demand-side accountability was that increasing citizens' 
voices would make public institutions more responsive to citizen needs or demands and, in turn, make them more accountable. Common approaches to decentralisation assumed it would reduce the space between citizens and decision makers, enhance citizen voice and strengthen accountability relationships between the two groups of actors. Similarly, increased transparency in state decision making was assumed to facilitate greater accountability to citizens.

While these "theories of change" seem reasonable, the case studies reveal that programming assumptions were, at times, far removed from power and political realities on the ground, and which were not able to adequately address the interaction between formal and informal political processes. The overall emphasis was on technical, rather than political, engagement, and so did not relate to functional accountability dynamics in these countries. Local donor communities appeared to have had great difficulties in coming to terms with the overlay of politics, power relationships and incentive structures that affected governance and accountability and within which their development co-operation approaches and instruments needed to function and achieve results.

For example, the majority of support to parliament involved technical assistance to draft bills; expert analysis; and support to strengthen parliaments' representational, legislative and oversight functions. In general, these generic forms of capacity development or technical assistance have not effectively engaged with the wider political context. At times, they have struggled to link support programmes to the realities of the wider political context or to the informal "rules of the game". In Mali, for instance, support to parliament does little to engage with informal accountability systems or traditions of consensual politics that challenge some of the prescribed roles for parliament in the formal budget process (Box 2.1).

Over the past decade, Uganda has benefitted from support for budget monitoring (largely conducted by national CSOs) and for encouraging more participatory planning processes. However, a number of historical legacies and structural constraints contradict current assumptions about how accountability systems operate. For example, the dominance of neo-patrimonial practices in Uganda means that its political system is reliant on the generation and distribution of substantial patronage resources, which flow outward from the centre, but also reach down to local levels (Box 2.2; Booth and Golooba-Mutebi, 2009). Some have argued that attempts to build accountability mechanisms in Uganda therefore face particular challenges when they make "...over-optimistic and simplistic assumptions about the feasibility and utility of popular participation in the context of a weak state with a history of political oppression and poor service provision" (Golooba-Mutebi, 2005:168-169). 


\section{Box 2.1. Characteristics of consensual politics in Mali}

Past experiences of colonialism and dictatorship, combined with ethnic and regional diversities, have contributed to a political culture in Mali which emphasises decision by consensus. This is reflected in the dominance of "cousinage" relations, in which patterns of political interaction are mediated through reference to familial relations, or the use of so-called "joking relationships" which allow conflict or tensions to be voiced in humorous rather than confrontational ways. These all potentially challenge models which assume that political competition is a part of decision making (for example as in many multi-party systems). Moreover, this culture of consensus creates strong informal accountability relationships within and between actors which can be overlooked by donors. Few aspects of donor support to parliament in Mali have engaged substantively with these realities.

Source: OECD (forthcoming), Donor Support to Domestic Accountability: Budget Processes and Service Delivery in Mali, OECD, Paris.

\section{Box 2.2. The realities of citizen participation in Uganda's budget monitoring arrangements}

The GOVNET case study identified a number of historical and structural features which limited citizens' substantive participation in planning and overseeing budgets. These included:

- practices of vote-buying and patronage, which complicated the ability of citizens to hold officials to account - instead, citizens reward politicians (with their votes) for the benefits they can expect to receive (in terms of preferential treatment or access to particular resources);

- political cultures and histories which reinforce obedience and deference to those in authority (see also Golooba-Mutebi, 2005); and

- widespread apathy and cynicism concerning public affairs, particularly the use of public resources.

This meant that budget conferences at district levels, for example, were mere "rituals" with little substantive space for citizens and civil society groups to contribute or influence planning decisions and little appetite on the part of citizens themselves to engage.

Furthermore, even though the weakness of political parties (particularly in relation to accountability) was readily evident across all the GOVNET case studies - characterised by poor links to citizens, weakly 
institutionalised structures, fragmented opposition and a lack of robust legal and regulatory frameworks - donors' standard political party support (where it existed) often focused on technical assistance which did little to engage with these deeper, structural challenges.

The case studies also revealed weaknesses in donor "standard operating procedures" and "comfort zones" that often resulted in either potentially dysfunctional or ineffective support (Box 2.3):

- Donors tended to provide significant resources to some actors or institutions (CSOs) but relatively smaller amounts to other actors (parliaments and political parties). Such "unbalanced" support tends to further skew disparities in capacity and influence across the wider accountability system. In countries like Uganda and Mali, for example, support to formal CSOs may actually crowd out support to other organisations (including community-based groups, social movements, religious groups, trade unions, professional associations, etc.). This creates accountability systems in which some actors and institutions have growing capacity (such as state accountability institutions including national audit offices, CSOs), while other parts of that system remain chronically weak (such as grassroots organisations, parliamentarians, or judiciaries). Recent research reinforces case study conclusions by showing that similar imbalances inhibit the effectiveness of donor support for other accountability functions, such as gender-sensitive policy making (Castillejo, 2011: 14, DFID, 2011: 4-14).

- Donors can tend to overestimate the ability of one set of actors (such as CSOs) to affect change on their own. In Uganda, Mali and elsewhere, significant support has been directed to CSOs engaged in budget monitoring for service delivery - but rarely in ways which facilitated connections to other processes, such as formal audit processes, parliamentary investigations, or political parties' policy development. Without this, these CSOs are constrained in their ability to gain traction and realise significant changes. Moreover, working with particular actors or institutions largely in isolation may in fact reinforce already weak links between institutions. For example, across the GOVNET case studies there was a common lack of sharing of relevant information among different accountability actors. This compromised scrutiny and oversight roles (e.g. audit institutions, parliaments, civil society, the media), undermining the accountability system as a whole. 


\section{Box 2.3. Dysfunctional versus joined-up donor support}

In Uganda, national urban-based CSOs were found to be competing against one another for donor funding rather than co-operating to support change.

In Mozambique, a survey conducted by the Foundation for Community Development found that CSOs competed for the same donor funds, which discouraged co-ordination, collaboration and coalition-building - in turn weakening their individual and collective advocacy work.

In Mali, donors recognised a similar shortcoming in their funding mechanisms and launched a multi-donor fund in 2009, the Programme d'Appui aux Organisaions de la Société Civile (PAOSC), designed to support networks and coalitions of CSOs around specific themes, rather than funding individual organisations.

\section{The need to understand the local political economy}

There is a real need for the donor community to invest more in political economy and governance analysis. An accurate reading of the political context underpinning and continuously shaping accountability institutions and processes is a critical first step in designing development co-operation activities. Political economy analysis - an approach which can reveal the incentives, power dynamics and relationships among different stakeholders and groups - is indispensible for understanding how domestic accountability systems operate in practice and the relative capacities, power and incentives of the different actors and institutions it involves (see Box 2.4).

Sound analysis of the power relationships and incentives structures of key actors can for instance be crucial in designing effective support to domestic accountability for gender-sensitive policy-making because women's rights are often tied up with conflict over wider patterns of power distribution. Recent research in Burundi thus found that a key achievement of lobbying by women's organizations - a draft bill giving women inheritance rights and providing for patrimonial land to be shared between sons and daughters - was subsequently blocked by government not mainly on the grounds of 'tradition' but because of concerns that its implementation would intensify land pressure. This, in turn, would threaten elite practices of land distribution for patronage and risk causing insecurity (Castillejo, 2011: 9/10, Kazovivo, 2011). The lesson for donors is that power and political analyses are a crucial first step in understanding challenges and opportunities for strengthening accountability systems. 
A growing number of development agencies recognise the need to develop more politically-informed strategies underpinned by analysis. But translating this priority into changed policy and practice remains a challenge: few donors invest in political economy analyses, and fewer still build their assistance around it. Newer generations of analysis (such as problem-driven political economy approaches) seem to be particularly promising, as they are more rooted in addressing operational challenges and issues (Box 2.4).

\section{Box 2.4. A spotlight on political economy analysis}

Political economy is "...concerned with the interaction of political and economic processes in a society: the distribution of power and wealth between different groups and individuals, and the processes that create, sustain and transform these relationships over time" (Collinson, 2003).

At its core, political economy analysis seeks to understand the power dynamics and incentives affecting key actors. The analysis is necessarily context-specific so avoids the use of standard models or blueprints that are more technocratic in approach and apply "best practice" solutions which may be ill-suited to local contexts.

Politically-informed approaches to domestic accountability can develop more realistic, incremental action grounded in countries' political realities. In particular, they highlight the need to pay close attention to the interaction between formal and informal rules and institutions.

Political economy analysis has been criticised for being insufficiently grounded in operational contexts or irrelevant to programming realities. It has also been criticised for focusing on what has not worked in the past, rather than suggesting ways for moving forward. In recent years, problem-driven forms of political economy analysis have been developed to address these critiques. This problem-driven analysis begins with the identification of a particular problem, opportunity or vulnerability (often arising from specific operational challenges). This process narrows the scope of the analysis, allowing researchers to "drill down" to understand which institutional arrangements are most relevant for influencing the particular problem. Specific and feasible options for reform can then be identified, which either seek to work within existing spaces for reform or else attempt to increase that space. These are often likely to be "second-best" options, rather than "first-best, textbook" solutions.

Sources: Collinson (2003); Fritz et al. (2009); Booth and Golooba-Mutebi (2009); Wild and Foresti (2011). 


\section{What prevents action based on political economy analysis?}

As well as the need to underpin governance support with a careful assessment of local conditions and politics, donors also need an informed approach to risk management, and a willingness to stay the course. Greater realism is also required, both about the reform space for accountability in each country and the longer timeframes involved in realising transformational institutional reform (World Bank, 2011).

Change happens slowly and effective support is often based on multi-year commitments. In Mali and Uganda, funding relationships of up to 10 years were able to build strong relationships between local partners and donors. The PACT programme in Mali, for example, is a 12-year initiative that has accompanied the country's decentralisation process (Box 3.4). The PACT operates at both local and national levels, helping to build multistakeholder governance mechanisms through local councils and to improve the decentralisation framework and procedures. Since its launch in 2002 it has helped the authorities to develop and test new tools for accountability, transparency and public participation in local governance, working with diverse stakeholders who include civil society, traditional chiefs, local authorities, the media and the private sector.

A growing number of development agencies and organisations are investing in tools for political economy analysis as well as in politics and governance research (Box 2.5). This means there is a growing evidence base - particularly for challenges that are inherently political (e.g. the influence of upcoming elections, the degree of political will to enact reforms, the realities of patronage/clientelistic relations, etc.). However, uptake in terms of significant changes in policy and practice and the realisation of more politically-informed approaches remains disappointing (Wild and Foresti, 2011).

Box 2.5. Donors' work on political economy analysis: some examples

Many donor agencies have sought to find ways of better appreciating the interdependence of institutions in governance and service delivery, especially through the use of various political economy techniques. For example, the Swedish development co-operation agency SIDA has developed an approach known as power analysis, which "involves gaining a deeper understanding of the political, social, cultural and economic issues at play in a country; the power relationships between actors at the societal level and the incentives of these actors to affect or impede change" (SIDA, 2005). In the same vein, DFID has invested significantly in its drivers of change analysis and subsequent tools such as the country governance analysis, which draw on many of the same techniques to help "understand how incentives, institutions and ideas shape political action and development outcomes in the countries where we work" (DFID, 2009). 
There are many different factors at play here. In part, a lack of uptake reflects weaknesses in the political analysis itself. For example, findings may not be translated into specific actions that could be implemented by programme staff. Significant steps have been taken to address this, including through the development of more problem-focused, operational research (see Box 2.4 above).

Understanding the political economy of donors themselves is also key reluctance to conduct political analysis also reflects the incentives and organisational cultures of development agencies. One of the most in-depth studies of the institutional incentives of a donor agency (the Swedish International Development Co-operation Agency, Sida) found that information asymmetries, rapid staff turnover and pressures to allocate funds can undermine attempts to foster strong understanding of the context in which development co-operation was delivered (Ostrom et al., 2001).

Undoubtedly, moves towards more political ways of working can be more risky for donors than purely technical approaches. At the same time, even technical approaches in practice shape political dynamics. Either way donor interventions in this area affect political realities. Adopting a more politically informed approach doesn't necessarily mean greater interference in domestic politics - but it will help to ensure more feasible support, including through the use of more realistic objectives, better monitoring and management of political risks, and the use of appropriate timeframes.

\section{Imposing "best practices" on developing country contexts}

The GOVNET case studies identified a number of instances of where the donor community had tried to "replicate" successful support for domestic accountability in their own countries in a developing country rather than identifying more appropriate, functional, "local" solutions to accountability gaps and deficits.

The Mali case study provides a particularly telling illustration (Box 2.6). Here support was given to establish an audit institution based on an Anglo-Saxon model of public financial management - despite the existence of a national accounts office already carrying out this work. The "smarter aid" approach here would have been to focus on supporting the audit function and to work through pre-existing institutions. More politicallyinformed approaches should ensure greater focus on the substantive functions of accountability - rather than on the broader forms it might take. 
Box 2.6. Duplicating effort: misaligned donor support in Mali

External audit has traditionally been the prerogative of the Section des Comptes in Mali. This is part of the Supreme Court and relies on a handful of magistrates to 1) verify the conformity of the state budget with the law;2) audit public sector accounts; and 3) verify the financial management procedures of administrative agents. However, the Bureau du Vérificateur Général was established with donor funding in 2002 - following an Anglo-Saxon model with an overlapping mandate to audit public financial management procedures. This is a classic example of how donor support to different models of oversight can result in overlapping mandates and responsibilities.

Source: OECD (forthcoming), Donor Support to Domestic Accountability: Budget Processes and Service Delivery in Mali, OECD, Paris.

The case studies also revealed the limitations inherent in focusing exclusively on formal processes and institutions. In Uganda, Mali and Mozambique, significant investments have been made in strengthening public financial management and promoting greater oversight (from both the supply and demand side). However, these "visible" reforms don't always relate well to the reality of how resources are actually allocated, or how formal budget systems and processes interact with the informal processes, power dynamics and incentives which influence how actors play their prescribed roles. For example, in Uganda - despite very significant improvements to financial systems over the past decade and growing capacity of some key accountability actors - fiscal and political decentralisation has not been fully implemented and corruption and patronage remain deeply entrenched. Donor support which relies on international best practice standards can struggle to engage with these realities.

These examples highlight one of the most important donor "pitfalls" revealed by the GOVNET case studies. Too often donors have provided support for institutions and processes based on models from their own countries, rather than support which starts with the context and focuses on building up substantive accountability functions (see Pritchett et al., 2010). The result has been a proliferation of countries with all the trappings of domestic accountability - but without most of its functionalities. In Mali, for example, government and donors assumed that new local governance arrangements set up in the decentralisation process would take hold. However, citizens lacked a basic awareness and understanding of their role, which was to participate in communal council meetings, voice budget priorities and use public information. As well, local governments often failed to understand that they should consult citizens; neither did they 
understand how to do so. In Peru, laws promoting access to public budget information have not yet fostered a functional oversight role by civil society because people cannot understand and act on the type of information provided. Authorities in both countries are learning that all actors need more guidance and support in implementing new local governance arrangements and that building these new relationships and capacities and developing common visions takes time.

In a broader sense, efforts to replicate or transpose "foreign" accountability institutions or processes can perversely undermine local ownership. As the 2011 World Development Report argues, "Institutional legitimacy is key to stability" (World Bank, 2011). Citizens themselves need to determine how legitimate they see their institutions, and what forms of accountability they prefer. Any understanding of accountability functions therefore needs to be grounded in what is locally appropriate and seen as genuine. Again, this reinforces the need to move away from standardised models towards approaches which fit the context best.

Moreover, donors need to remain sensitive to the interests of different formal and informal stakeholders within accountability systems in order to prevent unbalanced support, dominance by certain social groups and the reproduction of social hierarchies and inequalities. Otherwise accountability systems can run the risk of being hijacked by dominant social groups.

A more systems-focused approach, set out in the next chapter, is a very promising way forward for addressing these specific accountability problems or functions.

\section{References}

Booth, D. and F. Golooba Mutebi (2009), "Aiding Economic Growth in Africa - The Political Economy of Roads Reform in Uganda", ODI Working Paper, $\mathrm{N}^{\circ} 307$, Overseas Development Institute, London.

Castillejo, C. (2011), "Building a State that Works for Women: Integrating Gender into Post-conflict State Building", FRIDE Working Paper, $\mathrm{N}^{\circ} 107$ (March 2011), Madrid.

Collinson, S. (2003), "Power, Livelihoods and Conflict: Case Studies in Political Economy Analysis for Humanitarian Action", HPG Report 13, Overseas Development Institute, London, available at www.odi.org.uk/resources/download/241.pdf.

DFID (Department for International Development), (2009), "Political Economy Analysis", How to Note July 2009, p. 4, DFID, London. 
Eldon, J. and D. Gunby (2009), States in Development: State Building and Service Delivery, draft report for DFID, Department for International Development, London.

Fritz, V., K. Kaiser and B. Levy (2009), Problem Driven Governance and Political Economy Analysis: Good Practice Framework, World Bank, Washington, DC.

Golooba-Mutebi, F. (2005), “When Popular Participation Won't Improve Service Provision: Primary Health Care in Uganda", Development Policy Review, Vol. 23, N² 2, pp. 165-182.

Kazoviyo, G. and G. Pékagie (2011), The Issue of Inheritance for Women in Burundi, FRIDE, Madrid.

O'Connell, H. and W. Hartcourt (2011), Conflict-affected and Fragile States: Opportunities to promote gender equality and equity?, DFID, London.

OECD (forthcoming), Donor Support to Domestic Accountability: Budget Processes and Service Delivery in Mali, OECD, Paris.

Ostrom, E., C. Gibson, S. Shivakumar and K. Andersson (2001), "Aid, Incentives, and Sustainability: An Institutional Analysis of Development Cooperation", Sida Studies in Evaluation, Vol. 02, $\mathrm{N}^{\circ} 01$, Swedish International Agency for Development Co-operation, Stockholm.

Pawson, R. and N. Tilley (1997), Realistic Evaluation, Sage, London.

Pritchett, L., M. Woolcock and A. Andrews (2010), "Capability Traps? The Mechanisms of Persistent Implementation Failure", Working Paper, $\mathrm{N}^{\circ}$ 234, Centre for Global Development, Washington, DC.

Sida (Swedish International Agency for Development Co-operation) (2005), Methods of Analysing Power: A Workshop Report, Sida, Stockholm.

Wild, L. and M. Foresti (2011), Putting Politics into Practice, Overseas Development Institute, London.

World Bank (2011), World Development Report: Conflict, Security and Development, The World Bank, Washington, DC. 



\section{Chapter 3}

\section{Taking a systems-wide approach to accountability in developing countries}

This chapter sets out what an accountability systems approach might look like and the implications for development agencies' policies and practices. To avoid blueprint assistance, it underlines the advantages of a systemsbased approach to accountability, engaging a wide range of actors and institutions, including parliaments, political parties, elections and the media. 
Accountability works as a system, involving a wide range of actors and institutions alongside information flows and patterns of influence and incentives (Figure 3.1). Conventional modes of accountability support, however, often do not adequately capture the dynamic and interlinked nature of domestic accountability. Adopting a systems-wide approach (or systems approach) can avoid supply-driven, top-down, blueprint assistance targeted only at formal accountability institutions. Instead, it can help donors to understand the specific country context and do much more to work "with the grain" of local institutions and reformers. This chapter sets out what an accountability systems approach might look like and the implications for development agencies' policies and practices.

\section{Towards a systems-wide approach}

The point of departure in a systems approach should be to understand the particular accountability problem (or function) to be addressed and then to work back from that to the wider system or network of relevant actors and institutions. Working backwards like this reveals which stakeholders with whom to work. Crucially, it does not prejudge who to support and it also means working with what is already in place.

For instance, in Peru and Mali, a systems focus on accountability in the budget process revealed the importance of engaging with a wider network of actors and institutions:

- In Mali, the ability of the Bureau du Vérificateur Général to audit the government was directly linked to the quality of information it was able to collect from line ministries; in turn the ability of civil society and parliament to call government to account was directly linked to their access to reports from the Bureau du Vérificateur Général. In the education sector, the successful functioning of local school committees was dependent on effective multi-stakeholder processes that brought local counsellors together with citizens and decentralised education administrators. In health, local clinic associations have been set up to manage health services and bring together community members, health practitioners and local authorities. The circular relationships and mutual accountability processes among these various actors shows how a systems approach would better align both the supply and demand sides of accountability in Mali.

- In Peru, the decentralisation process meant that intervening with many actors in a few targeted regions offered the best opportunities for promoting multi-actor systems of accountability while at the same time supporting decentralisation. 
In Mozambique, by contrast, donors have continued to support individual institutions rather than build accountability relationships between and among institutions. Stakeholders argue that donors need to do more to consolidate relationships and networks where they already existed. For example, they proposed that the Poverty Observatories, which bring together government, civil society and international partners, could be strengthened to become multi-stakeholder arenas where government could respond - and therefore be more accountable - to citizens' concerns (Box 3.1).

\section{Figure 3.1. A model accountability system for budgeting}

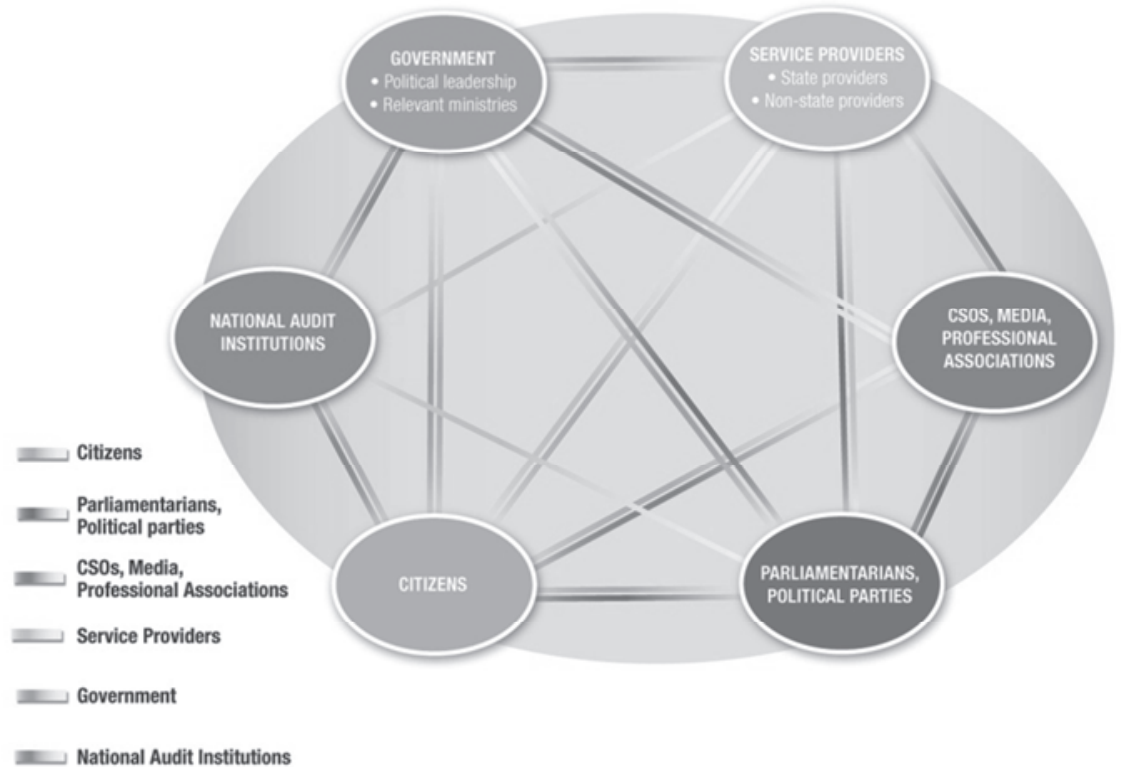

A systems approach to accountability will also ensure that support to specific actors will be 1) balanced (thus avoiding chronic and growing gaps in capacity and the scope for "capture" by dominant accountability actors); and 2) more inclusive (e.g. reaching community-based groups, social movements, the private sector, trade unions, professional associations and others). Similarly, it will strengthen the scope for more comprehensive approaches that facilitate linkages and connections across different actors or processes engaged in specific accountability functions - often crucial for achieving lasting change or greater impact. 


\section{Box 3.1. The Poverty Observatory system in Mozambique}

The Government of Mozambique established the Poverty Observatory as part of its efforts to evaluate and monitor implementation of its poverty reduction strategy. The observatory is a consultative forum operating at the national and regional level which brings together government representatives, civil society and international partners. The Poverty Observatories in theory play important roles in informing citizens of their rights and responsibilities in relation to public goods and service delivery. However, some stakeholders argue that their impact has been undermined, as these fora remain largely consultative and are not a substantive platform for mutual accountability and power negotiations (da Silva Francisco and Matter, 2007).

This links to a number of emerging political economy insights that question approaches focused exclusively on either the "supply" or "demand" side of accountability (CFS, 2010; Booth, 2011). The case studies of Uganda, Mali and Peru reveal that citizens can often be hindered from realising their demand potential by a variety of social and political factors (such as patronage patterns, power imbalances, cultural attitudes, or individual shortcomings such as illiteracy and disempowerment). These factors tend to be particularly powerful barriers to women's ability to demand accountability. This is illustrated by Peruvian women's limited access to official channels like the Defensoría complaint system (see Annex 1, Peru Case Study). This means that assumptions about latent citizen demand need further study to more fully understand the wider incentives at play. They also reveal the importance of supporting the connections or channels which can bring together demand and supply-side actors.

\section{Implications of systems-wide approaches for policy and practice}

What are the implications of systems-wide approaches for changing practice? This section highlights the main issues and steps for approaching accountability support on a systemic basis.

\section{Identify the core accountability problem or function and the wider political economy}

First, the design of any accountability programme needs to start with a strong understanding of the wider political economy and an initial analysis of the key accountability problem or function to be addressed (see Chapter 2). 
A systems-wide approach requires a well-founded diagnostic assessment of the relevant accountability system. It may be particularly helpful to adopt a problem-driven approach in identifying the core accountability gaps or weaknesses to address (but with a focus on the functions of accountability rather than just the forms of accountability). For example, if particular accountability weaknesses are identified in overseeing budgets or in government's responsiveness to service delivery needs, this should sit at the heart of any programme of support. From this, different dimensions of political economy analysis and stakeholder mapping can identify the key actors and institutions and the pivotal entry points for support.

It may prove especially helpful to ground accountability support in concrete issues. For example, in Peru a fruitful approach has been to focus on health issues as an entry point for political party support. USAID's support to Acuerdo de Partidos Politicos en Salud (Political Party Agreement in Health) has helped create consensus among political parties on important health reforms (Box 3.2). While it has not been linked to parliamentary assistance (a remaining gap), it is a useful example of linking political party support to core sectoral concerns and issues.

\section{Box 3.2. USAID support to political party platforms in Peru}

USAID's support to political parties in Peru has focused on a specific sector health - in an effort to stimulate endogenous political platforms and cross-party engagement in health policy making. Participating political parties were supported in their efforts to 1) generate health information and data; and 2) strengthen their capacity to analyse health priorities and advocate for reform. One approach was to develop a novel cross-party consensus on a "Political Party Agreement in Health". The project has also created space for other advocacy organisations to put forward policy proposals. This has reportedly been successful in influencing the platforms adopted by parties, although a lack of enforcement remains challenging since there is little monitoring to ensure that platforms are then implemented by participating parties.

\section{Understand the linkages between formal and informal institutions}

Looking at domestic accountability systems from a sectoral perspective may allow for finer grain analysis of the key incentives and dynamics at play, and the linkages between formal and informal "rules of the game" and institutions. For example, informal agents such as traditional chiefs can be significant actors in the provision of basic services in some countries, with implications for accountability systems (Box 3.3). In addition, understanding the role of informal institutions is particularly crucial in supporting domestic accountability for gender-sensitive policy making 
because these tend to regulate the personal and family issues central to women's lives. They can also be more accessible to women than formal alternatives, even though they may risk providing discriminatory outcomes (Castillejo, 2011; Chiongson et al., 2011; Swaine, 2003). However, informal institutions have often been ignored in accountability programmes focused only on formal institutions. Providing support directly to informal actors and institutions can be problematic for external actors: the examples from Mali show how a first step can be to integrate into programme design and implementation recognition of the role these actors play in practice.

\section{Box 3.3. The role of traditional chiefs in service delivery and taxation in Mali}

At the time of this study (2011), development partners in Mali's education sector had started to apply some lessons learned about the importance of engaging with informal, traditional accountability systems, such as traditional chiefs. Working through local NGOs, customary authorities were to be consulted early in the process of setting up new school committees so as to foster their buyin and support. Pilot projects on taxation were also reaching out to customary authorities, which formerly had the power to raise taxes and which may consider government taxation efforts as a threat to their status. In some cases, hybrid arrangements emerged, such as local councils working with customary authorities to help collect government taxes. These adaptations accommodated the fact that the chieftaincy system can have a significant impact on tax compliance at the local level - and that any attempts at reform which conflict with traditional authorities are unlikely to be successful.

Source: OECD (forthcoming), Donor Support to Domestic Accountability: Budget Processes and Service Delivery in Mali, OECD, Paris.

Understanding the linkages between formal institutions and informal practices can also ensure more feasible approaches to accountability reform. The Mali case study highlights that sound analysis of these relationships can be particularly crucial where women's rights are concerned. In 2009 a decade of lobbying by women's groups led to a draft family law which significantly extended women's rights. Yet, despite having been a strong backer of the draft law and despite its adoption by Parliament, the President ended up not signing it. He was forced to admit that the population did not fully support the new code, following extended protests by tens of thousands of religious activists who were against provisions giving more rights to women. The President returned the draft law to legislators, explaining he did so for the sake of national unity. In this case, "best fit" or incremental approaches were needed in order to progressively realise rights commitments, particularly in the face of domestic opposition. This 
underscores the importance of understanding how religious, cultural and social values and norms may affect reform agendas.

\section{Build linkages and relationships across accountability actors and institutions}

While conventional approaches to social accountability often focus on strengthening demand in response to weaknesses in the state supply of accountability, recent political economy research points to the need instead to identify bridging channels that bring together citizens and the state (CFS, 2010; Rocha Menocal and Sharma, 2008; Booth, 2011). Thus the work of the Centre for the Future State has emphasised that support to a particular set of actors (such as CSOs) alone is not particularly effective. Instead, support should be directed to "broad based alliances" which bring together a range of actors with common interests in reform (and which cross publicprivate divides) (CFS, 2010). The GOVNET case studies identified a number of examples where support was explicitly designed to facilitate multi-stakeholder coalitions or to build stronger relationships between different groups, actors and institutions. While the evidence base for this approach is still thin and should urgently be deepened, emerging examples are very promising.

In Uganda, for example, USAID's Linkages initiative explicitly seeks to support the links between actors, including at local levels, while in Mali a number of programmes seek to strengthen decentralisation processes by bringing actors together (Box 3.4). A Danish project to support accountability for gender-sensitive policy making in Mali by bringing together women parliamentarians, local politicians and civil society activists is another encouraging example. Where support is focused on a particular event or moment of political transition, such as elections or significant devolution of power, it seems to be particularly important to be as comprehensive as possible, so that support works across the many domestic institutions and sectors involved in the process.

Global transparency initiatives - such as the Medicine Transparency Alliance (MeTA), the Construction Sector Transparency (COST) initiative, and the Extractive Industry Transparency Initiative (EITI) - are proving to be useful platforms for building multi-stakeholder accountability networks. Experience with these initiatives suggests that in order to create successful and sustainable multi-stakeholder dynamics, group memberships need to be balanced, representative and formalised to ensure motivation and continuity. National regulatory and sectoral institutions also need to be involved, as well as the private sector and civil society organisations. These initiatives underscore the need for rigorous understanding of the political economy 
context and for acting politically to influence and help diverse stakeholders work together on specific accountability issues and functions.

\section{Box 3.4. Accountability support to multiple actors in Uganda and Mali}

In Uganda, the Linkages programme aims to strengthen democratic linkages within and among the Ugandan Parliament, selected local governments and CSOs, as well as to build their capacities to enhance accountability and improve service delivery (Tsekpo and Hudson, 2009). Linkages supports a number of parliamentary committees and the shadow cabinet - including outreach through policy forums. It also funds CSOs to: 1) run budget conferences at district level to strengthen participation in budget processes; and 2) provide training and capacity development to other, smaller CSOs. In this way, it supports links between, within and among different stakeholder groups.

In Mali, the Programme d'Appui aux Collectivites Territoriales (PACT) seeks to strengthen the capacities of communes in order to improve their performance and build synergies between actors promoting social and economic development. The Programme de Gouvernance Partagée (PGP) focuses on strengthening local democracy by working with citizens, civil society organisations and communal authorities on peacebuilding, statecraft and economic development. Its training programmes are designed to improve the efficiency, accountability and transparency of local government, its engagement with civic organisations and media coverage of decentralisation.

\section{Assess and identify promising leverage opportunities and weak links}

A systems-wide approach can help to reveal particularly weak links and potential areas of stronger leverage by: 1) identifying where capacity support and emerging opportunities exist to promote accountability; 2) providing a fuller understanding of the relationships among transparency, access to information and accountability; and 3) highlighting where there are particularly weak links in process or in the relationships among actors.

Greater awareness of the inherently dynamic nature of accountability systems opens up opportunities to recognise and respond to moments of transition or transformation. Social media and mobile communications technologies are increasingly shaping how people interact with politics and accountability around the world. New information and communication technologies have added new channels and platforms for citizens to hold their governments to account. Support for accountability needs to incorporate the fact that these technologies are changing the rules of the game completely and constantly. Examples such as Twaweza - which makes use of both new and old technologies to expand citizens' ability to 
access government information and hold leaders accountable in East Africa - signal how accountability systems are evolving in many countries, and how they are shaped by technological transformations, among other factors.

New technologies (including forms of social media) can have huge potential for facilitating such bridging channels, although their impact will depend on the processes, institutions and reforms they can tap into. Examples from Uganda, Mali and Peru suggest that more could be done to promote citizens' access to media and mobile technologies as well as to enhance citizens' media literacy and safety. This includes access to media products and infrastructure, as well as the ability to make sense of information and to use it in appropriate ways (Chapter 9). But this must be grounded in a strong understanding of local dynamics and incentives.

Moving onto transparency of information, Peru is instructive in this respect, as it has legally enshrined efforts to improve transparency. The Transparency and Access to Public Information Law (2002) stipulates that all information generated by state entities is public (with only limited exceptions for national security and confidentiality), and that it should be easily accessed at both national and local levels. All public agencies are therefore required to establish an online transparency portal which provides information on budgets, spending, purchases, plans and activities, and where citizens can request access to any information not available online.

While donor support in Peru is being channelled towards these formal processes, GOVNET research reveals that poor enforcement (including weak rule of law) and capacity gaps are eroding the impact of this legislation. The bulk of donor support is focused on activities such as supporting public agencies to publish more information online - but does little to address or combat local-level realities. In particular, little attention has been paid to the different experiences of women or other marginalised groups in trying to access and use these institutional channels for accountability. A systems-wide approach, underpinned by strong context analysis, might allow for more effective engagement with these dilemmas.

\section{References}

Booth, D. (2011), "Governance for Development in Africa: Building on What Works", Policy Brief 1, Africa Power and Politics Programme, Overseas Development Institute, London, available at www.institutionsafrica.org/filestream/20110406-appp-policy-brief-01-governance-fordevelopment-in-africa-building-on-what-works-by-david-booth-april2011. 
Castillejo, C. (2011), "Building a State that Works for Women: Integrating Gender into Post-conflict State Building", FRIDE Working Paper, $\mathrm{N}^{\circ} 107$ (March 2011), Madrid.

CFS (Centre for the Future State) (2010), An Upside Down View of Governance, Institute of Development Studies, University of Sussex, Brighton.

Chiongson, RA., D. Desai, T. Marchiori and M. Woolcock (2011). "Role of Law and Justice in Achieving Gender Equality", Input paper for 2012 World Development Report.

da Silva Francisco, A. and K. Matter (2007), Poverty Observatory in Mozambique: Final Report, May 2007, report by Gerster Consulting for the Swiss Agency for Development and Co-operation (SDC) and The Participation and Civic Engagement Team in the Social Development Department of the World Bank, Gertser Consulting, Switzerland, available at www.gersterconsulting.ch/docs/mozambique-povertyreport.pdf.

Rocha Menocal, A. and B. Sharma (2008), Joint Evaluation of Citizen's Voice and Accountability: Synthesis Report, Department for International Development, London.

Swaine, A. (2003), Traditional Justice and Gender Based Violence in Timor-Leste, Research report, International Rescue Committee, New York.

Tsekpo, A. and A. Hudson (2009), Parliamentary Strengthening and the Paris Principles: Uganda Case Study, Overseas Development Institute, London. 


\section{Chapter 4}

\section{Ensuring development co-operation helps rather than hinders accountability}

This chapter focuses on the implications of unbalanced development cooperation for accountability in developing countries. It underlines the potential harm that development co-operation can do to citizen-state relations and presents some specific development co-operation modalities and instruments that can help ensure greater service delivery and better development results. 
Aid is not a "silver bullet" for solving governance and accountability issues - these efforts fundamentally need to be led by internal reformers and processes. Despite continuing efforts to provide development assistance in line with Paris Declaration principles (e.g. respecting country ownership, ensuring alignment and harmonisation, focusing on results and promoting mutual accountability; OECD, 2005/2008), aid inflows can perversely compromise or short-circuit domestic accountability. The donor community needs to be aware of the overall magnitude of aid and development cooperation activities in a given country and be attentive to dynamics that may subvert or undermine accountability relationships between governments and their citizens. This chapter covers several ways in which aid can help improve accountability, while avoiding damaging citizen-state relations.

\section{How to avoid skewing accountability in developing countries?}

This phenomenon operates on two levels. Historical analysis from a wide range of countries points to the importance of taxation and domestic revenue generation - alongside revenue-bargaining between states and organised citizens - as crucial aspects of state-building and the development of accountability relationships (Bräutigam et al., 2008). Because aid is an additional, exogenous resource made available for government spending, it can undermine the development of more legitimate and sustainable tax-based social and fiscal contracts between citizens and the state - and diminish the incentives political leaders have to respond to the needs and demands of their constituents. In Uganda, for example, GOVNET case study research revealed perceptions that by reducing its reliance on tax revenues, the government's access to aid may have reduced its incentives to be held accountable to citizens.

Secondly, aid may encourage stronger state accountability to donors than to citizens, particularly where it finances a large share of public expenditure (Bräutigam, 2000) and where aid conditions call for close monitoring and reporting. If governments respond to these incentives by exercising exclusive oversight and control over core aspects of domestic policy and spending decisions, then domestic accountability institutions like parliaments will be marginalised (Eberlei and Henn, 2003; Langdon and Draman, 2005).

\section{The links between aid and taxation in strengthening citizen-state relations}

Partner countries and their development partners are increasingly aware of the diversity of finance that can be tapped into for investing in 
development. Domestic resources in developing countries - generated through private investment, savings and taxation - will continue to provide the bulk of development finance for years to come. Taxation looms large in this respect, as suggested by recent analytical findings. For example, Tanzania raised an additional USD 2.2 billion by increasing tax revenue from $10 \%$ to $16 \%$ of gross domestic product (GDP) between 1998 and 2008 . And the International Monetary Fund (IMF) has projected that basic tax reforms throughout sub-Saharan Africa could raise at least USD 20 billion a year based on today's GDP (Gates, 2011). Furthermore, taxation plays a supporting role in improving governance by promoting the accountability of government to citizens.

However, tax policies and administration systems in most developing countries are weak and dysfunctional, often giving rise to tax avoidance and evasion and inequitable burden-sharing. Many citizens are reluctant to pay taxes in these conditions. Relatively limited attention has been paid to issues of domestic resource mobilisation and taxation as part of domestic accountability support. In fact, overall only around $0.1 \%$ of all support for governance involves taxation, commonly in the form of short or long-term technical assistance. Recently, donor support to improve the effectiveness and transparency of tax administrations and to promote citizen debate and consensus on tax issues has been beginning to grow, as suggested by efforts in Mali and Uganda (Box 4.1).

\section{Box 4.1. Promoting local awareness and support for taxation in Mali and Uganda}

In Mali, many individuals provide support to their extended families and contribute to community and religious welfare activities. Direct taxation by government is often considered an unwelcome burden that brings little benefit. In response to this, several donors are funding pilot projects to raise citizens' awareness about the importance of increasing tax revenues. In return, citizens have requested improved financial transparency, highlighting a potentially important entry point for the exchange of accountability between state and citizen.

In Uganda debates on tax policy and reform have been organised on the basis of analytical work carried out by the African Development Bank. Donors are also beginning to support CSO advocacy work on taxation issues.

Recent OECD work on taxation reveals that government ownership and leadership is crucial, as aid can only support government programmes to improve tax systems - and these need to be aligned to domestic political incentives (Prichard/GOVNET, 2010). How revenue is levied and collected 
is as important as the total amount raised, so attention needs to focus on issues of efficiency and equity. Accordingly, there may be broad areas of synergy between accountability agendas and agendas for tax reform.

Strengthening the linkages between taxation and accountability also means supporting institutions and organisations outside the revenue system, including the justice system, parliament, and civil society. Accountability support programmes should therefore give special weight to activities that address these synergies (Prichard/GOVNET, 2010). Chapter 11 presents draft principles for supporting development country governments in revenue matters.

\section{Ensuring effective aid delivery}

Understanding key features of how aid is delivered may also help mitigate some of the potentially harmful impacts of aid on domestic accountability systems and actors. This includes ensuring that:

- Donors can be held to account by aid recipient countries, which means greater transparency and co-ordination by donors;

- Donor budget support is integrated into partners' domestic budget management systems and to co-ordinate in-country performance assessment arrangements; and

- The mix of aid instruments and cross-linkages among them foster synergies.

These issues are discussed below.

\section{Greater donor transparency and co-ordination}

Landmark aid effectiveness agreements at Paris, Accra and Busan have impelled donors to make aid information more transparent and accessible to development partners (OECD, 2005/2008; Fourth High Level Forum on Aid Effectiveness, 2011). This helps governments and civil society understand what is being financed and where, and enables them to exercise proper oversight over public budgets. It also fosters accountability between donors and partner country actors for promises and commitments that have been made. Making aid information about aid and development co-operation activities more widely available can also facilitate better co-ordination, inform shared data analysis and political economy analyses and improve the division of labour across the local donor community. 
The GOVNET case studies found evidence in Mali, Mozambique and Uganda of more accurate aid data being made available, often as a result of budget support frameworks and more ad hoc reforms. This seems to be particularly the case at the sectoral level, where sector working groups have established structured dialogue and information exchange between donors and a range of domestic stakeholders.

In Uganda, for example, the creation of a simplified reporting spreadsheet for donors in the Local Development Partners Group helped to capture - in one document - quarterly donor commitments and actual disbursements, searchable by sector. This echoes trends in other countries towards the better sharing of information about aid flows and development co-operation activities and attempts to collate it in usable ways, for example through management policies or platforms (Box 4.2).

An important step-change is now possible thanks to the International Aid Transparency Initiative (IATI), under which 28 international donors ${ }^{1}$ have so far agreed to provide more accurate, timely and comprehensive information on development co-operation commitments and disbursements (Box 4.2).

While the work of IATI and others represent significant improvements, some challenges remain. For example, donors often do not provide information in ways which are compatible with how governments record information (Moon and Williamson, 2010). Moreover, there has been little focus on helping partner countries strengthen their ability to interpret and use development co-operation data - a critical constraint for improving local capacity to hold government and the donor community to account. 


\section{Box 4.2. Making information on aid more transparent: Some recent initiatives}

International Aid Transparency Initiative (IATI): IATI is developing international standards for the way donors report information about aid spending. These will include:

- agreement on what information will be publish and its level of detail;

- a system for categorising different types of aid spending/commitments;

- a common electronic format making it easier to share information; and

- a code of conduct guiding what information donors will publish and how frequently, how users may expect to access that information, and how donors will be held accountable for compliance.

Aid management platforms: aid management platforms are web-based applications that allow governments to better manage and co-ordinate development assistance. Software developed by the Development Gateway Foundation provides a virtual workspace where governments and donors can share aid information from planning through to implementation - and then analyse this by donor, sector, status, region, timing and other factors. This is being complemented by other programmes, such as Mapping for Results (http://data.worldbank.org) developed by the World Bank Institute (WBI). This overlays the distribution of World Bank resources for programmes at country level with poverty statistics to ensure resources are hitting the right areas. These results are then shown on an interactive map. WBI is now working with IATI to incorporate all donor allocations into one map, which can be made readily available online.

\section{Aid instruments that support the scope for domestic accountability}

A number of aid practices and instruments can help improve accountability in partner countries:

- Ensuring project aid is embedded in government budget frameworks and systems (budget support). The Paris Declaration committed donors to base their overall support on partner countries' national development strategies and to progressively align their policies and procedures with partner country priorities, systems and procedures. Budget support is arguably the most effective instrument for delivering aid in line with these commitments. Project aid, on the other hand, can undermine budget processes in developing countries where it is not captured in national budgets. In Uganda, for example, a large proportion of aid to the health sector is still provided as offbudget, project-based aid. Given that most donor support will 
continue to mix budget and project support in the developing world in the near future, efforts must continue to ensure that project finance is captured in local budget frameworks and financial management systems.

- Streamlining, rationalising and refocusing donors' budget performance arrangements. Different donors use different indicators for measuring partner governments' performance against their various conditions for receiving aid. This creates complex monitoring and co-ordination challenges for partner countries, instead of providing a single, comprehensive set of targets against which governments can be held to account. This was the case in Mali, where differing donor disbursement requirements under budget support frameworks have heightened the donor role in partner country accountability processes. Further, programme-based approaches - which place a premium on government-to-government dialogue and relationships - can undermine broader participation or ownership. For example, in Mozambique donors are seen as dominating policy dialogue with government, to the detriment of civil society (Box 4.3). All these practical implications of budget aid practices reveal donor "clutter" and inefficiencies, and an unhealthy dominance by the donor community of budget accountability systems in partner countries.

\section{Box 4.3. Policy dialogue in Mozambique}

Some analysts argue that the donor community's increasing role in sectoral working groups and budget support joint reviews is usurping the participation of parliamentarians and civil society in domestic accountability. Although civil society groups, for example, are part of the joint review process, they often lack the capacity and resources to have significant influence. In a country with a strong ruling party and a centralised state, fora for dialogue around development co-operation could potentially serve as a platform to allow civil society and parliamentarians to challenge policies and hold government to account. In response, donors have now begun to support civil society in preparing their participation in joint reviews. 
- Maximising synergies among aid instruments and leveraging scarce aid resources. The development assistance community could do a much better job of ensuring that the various types of governance support - by individual donors and across the local donor community as a whole - work together to create synergies. All governance-related development co-operation interventions - both for public administrative functions such as financial management and procurement as well as for building more political institutions such as parliaments and political parties - could more systematically take account of, and address, the implications of such support for accountability actors and functions. The links and impacts that all governance-related development co-operation interventions have on accountability need to be leveraged: for example, more work is needed to ensure that ministries and government officials are more accountable to parliament and citizens, and that state institutions are accountable to their hierarchies or internal control functions.

\section{Special aid delivery arrangements that improve donor co-ordination}

Certain types of co-ordination frameworks and aid instruments, such as sector support and basket funds, can significantly enhance the impact and reduce the transaction costs of development assistance - including accountability support. Joint funding arrangements, a common and shared political economy analysis of the local context, and close co-ordination of programme planning and implementation, are especially useful features. Channelling development assistance through basket funds and sector budget support can facilitate more co-ordinated and coherent programme objectives, reduce overlap and fragmentation, improve division of labour, and provide more balanced support for the accountability system as a whole - so long as implementation arrangements are clear, roles and responsibilities have been identified and agreed, and communication channels established and used (Box 4.4).

\section{Managing risk and achieving results}

There are some concerns that an excessive focus on demonstrating development results could marginalise support to accountability and governance because progress in these areas is intrinsically difficult to measure in quantifiable ways. 


\section{Box 4.4. Co-ordinated donor approaches for deepening democracy in Uganda}

One of the more promising programmes identified in the GOVNET case studies is the Deepening Democracy Programme in Uganda, a multi-donor basket fund supporting a range of core domestic accountability institutions. Key aspects of its success appear to be: 1) joint funding and planning/implementation co-ordinated through basket fund arrangements; and 2) underpinning programme activities with a robust political analysis shared among the contributing donors. The programme has also prioritised the use of political analysis and research (including Afrobarometer data) to inform implementation; staff have a solid understanding of the power dynamics and challenges for accountability in Uganda. These staff appeared to have maintained regular contacts with most political parties.

Source: Wild and Golooba-Mutebi (2010).

A growing body of analysis, reinforced by the GOVNET country case studies, points to the lack of a robust evidence base for measuring and understanding the impact of accountability support. Too little has been invested in understanding what works and why in this field. "[M]any initiatives are not underpinned by a clear articulation of exactly what outcome or impact is sought.... or of how the actions and inputs contemplated are expected to generate that outcome or impact. That is, the assumptions underlying the causal chain, from inputs to outcomes and impact, are absent, vague or too implicit" (McGee et al., 2010: 9-10).

Incorporating political economy insights into accountability programming should help ensure that programme objectives are more realistic - and therefore more amenable to rigorous results measurement. This means paying much greater attention to programme objectives and assumptions at the outset of the design process. Being explicit about the theory of change justifying the support can be particularly helpful in testing starting assumptions. And assessing the wider political context and the enabling environment for reform will be particularly important for measuring the impact of development co-operation on domestic accountability.

Stronger, more well-founded results frameworks will enable development agencies to: 1) identify realistic programme objectives at the outset; 2) correctly gauge and manage risks; and 3) understand better what works and why. 
A key first step will be to identify and monitor risks (including political risks) and to develop forward-looking tools to help anticipate future risks (Phillips, 2006). Building in greater risk assessment (and using political economy tools where appropriate) throughout programme delivery will also be key (Wild and Foresti, 2011). This will require frameworks and approaches which allow for the observation of (and adaptation to) change over time (rather than a static evaluation at the end of a programme of support) (ibid.).

Note

1. As of January 2012.

\section{References}

Bräutigam, D. (2000), Aid Dependence and Governance, Expert Group on Development Issues (EGDI), Almqvist \& Wiksell International, Stockholm.

Bräutigam, D., O.H. Fjeldstad, and M. Moore (2008), Taxation and State Building in Developing Countries: Capacity and Consent, Cambridge University Press, Cambridge.

Eberlei, W. and H. Henn (2003), Parliaments in Sub-Saharan Africa: Actors in Poverty Reduction?, GTZ/Canadian Parliamentary Centre, Eschborn.

Fourth High Level Forum on Aid Effectiveness (2011), The Busan Partnership for Effective Development Co-operation, outcome document of the Fourth High Level Forum on Aid Effectiveness, Busan, Korea, 29 Nov-1 Dec, available at www.aideffectiveness.org/busanhlf4/images/stories/hlf4/OUTCOME_D OCUMENT_-_FINAL_EN.pdf

Gates (2011), A Report by Bill Gates to G20 Leaders, Cannes Summit

Langdon, S. and R. Draman (2005), PRSPs in Africa: Parliaments and Economic Policy Performance, GTZ/Canadian Parliamentary Centre, Eschborn.

McGee, R. et al. (2010), "Review of Impact and Effectiveness of Transparency and Accountability Initiatives: Synthesis Report", prepared for the Transparency and Accountability Initiative Workshop, 14-15 October 2010, Institute of Development Studies, University of Sussex, Brighton. 
Moon, S. and T. Williamson (2010), "Greater Aid Transparency: Crucial for Aid Effectiveness", Project Briefing, $\mathrm{N}^{\circ} 35$, Overseas Development Institute, London.

OECD (2005/2008), Paris Declaration on Aid Effectiveness and the Accra Agenda for Action, OECD Publishing, Paris.

Phillips, L. (2006), Assessing Governance: How Can Political Risk Analysis Help?, Opinion, Overseas Development Institute, London, available at www.odi.org.uk/resources/download/518.pdf.

Prichard/GOVNET (2010), Citizen-State Relations - Improving Governance through Tax Reform, OECD, Paris.

Wild, L. and M. Foresti (2011), Putting Politics into Practice, Overseas Development Institute, London.

Wild, L. and F. Golooba-Mutebi (2010), Review of International Assistance to Political Party and Party System Development - Case study Report: Uganda, Overseas Development Institute, London.

14-15 October 2010, Institute of Development Studies, University of Sussex, Brighton.

Moon, S. and T. Williamson (2009), "Greater Aid Transparency: Crucial for Aid Effectiveness", Project Briefing, N³5, Overseas Development Institute, London.

Phillips, L. (2006), Assessing Governance: How Can Political Risk Analysis Help?, Opinion, Overseas Development Institute, London, available at www.odi.org.uk/resources/download/518.pdf. 



\section{Chapter 5}

\section{Conclusions and strategic orientations to improve support to accountability}

This chapter presents the conclusions and strategic orientations to improve support to accountability. These revolve around three areas: (1) basing support on realism and a political economy analysis; (2) taking a systems approach to programme design; and (3) monitoring and evaluating risks and results. These issues have a number of implications for how development co-operation programmes for accountability are designed and implemented. 
As we have seen, donor support to domestic accountability needs to take greater account of the realities of power, politics and incentives; to do much more to ground support in strengthening core accountability functions; and to identify and bring together key institutions, groups and networks around local reform agendas. Recognising that domestic accountability works as a system which brings together a number of actors/institutions and incentives may be particularly helpful, and will support a focus on functions and mechanisms that work.

Our work suggests the following promising actions, described below. These raise a number of implications for programme design, implementation and evaluation (Box 5.1).

\section{Base support on realism and a political economy analysis}

- Ensure accountability support is political, not just technical, in its approach and design. The use of political economy analysis or other forms of political and social analysis can be particularly helpful in understanding incentives and power dynamics and ensuring a more politically-grounded approach.

- Work towards more shared analysis and pooled funding among donors, in order to strengthen coherence and co-ordination and promote an appropriate division of labour across the local donor community.

- Focus the analysis on identifying the core accountability functions and core weaknesses - to be addressed, rather than starting with a particular accountability actor. This allows one to work with the grain of local reform processes and to find "best fit" rather than standardised "best practice" approaches.

- Understand the interactions between formal and informal institutions, such as the roles of traditional chiefs, as highlighted in the Mali case study (Box 3.3).

- Accept the need for longer timeframes and greater realism when setting the objectives for support.

\section{Take a systems approach to programme design}

- See donors' roles in accountability support as conveners or facilitators of locally-driven processes. 
- Shift the focus of support towards the wider enabling environment for accountability and core accountability functions, rather than particular actors in isolation. More system-oriented strategies may be better placed to engage with sectoral dynamics, thematic issues or operational problems. Any work on particular issues or sectors should do much more to build links between local and national levels, and to address ongoing challenges where isolated accountability initiatives do not go to scale.

- Reflect on how development co-operation relationships overall shape the scope for domestic accountability. Donors need to be mindful that aid can undermine accountability relations between government and citizens. Avoid encouraging organisations to compete for funding rather than collaborating to achieve change.

- Increase the transparency, predictability and co-ordination of the aid. Support needs to be given to improve how available information can be used and acted upon by different groups.

\section{Monitor and evaluate risks and results}

- Prioritise approaches to monitoring and evaluating the results - and risks - of accountability. An accountability systems approach should make it easier to assess the wider context and the enabling environment for accountability reforms. This can help develop more realistic theories of change, which consider the incentives and relationships between actors - and thus ensure that project and programme objectives will be more realistic and easier to measure. However, much greater evidence is needed, as are new tools to better measure, monitor and manage political risks and to better capture results in this area.

- In reality, many providers of assistance to domestic accountability are likely to continue to channel separate funding lines to particular groups, organisations and institutions of accountability. Specific sets of principles for supporting parliaments, political parties, the media and electoral processes are contained in Part II to guide donors in achieving more effective, and more politically aware, programming in these areas. These principles make clear that the design of support to any of these organisations or processes must: 1) start with an assessment of the wider system or context; and 2) take care to consider the implications of support for one actor for other actors or institutions within that system. 


\section{Box 5.1. Core recommendations for programme design, implementation and evaluation}

\section{Programme design:}

- Draw on available context analysis (and where not available, consider commissioning analysis) as well as evaluations.

- Consider joint donor analysis or funding arrangements to develop shared understandings of the accountability system, and use this to avoid fragmented effort.

- Map formal and informal actors, institutions and processes which shape accountability. Understand the relationship among these actors and systems and draw on this as a basis for designing support programmes.

\section{Programme implementation:}

- An accountability systems approach means thorough analysis of the whole accountability system, and then targeted support to address particular weaknesses or gaps.

- Provide support in ways which build relationships, bring together coalitions and support dynamic change processes. This may require different ways of working, including brokering, facilitating and supporting local reform processes.

- Consider working with unconventional actors - such as the private sector, political parties, trade unions and others - as well as on new issues (taxation).

- Ensure greater transparency over how aid is given, integrate aid into partner country accountability systems and improve aid management in the field.

\section{Programme monitoring and evaluation:}

- Develop a theory of change for each intervention, underpinned by realities, which makes explicit assumptions about how and for whom a programme is intended to work.

- Reassess these assumptions at milestones throughout the programme and revise them where needed.

- Build in assessments of the wider context and risk management throughout the programme cycle (for monitoring and evaluation).

- Combine evaluation methods to capture medium-term and longer outcomes. 


\title{
Part II
}

\section{Principles for assistance to accountability actors and institutions:}

\author{
Elections, political parties, the media, \\ parliament and revenue matters
}





\section{Chapter 6}

\section{Introduction to principles for assistance to accountability}

The second part of this document sets out specific principles for targeted, support to key components of domestic accountability systems: electoral assistance, parliamentary support, political party assistance and media assistance. Taken together, these principles provide a guide for how to achieve more effective, and more politically aware, programming for support to particular actors or institutions, or as part of a wider systems approach. These principles have been developed through a series of highlevel roundtables and seminars on support to election, political parties, the media and parliament held by GOVNET in addition to the case studies undertaken. 
As highlighted in Part I, supporting accountability implies "working with the grain" of societies and developing country-specific strategies which fit their context best. This requires greater emphasis on facilitating or convening locally-driven reform processes. Such processes cannot be disconnected from the institutional actors who have initiated them and whose functions involve pursuing them in the long run. These include electoral commissions, parliaments, the media and political parties.

As part of its programme on accountability, GOVNET held a series of high-level roundtables and seminars during which it gathered expert advice in a multi-pronged effort to identify international good practice and develop several principles to guide support to key domestic accountability institutions such as political parties, parliaments, civil society and the media (Box 6.1).

\section{Box 6.1. GOVNET high-level seminars}

Between 2010 and 2012, the OECD (DAC and GOVNET) held a series of high-level roundtables and seminars to identify the trends in support to accountability actors and institutions. The first GOVNET roundtable International Support for Elections: Effective Strategies and Accountability Systems - was held on 1 March 2010 with the support of DFID, the United Nations Electoral Assistance Division, Department of Political Affairs, United Nations Development Programme, European Commission, European Commission-United Nations Development Programme: Joint Task Force on Electoral Assistance, and the International Institute for Democracy and Electoral Assistance (IDEA). A seminar on Trends in Support of Accountability: Political Party Assistance was then co-hosted by GOVNET and International IDEA on 9 December 2011. In addition, a seminar on Trends in Support of Accountability: Media Assistance Today - jointly sponsored by The World Bank Institute, Internews, BBC World Service Trust and the GOVNET - took place on 7-8 June 2011. Finally, the GOVNET hosted the Fourth Annual Donor Co-ordination Meeting on Parliamentary Support on 23 April 2012.

This part of the publication sets out specific principles for targeted, institution-specific support to key components of domestic accountability systems - electoral assistance, parliamentary support, political party assistance and media assistance - emerging from these seminars and roundtables. Electoral assistance has received most international attention because of the pivotal role of voting in providing the public with a political voice and calling the executive to account for its actions. While democracy involves more than holding free and fair elections, they are a fundamental building block of effective accountability. By contrast, political parties have been regarded more cautiously by donor agencies, being hesitant to 
interfere in the domestic politics of another sovereign nation. Yet political parties are an equally vital part of the public sphere, providing the principal vehicle for expressing and representing public concerns within the political systems of accountability. The quality of the party system is intrinsically linked with the quality of accountability. And, as Tom Carothers notes in the paper prepared for the seminar on Trends in Support of Accountability: Political Party Assistance (Box 6.1), party aid is inevitably political, but it has a legitimate place in foreign assistance which pursues democratic and development goals.

In addition, effective governance also depends on a functioning public sphere - where citizens come together (even virtually), share information, and deliberate on public issues. This depends on a vibrant media which provides information, highlights key issues and facilitates public debate, acts as a watchdog for the public interest and holds state and non-state actors accountable. The very nature of the media means that it interacts with accountability systems at all levels, and increasingly international assistance is seeking to buttress this vital role.

Parliaments are the key institution for securing executive accountability. While governments are directly accountable to voters at elections, in between elections it is the duty of parliamentarians to hold ministers and their departments to account on the public's behalf. Parliaments derive much of their authority from the fact that a number of accountability institutions usually report to them - ranging from the supreme audit institution, the ombudsman and the electoral commission, through to utility regulators, inspectorates and agencies. In other words, parliaments should sit at the centre of a web of domestic accountability and are potentially vital allies for donors in securing accountability and improving the quality of public services.

Taken together, the principles presented in this part provide a guide for how to achieve more effective, and more politically aware, support to particular actors or institutions, or as part of a wider systems approach. In particular, they stress the need to:

- Take context seriously: Assistance to any domestic accountability actor needs to be based on a deeper understanding of local conditions and examine the interconnections between institutions, sectors and actors.

- Align support programmes with wider accountability objectives: Reflecting the interdependence of systems of accountability, projects must be tied to other governance support efforts. A programme in a particular area - such as elections - 
should actively complement any assistance efforts in other areas such as parties, parliaments or media.

- Establish realistic objectives: Improving domestic accountability processes and institutions is likely to be slow and incremental. Projects need to be based on a realistic assessment of what is feasible, which will often mean having limited objectives rather than seeking to overhaul the entire system.

- Ensure local ownership: Achieving meaningful change means altering patterns of behaviour as much as increasing resources, reforming institutions or creating new laws. However, behavioural change cannot be imposed from outside - it must emerge from within. Projects should be fully "owned" by local partners and aligned with local incentives and coalitions for reform.

- Build long-term support: Because change happens slowly, support must be based on a multi-year commitment. The assurance of a long-term presence is likely to enhance the relationship with local partners and increase the chances of genuine impact.

Core elements of these principles are summarised in Box 6.2.

\section{Box 6.2. Support to domestic accountability actors}

\section{General principles for all domestic accountability support:}

- Take context seriously and align support programmes with wider accountability objectives.

- Establish realistic and long-term objectives.

- Ensure local ownership and work with incentives for reform.

- Pay attention to gender issues and inequalities.

\section{Principles on international elections assistance:}

- Be alert to electoral risk and the long-term causes of political violence.

- Ground electoral assistance in complementary diplomatic policies but don't instrumentalise it.

- Recognise the role of regional organisations.

- Be as comprehensive as possible. 


\section{Box 6.2 Support to domestic accountability actors (cont.)}

\section{Principles for political party support:}

- Be aware of but not paralysed by the sensitivities of party aid.

- Build on the interconnections between party aid and other elements of political aid.

- Don't confuse party diplomacy with party aid.

- Don't assume common goals between providers and recipients.

\section{Principles for media assistance:}

- Incorporate media indicators and audits into governance diagnostics and needs analysis.

- Co-operate with media development CSOs and determine media objectives and outcomes, not methodologies.

- Support independent, sustainable, and capable local media in developing countries.

- Support systematic research on the effects of media and information access on domestic accountability.

- Learn about and harness new technologies.

\section{Principles for support to parliaments:}

- Focus on institutional change leading to behavioural change.

- Understand parliaments' incentive structures.

- Don't ignore political parties.

- Identify and address the causes of underlying parliamentary weakness. 



\section{Chapter 7}

\section{Principles for international electoral assistance}

These principles were prepared by Thomas Carothers, Vice President for Studies at the Carnegie Endowment for International Peace for discussion at the first GOVNET Roundtable on International Support for Elections: Effective Strategies and Accountability Systems on 1st March 2010. They were revised based on the discussions and subsequent comments from the roundtable participants. 


\section{Preamble}

Supporting democracy is crucial for the international donor community, both because of the intrinsic value of democracy as a political system that helps foster human dignity, and because of the contributions that democratic governance make towards development for individual citizens.

Elections are only one element of democracy, yet they are an indispensable one - without genuine and credible elections democracy does not function. Elections give form to citizens' political voice, constituting both a fundamental root of political accountability and an orderly process for successions and alternations of power.

Through substantial support in many countries making democratic transitions over the past several decades, the international community has helped improve numerous electoral processes. By identifying lessons from these experiences and incorporating them into improved methods and practices, international elections assistance is evolving well.

Nevertheless, given the complexities, difficulties, and risks of electoral processes in many developing countries, electoral assistance continues to face numerous challenges. This is especially true in post-conflict contexts and in fragile states characterised by socio-political divisions, ineffective governance structures and the disenfranchisement of citizens, most often women, from electoral and broader political decision-making processes.

\section{Principles for international electoral assistance}

Marking a renewed commitment to make electoral assistance as effective and useful as possible, the major funders and implementers of international electoral assistance agree to the following strategic and operational principles:

1. Take the local context seriously through careful, comprehensive assessments especially in fragile situations. ${ }^{1}$ Elections assistance efforts should be grounded in incisive political economy analyses that identify and examine the determinant power dynamics and political constraints that shape the electoral environment, as well as the specific roles that elections are likely to play in particular settings.

2. Be alert to electoral risk. Elections assistance providers must respond to the recent rise in electoral and post-electoral violence in conflict-prone and developing countries by giving greater attention to electoral risk and structural causes of political violence that could 
ignite in election processes. These concerns should be reflected in the design and implementation of electoral assistance interventions.

3. Don't misuse electoral aid but do promote transparency. Electoral assistance should be based on the highest standards of impartiality. It should only be used to promote free and fair elections, not to advance other donor policy goals, such as burnishing the legitimacy of favoured partner governments or building friendly relationships with governments. Assistance should be provided transparently: information on who is providing funding and assistance should be readily available. Cost-effectiveness should be ensured so that state expenditure is in line with efforts to meet the Millennium Development Goals (MDGs).

4. Ground electoral assistance in complementary diplomatic policies. Electoral assistance should be grounded in complementary diplomatic policies that seek to nurture or reinforce the commitment on the part of partner governments to follow accepted electoral norms and meet the international obligations for democratic elections.

5. Recognise the role of regional organisations. Electoral assistance providers should take full account of the valuable role that regional organisations can play, both in election monitoring and electoral assistance, and seek the greatest possible complementarity with such organisations.

6. Embrace a full concept of ownership. Electoral assistance should be owned not only by the relevant partner government, but also by the broader political society in question. Electoral assistance providers should embrace an interpretation of local ownership that takes account of this political imperative.

7. Build on donor co-ordination. Electoral assistance providers should build on the progress they have made in creating co-operative mechanisms for electoral assistance by assessing the record of such mechanisms and seeking ways to broaden and deepen communication, co-operation, and co-ordination among all relevant assistance providers. Planning, financial arrangements, evaluation and reporting should be harmonised.

8. Be as comprehensive as possible. Designing elections assistance to be comprehensive horizontally across the many domestic institutions and sectors involved in an electoral process will ensure better synergies and overall coherence. Elections assistance and observation should be well co-ordinated, as observation plays a key role in effective electoral support. 
9. Think and act across the electoral cycle. Elections assistance should be designed, planned, and implemented over the long term across the full length of electoral cycle and if possible across multiple cycles, avoiding the common tendency to focus primarily on activities leading up to election day. Donor support should encourage sustainability to ensure that local capacity is built as quickly as is reasonably possible.

10. Push for integration. Electoral assistance should be actively integrated into the wider domain of democracy support, especially assistance for political party development, legislative strengthening, media assistance, and civic education programmes.

11. Emphasise citizens' understanding and engagement. Efforts to help citizens understand the utility and significance of elections within a broader set of accountability mechanisms should be an integral element of elections assistance. Experience shows that it is important to support consultative approaches to help election stakeholders be jointly responsible and to build their confidence, and that of the wider public, in election management bodies and other institutions involved.

12. Add the local to the national. Electoral assistance providers should complement their traditional focus on national elections with greater attention to strengthening local elections.

13. Make the connection with accountability. Election assistance providers should actively connect their activities with the wider set of strategies and programmes supporting accountable governance at all levels.

14. Don't neglect gender. Although progress has been made to widen and deepen the role of women in politics in many developing countries, electoral assistance providers should do more to incorporate a full gender dimension in election assistance, especially to eliminate legal and practical limitations on women's rights to freely participate in electoral processes as voters and candidates.

15. Respond more consistently to flawed elections. Donor governments committed to advancing free and fair elections should strive towards greater consistency in responding to flawed elections.

16. Keep learning about impact, and act on it. Building on the important learning efforts undertaken in recent years, election assistance providers should carry out deep-reaching evaluations of the impact of election assistance in varied contexts and incorporate the learning from those evaluations into practice. 


\section{Draft action plan for further elaborating the principles}

The first Roundtable on International Support for Elections agreed to further discuss and develop the Principles for International Support for Elections over the coming year in various international and regional fora on elections. Below are some initial ideas on next steps:

- Take the principles to a higher political level and develop them further in light of feedback from different communities and international and regional fora. The Global Electoral Organisation, organised by International IDEA in March 2011 in Botswana, was an excellent opportunity to present and discuss the principles more widely, in particular with regional organisations and electoral bodies. Other ideas on opportunities for discussion should be collected.

- Increase understanding of how to build coherence between the technical and the political level of electoral assistance. For example:

- The challenges of electoral assistance in fragile and conflict-affected states need further exploration. The International Network on Conflict and Fragility (INCAF) and GOVNET are exploring collaboration on a workshop on elections in fragile and conflict-affected states.

- It was agreed that the group should further explore basket funding issues, led by the EC-UNDP Joint Task Force. It may also be interesting to hold a seminar on whole-of-government approaches for elections and to reach out to colleagues working on elections in the Ministries of Foreign Affairs.

- Increase consultation with regional organisations and electoral bodies. As noted, the GEO in March 2011 allowed for considerable advancement on this front.

- Pilot the principles in an upcoming election in a developing country.

Note

1. See the New Deal for Engagement in Fragile States (www.pbsbdialogue.org) as well as the Monrovia Roadmap (www.oecd.org/dataoecd/23/24/48345560.pdf). 



\section{Chapter 8}

\section{Principles for political party assistance}

These principles were prepared by Thomas Carothers, Vice President for Studies at the Carnegie Endowment for International Peace for the Seminar on Trends in Support of Accountability: Political Party Assistance, co-hosted by GOVNET and International IDEA on 9 December 2011, and to the 14th Plenary Meeting of the OECD/DAC Network on Governance on 10 December 2011. They have been revised based on discussions and subsequent comments by GOVNET members. 


\section{Roles of political parties in democracy and development}

When functioning well, political parties can play a number of fundamental roles in democratic politics, including:

- aggregating citizens' views and interests;

- providing structured political choices to citizens;

- engaging citizens in the democratic process;

- training and socialising political leaders;

- developing policies and taking responsibility for implementing them; and

- facilitating co-ordination within legislatures and between branches of government.

In addition, political parties can help advance governmental accountability. Opposition parties have a direct interest in monitoring the actions and checking the power of ruling parties and putting forward viable policy alternatives. Parties are also held accountable for their performance by voters. Compared to individual politicians, parties tend to have longer time horizons and a stake in maintaining a long-term reputation. Any individual politician who ignores the electorate or abuses his power can face pressure from within the party to reign in his or her behaviour.

Although it is most common to think of political parties in terms of their role in democratic politics, they can also be key players in promoting sustainable development. Parties can initiate pro-development policies which reflect the interests of key social sectors and can gain public legitimacy for these policies through electoral competition. Parties can then ensure the necessary co-ordination within government to implement these policies. The long-term interest of parties lies in promoting sustainable development to continue winning popular support. Thus, the important roles that parties play in establishing political accountability potentially contribute to positive socio-economic development.

\section{Common shortcomings of political parties}

Two striking facts stand out about political parties in developing countries: first, parties are exceptionally unpopular - on the whole they are the least-respected public institution in most countries; and second, the complaints that citizens have about parties are remarkably similar across different countries and regions. Taken together these complaints form what I call the "standard lament" about parties in new and struggling democracies: 
- that parties are corrupt, self-interested organisations dominated by power-hungry elites;

- that they do not stand for anything and only hold to ideological positions opportunistically;

- that they waste endless time and energy squabbling with each other over petty issues;

- they only become genuinely active at election time; and

- they are ill-prepared for governing and do a bad job of it when voted in.

Although the characteristic shortcomings of parties are very common throughout the developing world, the overall party systems vary considerably. Some of the major types include:

- dominant party systems: one party holds most of the political power and occupies most of the political space, with scattered opposition parties at the margins;

- inchoate party systems: most political parties are unstable organisations that come and go from the political stage; and

- stable distributed party systems: in which a small number of relatively stable parties trade power back and forth across successive elections.

The causes of the standard deficiencies of parties in developing countries are complex and multiple. They include:

- compressed transitions: the relatively rapid movement from authoritarianism to multiparty politics characteristic of democracy's "third wave" has left parties with little time to develop a broad grassroots base; instead they were thrown immediately into electoral competition and forced to become electorally-focused, with negative consequences for their long-term organisational development;

- weak rule of law: the weak rule of law characteristic of many developing countries works against party development by providing an inadequate framework for regulating the financial and other activities of parties;

- poverty and inequality: widespread poverty and high inequality in many developing countries contribute significantly to the rise and endurance of neo-patrimonial, clientelistic politics marked by high levels of political corruption and politically-passive citizens; 
- anti-party legacies: in many new or struggling democracies citizens have a deeply anti-political outlook based on their previous experience with authoritarianism. Withdrawn, cynical citizens make it very difficult for political parties to establish successful representational links; and

- presidential systems: the presidential systems that predominate in Latin America, the Middle East, the former Soviet Union, sub-Saharan Africa, and parts of Asia tend to encourage top-down leader-centric parties and weak parliaments.

\section{The party aid domain}

\section{Initial phase}

Various international actors have provided assistance to parties over the last three decades in response to the disjunction between the potential importance of political parties and their weak state in most new or struggling democracies. From the mid-1970s to the middle years of this decade, such aid was dominated by the German political foundations (Stiftungen) and the US party institutes (with USAID playing a significant role as the largest funder of these institutes). Some other European political foundations were also active, the largest of these being Olof Palme International Center (Sweden).

The most common type of assistance was training - seminars for party cadres on all aspects of party development, usually carried out by outside trainers. The assistance often also included a wider menu of support as part of a general partnership approach between the party aid providers and the target parties - strategic advice, provision of consultants, exchange visits and study tours, minor material assistance, logistical facilitation, and the provision of political polls.

Some of the assistance, including most of the European assistance, took a fraternal approach - party-to-party partnerships based on a common ideological identity. Other assistance, including most of the US's, followed a multiparty approach - in which the party aid provider worked with all of the main parties in the country simultaneously. Debates over the relative advantages and disadvantages of the two approaches are common; each has particular strengths and weaknesses, depending on the context.

\section{New phase}

From the middle years of this decade, international party assistance entered a new phase of expansion and diversification, characterised by: 
- the entry of new actors into the party aid domain, including: 1) multiparty party aid organisations (e.g. Netherlands Institute for Multiparty Democracy - NIMD, Demo Finland and the Danish Institute for International Multi Party Co-operation); 2) multilateral organisations (e.g. UNDP, International IDEA, the OAS); and 3) at least one major bilateral aid agency (DFID);

- a broadening of types of assistance to include direct funding of parties and a greater focus on strengthening party systems rather than individual parties, including efforts to build interparty dialogues, help reform party finance systems, and support constitutional reform processes;

- a wider geographic reach: much more party assistance is now going to non-Western countries - in Africa, the Middle East, and Asia - as opposed to the earlier concentration of party aid in Central and Eastern Europe and Latin America.

This expansion of party assistance reflects the widening realisation within the development community that political parties are often the weakest link in attempted processes of democratisation and in development more generally. It also reflects growing recognition, after the surge of attention to civil society development in the 1990 s, that no matter how vibrant it becomes, civil society is not a substitute for political society. Political parties play some crucial roles that civil society organisations cannot. Despite this expansion of political party assistance, however, significant parts of the development community remain wary of giving political party assistance, uncertain about the links between political party development and socio-economic development, concerned about the political sensitivities of such assistance, and worried that working with political parties will entail engagement with corrupt, tawdry politicians.

\section{Evaluation}

Throughout the first phase of party assistance, party aid groups paid relatively little attention to evaluation. They felt convinced about the importance of political party development and the value of their core methods. This situation is changing in the new phase of expanded, diversified party assistance, which coincides with greater attention generally in the development assistance community to evaluations. This attention is naturally spilling over to party assistance - the earlier sense among some providers that party aid was a kind of reserved domain sheltered from the everyday bureaucratic imperatives of development assistance is fading. 
In addition, some of the new actors in the field of party assistance have brought with them much greater attention to evaluation. NIMD, for example, has always emphasised both programme and institutional evaluations, and made these evaluations available on its website. DFID has sponsored reviews of party assistance as well as a major workshop (co-sponsored with International IDEA at Wilton Park in March 2010) to bring together party aid practitioners to reflect on the lessons of experience. International IDEA undertook significant efforts to disseminate the findings of a searching external evaluation of its own political parties programme. USAID has recently commissioned a major review of party assistance, which is being carried out by a team of experts at the University of Pittsburgh.

As with other areas of democracy and governance assistance, finding highly precise ways to measure the impact of party assistance is difficult. Problems of causality or attribution are significant. If a party that has received external campaign-related assistance does better in one election than in a previous one, many different factors could have caused that improvement beyond just the injection of party assistance. More importantly, settling on the relevant indicators of successful party development or party system development is a challenge. What may appear obvious indicators - such as electoral performance - can be misleading. If, for example, a party with significant deficiencies with regard to internal democracy and the inclusion of women performs better in an election thanks to campaign assistance, but without ameliorating such deficiencies, the improved electoral performance is not necessarily a positive step in terms of democratic development. Some of the most important elements of political party development, such as effective representation of citizen interests, are hard to measure in any productive, quantifiable fashion.

\section{Results}

Previous research of mine pointed to two major conclusions about the results of political party assistance (Carothers, 2006). First, it is very difficult to find examples of transformative effects of such assistance. I did not find any examples of countries receiving international party assistance whose parties had made clear progress in resolving the various shortcomings listed above. Despite three decades of party assistance, political parties are in bad shape almost everywhere in the developing world.

Secondly, however, I did find evidence of many small to medium-sized changes in parties that seem to have been facilitated by party assistance parties that have learned to deliver campaign messages more effectively, that are allowing a greater place for women, that are experimenting with more democratic methods of internal selection, that are using polling to 
better understand citizens' desires, and so forth. I was also able to observe meaningful interparty dialogues that were facilitated by international assistance, some system-wide reforms on party financing, and some efforts to develop ethical standards for parties. Given that party assistance is on the whole not a very expensive enterprise compared to the larger pool of official development assistance, these modest changes seem to be worth the effort.

Nevertheless, frustration and disappointment are characteristic of many party aid efforts. Many parties absorb significant amounts of aid for many years without showing important signs of positive change. Expectations about what party aid can accomplish are often too high. The very modest results of most party assistance can be ascribed to two main factors. Firstly, political parties are very difficult organisations to assist. Many parties are highly resistant to reforms. They are leader-driven vehicles, serving the interests of a narrow party elite willing to use any methods to gain and maintain power. For the leadership of these parties, the reform agenda of international party aid providers is largely unappealing and even threatening. Almost every element of that agenda - whether greater financial transparency, more internal democracy, greater inclusion of women, more role for youth or more rational management systems - represents a potential reduction of the power of the entrenched party elite.

Moreover, the rational assumptions that international party aid providers hold on the basic aims of parties with which they work - that parties seek to represent citizens' interests, to elaborate a well-conceived, technocratic political platform, to compete hard but fairly, to emphasise substance over personalism, and so forth - often are not shared by the party elites in question. They see their own parties in very different terms, as vehicles useful for advancing particularistic interests of the elites themselves. Even when party elites look beyond their personal interests, they often do not believe that donor suggestions will serve the overall interest of the party. In an electoral environment which rewards charismatic leadership and patronage ties, the party may consider strengthening internal democracy or financial transparency to be detrimental to its ability to effectively compete in elections.

Secondly, few of the main deficiencies of parties in new or struggling democracies are rooted in a lack of knowledge. Therefore, the provision of technical assistance, which is by far the largest element of party assistance, does little to ameliorate parties' shortcomings. Instead, as noted above, the principal causes of the weak state of parties in most of these countries are much deeper structural factors, such as the wider lack of rule of law or the socioeconomic conditions that fuel patronage-based politics. These factors are not very easy to improve through conventional party assistance. This gap between the nature of the assistance offered and the full nature of the 
underlying problems is of course not unique to political party assistance, but it is strongly felt in the party aid arena.

\section{Special challenges}

In addition to these various issues, political party aid also faces two significant additional challenges. Firstly, party aid is fraught with an unusually high level of political sensitivity. All aid relating to the core political processes of recipient countries - elections, parties, and legislatures - is inevitably politically sensitive. But party aid is especially so given that parties are the institutions that are competing for power and, when successful, assuming power. Training parties to campaign more effectively, to build their membership, to refine their party programmes, and other typical elements of party assistance all easily raise questions about political favouritism and interference. Given how tightly most established democracies restrict any foreign assistance to their own political parties, it is not surprising that party aid often encounters questions in developing countries about its legitimacy and appropriateness.

In the context of the current backlash against democracy assistance which emerged in the middle years of this decade, party aid is facing an even higher level of political sensitivity and suspicion than before. Party aid programmes have been a target of governments pushing back against Western democracy assistance in the former Soviet Union, the Middle East, and South America. Nevertheless, party aid continues in dozens of countries in these regions and elsewhere.

The special sensitivity of party assistance turns up not just in the recipient countries but also in the donor countries themselves. Depending on how donors are engaging with political actors, party aid programmes often provoke doubts and questions within political circles and among the citizens of donor countries. The most common doubts that arise are: 1) are we interfering in the legitimate political processes of other countries by assisting their parties?; 2) are we engaging and possibly helping corrupt politicians?; and 3) are our own parliamentarians using the party assistance to go on frivolous trips abroad? As one example of this domestic sensitivity, Norway established a political party assistance organisation and then closed it several years later as a result of criticisms within Norway about how that assistance was being used. Furthermore, a part of the development aid community remains concerned about political party assistance being part of the ODA system. They argue that support to political parties and party systems could undermine official bilateral development co-operation and should therefore be left to the sphere of diplomatic relations between countries because of its highly political nature. 
Secondly, party assistance must live with a relative lack of confidence about its underlying institutional model. Given the many flaws of established Western democracies, people in aid-receiving countries often ask what basis Westerners have to come to their country and offer solutions. This question hits especially hard with regard to party assistance. Only in a few established democracies can it be said that political parties are in a good state of health and closely resemble the rather idealised political party model that party aid providers implicitly seek to re-create abroad. In at least some established democracies, political parties seem to share many of the deficiencies of parties in new or struggling democracies, especially with regard to legitimacy among citizens, internal democracy, and transparency of financing. In simple terms, it is hard not to ask how political party aid providers can be confident that they know how political party development can be nurtured or whether the party model they seek to export is already fading from the global political scene.

\section{Principles for political party assistance}

Common principles for political party assistance could be helpful in alleviating some of the suspicions and doubts about party assistance both in recipient and donor countries. They could also be useful as a way of capturing important lessons learned for a field in a period of expansion and diversification.

Yet identifying - let alone agreeing on - such principles is not simple. Different aid actors are taking quite divergent approaches to this work and there remains a weak base of understanding of the results of such efforts over the years. Moreover, what might seem like obvious principles at first sight are often untenable. For example, it might be tempting to suggest that party aid should strive to be non-partisan. Yet this would not work for those party aid organisations that use the fraternal approach, in which party aid actors link up with and favour particular parties in partner countries. Or it might be suggested that party assistance should not entail direct financial transfers to recipient parties. Yet some of the new entrants to the party aid domain have been using direct grants to parties and believe that the results are positive. With these caveats in mind, the following principles have been developed based on the discussion at the OECD-DAC-GOVNET and International IDEA Seminar on Political Party Assistance, 9 December 2010 (Box 6.1). These principles can be used as a starting point for discussion on the role of official development co-operation in political party assistance. 


\section{The value and place of political party assistance}

1. Recognise the value of effective political parties, not just for democracy but also for development. Political parties play potentially crucial roles in articulating policy alternatives, helping spark public engagement in and legitimacy for pro-development policies, and establishing governmental accountability.

2. Be aware of but not paralysed by the sensitivities of party aid. Party aid is inevitably politically sensitive given its reach into core political processes and institutions. At the same time, however, it has a legitimate place in foreign assistance if pursued openly in genuine pursuit of democratic and developmental goals.

3. Build on the interconnections between party aid and other elements of political aid. Political party work connects naturally to other forms of assistance for strengthening democratic processes including work on legislatures, elections, civic advocacy, and local government performance.

4. Don't confuse party diplomacy with party aid. Western political parties sometimes engage abroad to build political alliances or coalitions in multilateral organisations, or to enhance bilateral diplomatic relations. Such party-to-party diplomacy is legitimate, but is significantly different from party assistance.

\section{Operational issues}

5. Base party aid on a sophisticated understanding of the political economy of the relevant parties and party systems. Given the wide range of party types, roles and systems, it is imperative that party aid providers develop deep knowledge of the actual nature, history and function of parties within their national contexts before undertaking party assistance.

6. Don't assume common goals between providers and recipients. Party aid providers must be careful not to take recipient parties at face value in terms of their political role and goals. Aligning the goals of party aid providers and party aid recipients is crucial to success. Party aid providers should pay attention to actors within political parties who may share their goals more closely than party leaders because this will foster local ownership and contribute to sustainable results.

7. Stress co-operation rather than competition among party aid providers. As party aid increases, so does the need for party aid providers to communicate with each other and avoid overlap or 
competition. New entrants to the party aid domain should take special care to ground their work in a thorough analysis of what other aid actors are already doing in the same countries.

8. Embrace transparency. Operating transparently is crucial to managing the political sensitivities inherent in political party aid.

9. Emphasise gender and youth issues. Fostering greater inclusion of women in political parties has been an element of many party aid programmes. Encouraging progress has been made in this area in some countries, more so than for many other aspects of party change. But this focus must be sustained and even deepened. In addition, as the Arab Spring demonstrated, young people are playing a critical role in driving behavioural change. Support to youth participation and inclusion must continue to be encouraged in the future.

\section{Monitoring and evaluation}

10. Pursue realistic, incremental goals. Given the uncertain and often troubled state of political parties - even in established democracies - political party aid must be based on very modest, realistic, and incremental goals, rather than on ideal models. This will require in-depth studies of the local political environment. Local realities on the ground change rapidly in often highly complex political environments. Setting realistic goals and being flexible in implementing them will enable party aid providers to respond swiftly to realities on the ground and avoid losing the momentum for change.

11. Keep strengthening evaluations, but don't overemphasise numbers. Whether and how party assistance works have been insufficiently examined empirically. Party aid organisations should continue to deepen their evaluation efforts and support research and other learning exercises. At the same time, however, funding organisations should recognise that any efforts to reduce the success of political party development to strict quantitative indicators are likely to be unhelpful.

12. Recognise the long-term challenge, but focus on tangible outcomes. Problematic features of political parties and party systems are not amenable to quick fixes and party aid is most effective when pursued on a long-term basis. Nevertheless, party aid programmes should define tangible medium-term outcomes to define the path of such longer-term engagement. 


\section{Reference}

Carothers, T. (2006), Confronting the Weakest Link: Aiding Political Parties in New Democracies, Carnegie Endowment for International Peace, New York. 


\section{Chapter 9}

\section{Principles for media assistance}

These principles were prepared jointly by Sina Odugbemi from the World Bank's Communication for Governance and Accountability Programme (CommGAP) and James Deane from the BBC World Service Trust (BBC Media Action) and presented for discussion (and subsequent revision) to the Seminar on Trends in Support of Accountability: Media Assistance Today on 7-8 June 2011 and at the 15th Plenary Meeting of the OECD/DAC Network on Governance on 9 June 2011. 
"If it were left to me to decide whether we should have a government without newspapers or newspapers without a government, I should not hesitate a moment to prefer the latter". (Thomas Jefferson)

\section{Context}

For much of modern democratic history, the media has been considered one of the most powerful and central forces for accountability. It receives special protection within most democratic constitutions expressly because an informed citizenry and a "fourth estate" capable of acting as a check on executive power are considered to be critical to good governance. Box 9.1 provides a useful and succinct contextual framing of accountability and its link to information and the media.

Within the context of aid effectiveness and democratic governance agendas, few question the importance of a free, professional and plural media in contributing to good governance (BBC World Service Trust, 2009). Nevertheless, few within the development community accord the media the same importance as other national accountability institutions. The media is mentioned (once) within the Accra Agenda for Action on aid effectiveness within the context of helping to contribute to mutual accountability. ${ }^{1}$

\section{Box 9.1. Political accountability and information deficiencies}

"The idea of political accountability has been at the center of the development debate in recent years. The hope is that once democratic institutions reflect the will of the majority, effective development policies focusing on the poor will be implemented. Economic theory supports these beliefs. Becker (1983) shows that when political competition is fully secured, efficient policies will arise. Yet developing democratic institutions that depend on the will of the general population has been particularly difficult to achieve in many countries. These problems have often been linked to information deficiencies, i.e. voters' unresponsiveness to policies (e.g. Grossman and Helpman, 1996) in theory; media shortcomings (Besley and Burgess, 2002) and lack of accountable local institutions (Bjorkman and Svensson, 2009) in practice. These problems have often been linked to information deficiencies, i.e. voters' unresponsiveness to policies (e.g. Grossman and Helpman, 1996) in theory; media shortcomings (Besley and Burgess, 2002) and lack of accountable local institutions (Bjorkman and Svensson, 2009) in practice."

Source: Aker, JC., P. Collier and P. Vicente (2011), "Is Information Power? Using Cell Phones During an Election in Mozambique", paper presented at School of Business and Economics, Universidade NOVA de Lisboa, 20 May 2011, available at www.pedrovicente.org/cell.pdf. 
Several surveys suggest that the issue ranks low on the list of governance priorities within development agencies. Outside of the United States and the World Bank, only Sweden has a full-time staff member focused on support to media within the context of democratic governance and Norway has one half-time professional. That constitutes the entirety of specialist capacity within the OECD DAC system. Neither UNDP nor the European Commission has any clear capacity on the issue of media support within the governance agenda at the international level. ${ }^{2}$

Many DAC members have indicated that the issue should be a priority for domestic accountability, but many also lack understanding, capacity and resources to give effective support to the media as an accountability mechanism. Funding is allocated to media work, but is often not institutionalised or integrated into an overarching policy structure, ${ }^{3}$ and may therefore not be efficiently used.

\section{Media and accountability in the democratic public sphere}

Good governance depends on a functioning national public sphere - the space between government and citizens, where citizens come together (even virtually), share information, and deliberate on public issues. The media provides news and information to the public, brings issues to the public agenda and facilitates public debate and discussion. It serves as a watchdog for the public interest and holds state and non-state actors accountable. The media is crucial for good governance: it creates the conditions for inclusive policy dialogue, as well as providing a platform for broad-based participation in actual policy processes.

While the media is one of many domestic accountability mechanisms, it has the unique ability to enhance dramatically the visibility and effectiveness of other accountability mechanisms within society (Box 9.2). ${ }^{4}$

\section{Box 9.2. Using the media to enhance accountability mechanisms}

As part of an anti-corruption programme, Brazil's federal government audited the expenditure of federal funds by randomly-selected municipalities. Results of these audits were made publicly available and covered by the media. Researchers found that citizens used this information to punish politicians who were performing badly. This effect was more pronounced in areas where local media disseminated the audit results.

Source: Ferraz, F. and C. Finan (2008), "Exposing Corrupt Politicians: The Effects of Brazil's Publicly Released Audits on Electoral Outcomes." Quarterly Journal of Economics, Vol. 123, N. 2, pp. 703-45. 


\section{The media, domestic accountability, and the role of development assistance}

The GOVNET has selected the media, alongside parliaments and political parties, as one of three key strands requiring greater clarity and focus in donor support to domestic accountability. As investment grows in other domestic accountability initiatives (many of which - such as budget monitoring, access to information, aid transparency - are informational in character), a key challenge is to create more productive linkages with efforts supporting the domestic accountability role of the media.

Media development promotes voice, accountability and transparency through supporting the media's editorial independence, financial sustainability, professional capacity, and a lively civil society. Interventions range from supporting legislation to safeguard media freedom to equipping a small radio station with laptops and transmitters. Historically, media development has focused on journalism training, but donors increasingly understand that the media are part of a country's political economy and therefore require broader, more substantial, and longer-term support. Support to the media in developing countries is most effective if it is longterm, aims at financial sustainability beyond the donor intervention, involves local as well as international partners, and sees the media as part of a larger system of domestic accountability. The most effective media interventions are often based on existing platforms and initiatives - these have the advantage of having existing audiences, infrastructure, monitoring and evaluation frameworks and known reach. Interventions do not need to be new to have an impact on accountability.

\section{Evidence}

\section{Politics and corruption}

A substantial literature exists in the disciplines of economics, political science, communication research and others on the impact of the media on accountability. The media has been shown to play a role in fighting both systemic and petty corruption (Box 9.3). Media coverage of corruption can lead to investigations, trials, resignations, and government policies. It can also influence the social climate in a society towards more openness and less tolerance of corrupt behaviour.

Journalists in free media systems have fewer constraints on their reporting and more incentives to actively investigate the misconduct of public officials. This is reflected in empirical evidence showing that countries that score high on the Press Freedom World Wide Index or that 
have high coverage of information and communications technologies and high newspaper circulation also score lower on international corruption indices (Stapenhurst, 2000; Brunetti and Weder, 2003; Bandyopadhyay, 2006). Evidence also shows the causal direction of this relationship: more press freedom leads to less corruption, there is no evidence that more corruption leads to less press freedom (Ahrend, 2002).

On a project level, studies have shown that citizens use the media as a channel for accountability to monitor the delivery of public services. Once a grievance has been made public, public outrage and increased public monitoring will motivate public authorities to correct it. For example, media coverage has been shown to level prices for school lunches (Ahrend, 2002), increase the portion of public funding that actually reached intended programmes (Reinikka and Svensson, 2005), and curb corruption in public sectors Franken (et al., 2005). By using adequate statistical controls, these studies were able to ascertain that media was indeed the main factor contributing to improved domestic accountability.

\section{Box 9.3. The power of the media as measured by the corrupt}

"Which of the democratic checks and balances - opposition parties, the judiciary, a free press - is the most forceful? Peru has the full set of democratic institutions. In the $1990 \mathrm{~s}$, the secret-police chief Montesinos systematically undermined them all with bribes. We quantify the checks using the bribe prices. Montesinos paid television-channel owners about 100 times what he paid judges and politicians. One single television channel's bribe was five times larger than the total of the opposition politicians' bribes. By revealed preference, the strongest check on the government's power was the news media."

Source: McMillan, J. and P. Zoido (2004), "How to Subvert Democracy: Montesinos in Peru", Journal of Economic Perspectives, Vol. 18, Nº. 4, pp. 69-92.

\section{Service delivery}

Most governance actors acknowledge that citizens need information about public services if they are to hold government accountable for their provision. Access to information movements, budget monitoring initiatives and aid transparency efforts are just some initiatives that have focused on enhancing accountability by ensuring that citizens have better access to information on the services or initiatives that are designed to benefit them.

Politicians have been shown to be more responsive to citizen needs if citizens have access to information on political decisions. This effect is particularly strong in clearly-defined media markets, where elected officials tend to act more in the interest of their constituents, attend more committee 
hearings, and cast their vote less frequently according to their party's agenda (Snyder and Strömberg, 2008).

The media improve domestic accountability by putting issues on the agenda that directly concern the interests of citizens and public institutions (Box 9.4). This forces governments to take note of and respond to these interests. The relationship between a free media and government responsiveness has been demonstrated in the areas of public spending on education and health (Petrova, 2008), prevention of famine and public food distribution (Sen, 1981), and relief spending (Besley and Burgess, 2002). Disasters that are covered by the national media are more likely to receive foreign aid and receive more money than those not covered (Eisensee and Strömberg, 2007; van Belle, 2010).

\section{Box 9.4. When a radio programme turned the lights on in Angola}

In Angola, the neighbourhood of Ilha da Madeira in Hoji-Ya-Henda now has light and electricity after 30 years. This is a direct result of the 100 Dúvidas radio programme broadcast on Radio Ecclesia - Angola's only independent radio station. Supported by the BBC World Service Trust as part of a multi-country, DFID-funded governance and transparency project, 100 Dúvidas has helped the radio station focus on the concerns of the poor, mainly service delivery (water, health, roads and bureaucracy). Most of the issues explored in the programme spring from specific local complaints, but have widespread resonance as many people are affected by them. It is the first programme on Radio Ecclesia to derive content directly from the input of audience members, who feed in through SMS, emails or hand-written letters.

\section{Political participation}

The relationship between politics, the media and interpersonal communication is complex and has been substantially researched over several decades. Early evidence indicated a particularly significant role for radio in providing a critical platform for political debate and informing the electorate, as well as affecting government resource allocation and responsiveness.

More recently, there has been substantial research into the impact of the media on political participation in developing economies. Findings are consistent with earlier studies: in a wide variety of contexts, the media have a key role to play in informing individuals; providing an inclusive and critical platform for public dialogue and debate; stimulating interpersonal communication and ultimately ensuring that policy making benefits a greater number of people (Snyder and Strömberg, 2004; Leeson, 2008; 
Olper and Swinnen, 2009). Research has also shown that the larger the share of uninformed voters in the electorate, the higher the likelihood that politicians will manipulate policies to increase their chances to get re-elected, even of those policies are not in the public's interest in the long term (Shi and Svensson, 2002).

There is a particularly strong body of evidence from both developed and less developed countries that shows that people exposed to and engaging with high quality media that cover political issues are better informed, more civically engaged and more likely to vote (see de Vreese and Boomgaarden, 2006; Aker et al., 2010; Delli Carpini and Keeter, 1996 and many others).

\section{Challenges}

\section{Lack of systematic evidence}

Although there is a substantial amount of research on the role of the media in domestic accountability, it is scattered and inconsistent. Studies use vastly different definitions and measurements of accountability and interpret results inconsistently. Anecdotes of successful media interventions outnumber rigorous studies with strong empirical measures.

The research also lacks an overarching theoretical framework to enhance our systematic understanding of the role of the media in accountability. Donor organisations are increasingly seeing the need to construct such a framework. In its publication Public Sentinel: News Media and Governance Reform, the World Bank situates the interaction between the media and accountability within the framework of a democratic public sphere. DFID and AusAID are in the process of commissioning a systematic review of effective approaches by non-government organisations (including the media) for improving service delivery in developing countries. The aim is to strengthen the international community's capacity for evidence-based policy making when enhancing accountability. ${ }^{5}$

\section{Lack of institutional support structures}

The US Department of State and USAID have spent more than half a billion dollars on media development in the past five years. Their combined budgets for 2010 saw USD 140.7 million allocated to media support - a $36 \%$ increase over 2009 spending and an even more dramatic rise from the USD 68.9 million spent five years earlier (Mottaz, 2010).

Figures are available for expenditure on media support outside of the US, though comparative figures are not available for 2010. OECD reporting from 2005 through to 2007, however, indicated an increase in donor 
assistance to the media sector - up from USD 47.9 million to USD 81.7 million over two years. ${ }^{6}$ While consolidated figures are not available, EU mechanisms also provide considerable financial support to the media.

Despite this substantial level of investment, there are few institutional focal points (outside of the US) within key donor organisations attempting to make sense of the media's role in development, let alone as an accountability mechanism. The lack of an institutional home for these issues will continue to undermine efforts to better understand, measure and strengthen the role of the media as a domestic accountability mechanism.

\section{Keeping pace with a shifting media landscape}

Social media and mobile technologies are increasingly shaping the way people interact with politics and represent an increasingly important accountability mechanism. New information and communication technologies (ICT) have added channels and platforms for citizens to hold their government accountable.

A more limited body of evidence exists on ICT (mostly focusing on European and American contexts), but given the pace of change and the rate of Internet/mobile proliferation in many developing economies, building an evidence base remains very much a work in progress. However, a growing list of initiatives illustrates the possibilities and potentials of using social media and mobile technologies to increase domestic accountability. ${ }^{7}$ Donors need to be aware that new technologies and mobile applications change the rules of the game completely and constantly.

\section{Strategic principles for media assistance}

1. Incorporate media assistance into a larger framework of development aid. Access to information is crucial for domestic accountability. Media institutions in particular provide tools and channels for accountability that can complement and enhance other accountability mechanisms, but also add new instruments that may be at least as powerful and efficient as the more commonly supported accountability measures. A weak and/or highly constrained media can undermine domestic accountability. The risk of not considering and supporting the media as part of broader accountability programmes is significant.

2. Incorporate media indicators and audits into governance diagnostics and needs analysis. The state of the media is inseparable from the state of governance in general. For instance, 
the UNESCO standard media development indicators (UNESCO, 2008) could usefully be incorporated into governance needs assessments to more effectively guide interventions for improving media as an accountability mechanism.

3. Co-operate with media development CSOs and determine media objectives and outcomes, not methodologies. Given a lack of specific expertise on media development within the majority of donor organisations and local media beneficiaries, there is a strong argument for developing media support strategies and specific interventions in partnership with media development CSOs. Some donors are already taking this approach. Media development organisations, along with local partners, are often best positioned to assess context and needs and to develop effective interventions to address these. While there is a clear need to ensure that media strategies complement overarching accountability objectives, there is a strong argument for providing CSO implementers with substantial scope - and the ability to propose creative solutions - as opposed to highly prescriptive requirements.

4. Focus on building public demand for inclusive policy dialogue. The Accra Agenda for Action calls for "broadening country-level policy dialogue on development" (OECD, 2005/2008). One concern is a paucity of "evidence from which to systematically assess progress in implementing these commitments". There is clear potential for media support that enables and fosters policy dialogue to contribute to this goal; research incorporated into such support can assist in building a body of evidence and understanding of effective strategies for stimulating policy dialogue.

5. Support independent, sustainable, and capable local media in developing countries. Local media in developing countries often enjoy significant reach and audience interest, but lack the resources, skills and support to better understand the needs of populations and effectively hold government to account. In supporting these organisations to improve their watchdog role, donors can effectively enhance non-media accountability interventions, build people's demand for domestic accountability, and strengthen local media as an accountability institution.

6. Foster ownership as a central component of support. The nature of productive relationships between the media and audiences is one that engenders a sense of ownership. Where people see the media acting on their behalf and critically - enabling them to engage 
directly with issues and politicians - there exists a clear sense of trust and ownership of media programmes.

7. Promote citizen access to the media and mobile technologies as well as citizens' media literacy. The media can only be an effective accountability mechanism only if citizens are able to use them. This includes access to media products and infrastructure as well as the ability to make sense of information.

8. Encourage links between media institutions and the rest of civil society. Media and civil society organisations together can form a formidable coalition for accountability and good governance. Donors should consider joining support for several accountability mechanisms, including media support, in appropriate situations.

9. Support systematic research on the effects of media and information access on domestic accountability. As outlined in this discussion paper, there is empirical evidence of the media's impact on domestic accountability, but it is not integrated into a larger theoretical framework. Research, including monitoring and evaluation, should be part of any media support project, but should also be supported in its own right to advance our understanding of the role of the media in domestic accountability in different political, economic, and social contexts.

10. Learn about and harness new technologies. Internet and mobile-focused support is not appropriate in all contexts. Needs analyses must properly assess media and communications environments to determine the most appropriate media platforms for supporting accountability. Where interventions do focus on new technologies, research should be incorporated to build a body of policy-relevant evidence to guide subsequent support.

Notes

1. The word "media" was inserted, within the context of mutual accountability, only a few weeks before Accra as a result of advocacy by the BBC World Service Trust.

2. UNESCO does have such capacity but has not been significantly involved in the DAC.

3. It is notable that the most recent and perhaps most useful published analysis of European spending on support to media was commissioned from the National Endowment for Democracy in the United States. 
4. According to the World Bank Social Accountability Sourcebook, "a common element of almost all successful social accountability initiatives is the strategic use of and support to both traditional and modern forms of media." (World Bank, 2006)

5. Information from the International Initiative for Impact Evaluation website, at www.3ieimpact.org/systematicreviews/3ie-ausaid-dfid.php, accessed 18 September 2012.

6. These figures are indicative only: it is not clear what form communications spending or spending specifically earmarked as ODA for radio, television and print media actually takes, and there is no clear OECD definition of this area of support (Myers, 2009).

7. The Technology for Transparency Network initiative catalogues accountability projects that use mobile technology and social media as accountability tools (http://transparency.globalvoicesonline.org).

\section{References}

Ahrend, R. (2002), "Press Freedom, Human Capital and Corruption", DELTA Working Paper, No. 2002-11, École Normale Supérieure, Paris.

Aker, J.C., P. Collier and P.C. Vicente (2010), Is Information Power? Using Cell Phones during an Election in Mozambique, draft research report, available at: $w w w . p e d r o v i c e n t e . o r g / c e l l . p d f$.

Bandyopadhyay, S. (2006), "Knowledge-driven Economic Development," Department of Economics Discussion Paper Series, № 267, University of Oxford, Oxford, available at www.economics.ox.ac.uk/Research $/ w p / p$ df/paper267.pdf.

BBC World Service Trust (2009), Governance and the Media: A Survey of Policy Opinion, BBC World Service Trust, London.

Becker, G.S. (1983), “A Theory of Competition among Pressure Groups for Political Influence", Quarterly Journal of Economics, Vol.98, pp. 371-400.

Belle, van D.A. (2010), "Media Agenda Setting and Donor Aid," in Norris, P. (ed.), Public Sentinel: News Media and Governance Reform, World Bank, Washington, DC.

Besley, T. and R. Burgess (2002), "The Political Economy of Government Responsiveness: Theory and Evidence from India", Quarterly Journal of Economics, Vol. 117, № 4, pp. 1 415-51. 
Bjorkman, M. and J. Svensson (2009), "Power to the People: Evidence from a Randomised Field Experiment on Community-based Monitoring in Uganda", Quarterly Journal of Economics, Vol. 124, № 2, pp. 735-69.

Brunetti, A. and B. Weder (2003), "A Free Press Is Bad News for Corruption", Journal of Public Economics, Vol.87, $\mathrm{N}^{\circ} 7-8$, pp. $1801-24$.

Delli Carpini, M.X. and S. Keeter (1996), What Americans Don't Know About Politics and Why it Matters, Yale University Press, New Haven.

Eisensee, T. and D. Strömberg (2007), "News Droughts, News Floods, and U.S. Disaster Relief", Quarterly Journal of Economics, Vol. 122, N2, pp. 693-728.

Ferraz, F. and C. Finan (2008), "Exposing Corrupt Politicians: The Effects of Brazil's Publicly Released Audits on Electoral Outcomes." Quarterly Journal of Economics, Vol. 123, Nº. 2, pp. 703-45.

Franken, N., B. Minten and J. Swinnen (2005), "The Impact of Media and Monitoring on Corruption in Decentralized Public Programs: Evidence from Madagascar", LICOS Centre for Institutions and Economic Performance Discussion Paper, $\mathrm{N}^{\circ} 155 / 2005$, Katholieke Universiteit, Leuven, available at www.econ.kuleuven.be/licos/DP/DP2005/DP155.pd $f$.

Grossman, G.M. and E. Helpman (1996), "Electoral Competition and Special Interest Politics", Review of Economic Studies, Vol. 63, N 2, pp. 265-286.

Leeson, P.T. (2008), "Media Freedom, Political Knowledge, and Participation", Journal of Economic Perspectives, Vol. 22, $\mathrm{N}^{\circ} 2$, pp. 155-69.

McMillan, J. and P. Zoido (2004), "How to Subvert Democracy: Montesinos in Peru", Journal of Economic Perspectives, Vol. 18, No. 4, pp. 69-92.

Mottaz, L. (2010), US Government Funding for Media Development, a special report to the Center for International Media Assistance, Washington, DC, available at http://cima.ned.org/sites/default/files/CIM A-U.S._Government_Funding_for_Media_Development-Report\%20123-2012.pdf.

Myers, M. (2009), Funding for Media Development by Major Donors Outside the United States, Center for International Media Assistance, Washington, DC, available at: http://cima.ned.org/sites/default/files/CIM A-Non-US_Funding_of_Media_Development.pdf. 
OECD (2005/2008), Paris Declaration on Aid Effectiveness and the Accra Agenda for Action, OECD Publishing, Paris.

Olper, A. and J.F.M. Swinnen (2009), "Mass Media and Public Policy: Global Evidence from Agricultural Policies", paper prepared for presentation at the International Association of Agricultural Economists Conference, Beijing, China, 16-22 August 2009, available at: http://ageconsearch.umn.edu/bitstream/51694/2/OlperSwinnen\%20IAAE\%2009_2.pdf.

Petrova, M. (2008), "Political Economy of Media Capture", in Islam, R. (ed.), Information and Public Choice. From Media Markets to Policy Making, The World Bank, Washington, DC.

Reinikka and Svensson (2005),

Sen, A. (1981), Poverty and Famines, Oxford University Press, Oxford.

Shi, M. and J. Svensson (2002), "Conditional Political Budget Cycles", CEPR Discussion Paper, $\mathrm{N}^{\circ} 3$ 352, CEPR, London.

Snyder, J.M. Jr. and D. Strömberg (2004), Media Markets' Impact on Politics, working paper available at http://americandemocracy.nd.edu/sp eaker_series/files/SnyderPaper.pdf.

Snyder, J.M. Jr. and D. Strömberg (2008), "Press Coverage and Political Accountability", NBER Working Paper, $\mathrm{N}^{\circ} \mathrm{W} 13$ 878, available at http://ssrn.com/abstract $=1106604$.

Stapenhurst, R. (2000), The Media's Role in Curbing Corruption, World Bank Institute, Washington, DC, available at www.worldbank.org/wbi/governance/pdf/media.pdf.

UNESCO (2008), Media Development Indicators: A Framework for Assessing Media Development, endorsed by the Intergovernmental Council of the International Programme for the Development of Communication (IPDC) at its 26th session (26-28 March 2008), UNESCO, Paris, available at http://unesdoc.unesco.org/images/0016/001631/163102e.pdf.

de Vreese, C.H and H. Boomgaarden (2006), "News, Political Knowledge and Participation: Differential Effects of News Media Exposure on Political Knowledge and Participation”, Acta Politica, $\mathrm{N}^{\circ}$ 41, pp. 317-41.

World Bank (2006), Social Accountability Sourcebook, The World Bank, Washington, DC, available at www.worldbank.org/socialaccountability sourcebook/PrintVersions/Conceptual\%2006.22.07.pdf. 



\section{Chapter 10}

\section{Principles for parliamentary assistance}

These principles were prepared by Greg Power, Director of Global Partners \& Associates for the OECD/DAC/GOVNET and presented to the Fourth Annual Donor Co-ordination Meeting on Parliamentary Support and the 16th Plenary Meeting of the OECD/DAC Network on Governance on 24-25 April 2012. 
Parliaments perform a vital role in any system of representative democracy, but they play an especially important role in emerging democracies - not only in improving the quality of governance by ensuring transparency and accountability, but also in shaping the public's expectations and attitudes to democracy. Parliaments are the single most important institution in overseeing government activity, scrutinising legislation and representing the public's concerns to those in power. Their performance in holding government to account and engaging with voters will help to establish the norms and values in the early years of a democratic culture.

Although traditionally a small part of international support programmes, donors have paid greater attention to the role of parliaments in the last decade or so. Most support programmes usually seek to improve the effectiveness of the institution in one of their three key functions:

1. Legislation: Assessment of the legislative function will be concerned with how well parliament scrutinises and amends bills, or whether it instead simply acts as a rubber-stamp for the executive.

2. Oversight: Parliamentary oversight is the main means by which government is held to account; parliaments should ensure government departments are run efficiently and that ministers are regularly called to account for their actions, policies and spending.

3. Representation: Parliament ultimately derives its legitimacy from its ability to represent and articulate public concern. Programmes tend to concentrate on the "representativeness" of parliament (how its make-up reflects wider society) and the extent to which MPs consult and engage with voters.

\section{Parliaments and domestic accountability}

The overarching purpose of parliamentary oversight is to hold government to account. While governments are directly accountable to voters at elections, in between elections it is the duty of parliamentarians to hold ministers and their departments to account on the public's behalf. The Inter-Parliamentary Union's Tools for Parliamentary Oversight sets out four key oversight roles:

- Transparency and openness. Parliament should shed light on the operations of government. It provides a public arena in which government's policies and actions are debated, exposed to scrutiny and held up to public opinion. 
- Delivery. Parliamentary oversight should test whether the government's policies have been implemented, and whether they are having the desired impact.

- Value for money. Parliament needs to approve and scrutinise government spending. It should highlight waste within publicly-funded services, and aim to improve the economy, efficiency and effectiveness of government expenditure.

- Tackling corruption and misuse of power. Parliament should protect the rights of citizens by detecting and preventing abuse of power, arbitrary behaviour and illegal or unconstitutional conduct by government.

In short, a parliament's role is to provide a check on the activity of government. The role might be thought of as providing "government by explanation". That is, highlighting issues of concern and ensuring that government is able to justify its actions to the public, or where that policy is deficient, forcing a change. The tools available to MPs to achieve these objectives vary from parliament to parliament, but they tend to be pursued through three main routes, namely via the plenary session (through questions and debates), the committee system (through investigations) or in conjunction with outside agencies that report to parliament.

It is in this last area where parliaments have the potential to be most effective in strengthening systems of domestic accountability. Parliaments derive much of their authority from the fact that a number of accountability institutions usually report to them. These range from the supreme audit institution, the ombudsman and the electoral commission, through to utility regulators, inspectorates and agencies. Such institutions provide a wealth of information on the performance of government in specific policy areas, and provide the evidence on which parliament can hold ministers, and ministries, to account.

In other words, parliaments should sit at the centre of a web of domestic accountability, liaising with the range of independent experts and institutions, absorbing the detail of their investigations and drawing out the salient political points for which the executive should be held to account.

Parliaments are therefore potentially vital allies for donor agencies in improving domestic accountability. Yet in many parts of the world legislatures have fallen far short of public (and donor) expectations. In emerging democracies, parliaments are frequently ineffective in the face of a powerful executive, and have little public legitimacy and authority. 


\section{Traditional international assistance to parliaments}

International support to parliaments has a poor record in improving parliamentary performance. In the last decade donors have placed greater emphasis on parliamentary assistance and there has been a much greater degree of co-ordination and lesson-learning amongst donor agencies. However, the approach taken to parliamentary support is still rather traditional. This approach can be grouped under three main headings:

1. Infrastructural support programmes, designed to improve institutional infrastructure and technical capacity. These stretch from the very basic provision of computers, audio recording equipment, and office furniture through to support for management systems, staff training and library and research services.

2. Procedural support, which relates to the powers and procedures of the institution. A lot of donor effort has been aimed at improving parliamentary procedures to develop an appropriate framework for both committees and plenary sessions, and in some cases, to extend the powers of parliament over legislation or scrutiny of the executive.

3. Functional approach, which is designed to improve MPs' ability to understand and perform their representative, legislative and oversight functions. Training and induction for MPs is a key feature of most support programmes and often is targeted at new members of parliament, covering aspects such as committee oversight, constituency service or legislative drafting and analysis.

The traditional approach to parliamentary support is essentially technical, and has suffered from three main problems. First, it relies on too superficial an analysis of the problems facing parliaments and has rarely understood the political, social and economic context within which they operate. As a result, too many programmes are built around generalisations and attempt to replicate the same programme in different countries, using unsuitable methods and inappropriate techniques.

Second, the approach reflects donor preferences for technical support to parliaments. Most donor agencies have traditionally been wary of being seen as interfering in the domestic politics of another sovereign nation. Parliamentary support is therefore highly sensitive if it seeks to improve the accountability of a dominant executive. Providing equipment, resources or training is, by contrast, much less controversial.

Third, as a result of the above, programmes tend to treat symptoms rather than causes. That is, focusing on a lack of resources, skills or planning 
frequently leads programmes to use them as identifiable outcomes. However, these tend to be signs of ineffectiveness rather than causes. Programmes might be better to start by asking why the skills or resources are absent.

The technical approach is based on the assumption that given the right structure and resources politicians will automatically behave in a way that ensures an effective parliamentary democracy. By providing more institutional resources, delivering training courses or changing the structure of the parliament, the hope is that MPs will spend more time on their core parliamentary functions - of scrutinising legislation, holding ministers to account and representing their constituents - and be more effective in each of them. In practice, of course, this has rarely, if ever, worked.

\section{The next phase of support to parliaments}

In every parliament there is a gap between the formal powers of the institution, and the willingness or ability of politicians to use those powers. The key to effective parliamentary assistance is to understand why that gap exists and to design programmes which seek to minimise it. From this perspective, the ultimate purpose of a support programme is not solely to change the structure of the institution, but to change the behaviour that goes on within it.

The EC's guide to parliamentary support, published at the end of 2010, tackles the causes of parliamentary underperformance. It sets out five categories of analysis to inform support programmes:

1. Constitutional power. If the parliament lacks formal powers within the constitution this is likely to indicate the need for a wider programme of political reform which reinforces parliamentary authority. If parliament's power is being curtailed because of the way the constitution is interpreted, this may offer more scope for intervention, but again would need to be couched in terms of a broader political programme.

2. Procedural clarity. A lack of clarity, inconsistency or contradictions in the parliamentary rules can be exploited by one party or group to undermine parliamentary effectiveness. This may require engagement with senior parliamentary figures (such as the Speaker) or the procedural committee in order to redraft sections of the rules. This can be a complex and highly-charged political process. Alternatively, it may be that the rules are being misinterpreted or not followed, which would suggest a need to build 
a common understanding of procedure amongst staff and members through training and parliamentary publications.

3. Capacity and resources. A lack of properly-trained staff or enough resources is likely to have an impact across parliamentary functions. This may simply require the provision of resources such as books, ICT or basic infrastructure. But it is also likely to rest on staff development, either recruiting more staff or building the technical skills of staff in areas such as parliamentary procedure, legislative drafting and financial oversight. At a more strategic level, it may mean working with parliamentary authorities on the development of a staff career structure within the parliament so that staff have an incentive to stay within the institution.

4. Experience and expectations. Where there is limited experience in the parliament (such as in a new democracy), a support programme may wish to build a parliamentary culture, common practice and acceptable standards of behaviour. This might include the development of an induction programme for new MPs or other forms of training; the establishment of a code of conduct for politicians and staff; and drawing on international experience to identify effective scrutiny techniques. Working with MPs on such goals is likely to be most effective if built around specific policy concerns (e.g. how to improve parliamentary involvement in poverty reduction strategy papers), rather than abstract concepts of "scrutiny". Mentoring by, or discussion with, politicians from similar parliaments may generate a common understanding of parliamentary role and function.

5. Politics. In many cases, especially where patron-client politics operate, certain interests are likely to dominate and distort parliamentary activity. Frequently, it is the governing party which will control the parliament. There may be a limited amount that parliamentary support projects can do in the short-term to address such deeply-entrenched factors. However, they should seek to build opportunities, structures and incentives for politicians to act as "parliamentarians", developing cross-party initiatives, rather than just as party politicians. For example, parliamentary committees provide the opportunity for MPs to work regularly across party boundaries, and to shape policy on that basis. Enhancing the impact and influence of committees may increase the desire of MPs to serve on them. But projects might also seek to loosen executive control over the parliamentary budget, key parliamentary appointments or the parliamentary timetable. 
Two key points flow from this analysis. The first is that support to a parliament has to suit the specific circumstances. That is, it needs to work from the position of the parliament within the overall system of domestic accountability, as well as examining the parliament's internal procedures, resources and operation. Second, changes in behaviour cannot be enforced from outside: they have to be owned by local partners. This means that the programme must start from a shared analysis of the challenges that the parliament faces. There must be some level of internal agreement within the parliament that it faces particular problems and, more importantly, that certain reforms or changes are the best way to rectify those problems. Programmes need to work with the incentive structures that exist within the parliament and gear them towards changes which strengthen the institution as a whole.

\section{Principles for parliamentary assistance}

The following principles are neither exhaustive nor comprehensive, but provide a possible starting point for guidance on parliamentary support projects:

1. Integrate objectives. Support to parliamentary institutions should be integrated with wider efforts to support domestic accountability. Given that parliaments could and should sit at the centre of a web of domestic accountability, the interaction among parliaments and other institutions should be a key feature of support programmes. Support programmes should seek to increase the extent to which parliaments engage with outside institutions (such as the supreme audit institution), and ensure that other programmes designed to strengthen other mechanisms of accountability feed into and strengthen the parliament.

2. Ensure institutional change leads to behavioural change. Ultimately, the effectiveness of the parliament will be determined by the behaviour of the individuals within it. The purpose of a support programme should ultimately be to change that behaviour so that parliamentarians understand their role in holding government to account, have the resources and capacity to use the relevant procedures effectively, but also have the incentive to perform their accountability function.

3. Understand the parliament's incentive structures. Many support programmes assume that all parliamentarians would like a stronger parliament and that donor assistance will inevitably be welcomed. This is rarely the case. A politician's attitude is likely to depend on a number of factors, including party allegiance, whether their party is 
in government or opposition, whether it affects their chances of re-election, and how it affects their working conditions and pay. Support programmes need to understand the various incentive structures within a parliament, how they are currently shaping political behaviour and how they might be used to generate cross-party backing for the initiative.

4. Don't ignore political parties. One of the strongest influences on behaviour in parliament will be the political parties. However, fears of "political interference" often discourage donors from engaging directly with parties. A stronger parliament will depend on politicians behaving as parliamentarians rather than simply party representatives. But, to encourage a less partisan role, programmes will need to understand and work with the political parties in parliament. Programmes should provide them with the opportunities and incentives to engage on a cross-party basis, without compromising donor neutrality. Promoting inter-party dialogue outside the parliamentary limelight is also an option for donors to strengthen co-operation, trust and confidence between political parties across the political spectrum.

5. Identify and address the causes of parliamentary weakness. Programmes must be clear about the underlying causes of the parliament's underperformance. It may be immediately apparent that the parliament is poor at financial oversight, but support projects need to assess whether this is to do with the parliament's constitutional position, its procedures, resources, experience or political complexion. Most often, it is a combination of several factors. Even if projects cannot address all of them, they need to identify and understand them in order to have an impact.

6. Ensure parliamentarians own the problems - and the solutions. Local ownership is a key tenet of the Paris Declaration on Aid Effectiveness (OECD, 2005), but is particularly significant in trying to foster political and behavioural change. Political change rests on the parliament recognising the benefits of adopting new patterns of behaviour and embedding them in the institutions, perhaps through rule changes or institutional reforms, so that they eventually become part of the accepted political culture. Given the complexity of getting change through a parliament, there should be 1) a widespread concern that parliament is underperforming; 2) crossparty agreement on the reasons for that weakness; and 3) some internal consensus that the project's objectives are the best way to address those problems. As such, parliamentary support projects 
need to be developed in partnership with key interlocutors within the institution, often politicians and staff.

7. Keep gender in mind in tackling parliamentary performance. The under-representation of women in political decision-making structures has implications at many levels. Evidence shows that more women in parliament not only affects the tone and culture of parliamentary debate, but also the range of issues that are debated. Support to parliamentary institutions should be conceived within this context. There are two distinct, but inter-related challenges. The first is to increase the number of women elected to national parliaments and promoting their influence within the institution. The second is to improve the impact of parliaments in developing policies that take into account their effect on women and men, and seek to address the imbalances that exist.

8. Design projects around outcomes rather than activities. Critically, programmes should maintain a clear sense of what they are designed to achieve. Too often this obvious point is lost during the lifetime of a project. The initial analysis of a parliament might identify areas where support should effect change (for example, the improvement of financial scrutiny) and the means for delivering this (providing training and support to MPs and staff, additional resources and the creation of a budget support office, etc.). But frequently process and outcomes are confused with one another, with donors measuring activities (e.g. the number of training sessions, existence of a budget office) instead of the impact they were originally designed to have. An outcome-driven approach would need a much greater degree of flexibility in the design and delivery of programmes, requiring co-ordinated interventions in different parts of the parliament, designed to achieve the same end.

9. Set realistic objectives and a realistic timescale. The conditions for achieving parliamentary change will vary between institutions, but donor-supported programmes need to work from the understanding that in most parliaments change will be haphazard and unpredictable, and that the interests of MPs will wax and wane over time. Parliaments are rarely amenable to neat designs or detailed reform plans, which has three implications for project design. First, it should not be assumed that specific activities will inevitably result in particular outcomes. Second, the scope for political change is often limited, and projects which seek discrete objectives will frequently be more effective than institution-wide reform. Third, political change happens slowly. At a Wilton Park conference in early 2010, one participant's comment resonated 
around the room when he begged the representative of a major donor organisation as follows: "What we need", he said, "is less money and more time."

10. Set the right indicators. Once indicators are in place they tend to determine subsequent project activity - with the wrong indicators, projects do the wrong things. Project objectives may lend themselves partly to quantitative measures, such as the number of bills passed, the number of committee reports published, the amount of public evidence compiled or the number of questions asked of ministers. However, these do not capture the quality of oversight or accountability. Much is likely to depend on a more thorough form of analysis which involves stakeholder perceptions of performance through interviews and opinion polling of the public, civil society, the media and special interest groups. This sort of monitoring and evaluation needs to be built in at project design stage, and should be a regular and on-going feature of parliamentary support programmes. From this perspective, peer-learning and South-South collaboration could be good mechanisms to directly involve stakeholders and build up owned evaluation processes and shared indicators.

11. Get the timing right. The timing of any project will be a key determinant of its success. For example, the best point to establish new ways of working is immediately after an election. At this point there is likely to be a large number of new MPs, the committees will have a new complexion and the government ministries they monitor are also likely to have changed personnel. Induction programmes should aim to establish new patterns of working and reinforce key principles. By the same token, working with MPs just before an election is likely to have very little effect, as most will be thinking about their election campaign - and many will not return.

\section{References}

OECD (2005), Paris Declaration on Aid Effectiveness, OECD Publishing, Paris.

Power, G. (2008), Donor Support to Parliaments and Political Parties: An Analysis Prepared for DANIDA, Global Partners and Associates, London. 


\section{Chapter 11}

\section{Principles for supporting developing countries in revenue matters}

These principles have been initiated by the OECD's Task Force on Tax and Development and drafted by the OECD's Tax and Development Secretariat. An initial draft was welcomed by GOVNET members, involving the African Tax Administration Forum, at a meeting in November 2011. Further drafts were well received by the Sub Group on State-building, Taxation and Aid in February 2012 and by the Task Force plenary in Cape Town in May 2012. The current version includes comments made at these events. The Task Force has also recognised the importance of testing and validating the principles in developing countries to ensure their relevance before seeking OECD Committee agreement. This set of principles is a living document and will be validated before being endorsed by the Committee on Fiscal Affairs and the DAC in 2013. 


\section{Preamble}

Revenue from taxation and customs provides governments with the funds needed to invest in development, relieve poverty and deliver public services; and the physical and social infrastructure required to enhance long-term growth. Strengthening domestic resource mobilisation is not just a question of raising revenue: it is also about designing a revenue system that promotes inclusiveness, encourages good governance, improves accountability of governments to their citizens, and cultivates social justice. Revenue system design and delivery is also closely linked to domestic and international investment decisions, including in terms of transparency, anti-corruption and fairness, as it may serve to improve the framework for attracting increased private investment.

Low-income countries face a number of challenges in increasing their revenue from domestic sources. These include a small tax base, a large informal sector, misuse of transfer pricing, low levels of per capita income, domestic savings and investment plus weak governance and capacity. Though many economies have made noticeable progress in revenue collection in the past decade, half of sub-Saharan African countries mobilise less than $17 \%$ of their GDP in tax revenues, below the minimum level considered by the UN as necessary to achieve the Millennium Development Goals. Several Asian and Latin American countries fare little better. Moreover, in Africa the increase has been primarily driven by resource-related tax revenues in oil-producing countries (OECD, 2010).

Developing countries and development partners have identified the mobilisation of domestic financial resources for development as a priority. This is the case, for example, in the Doha Declaration on Financing for Development (UN, 2009) and the Busan Partnership for Effective Development Co-operation (Fourth High Level Forum on Aid Effectiveness, 2011). The international development community is gearing up support to developing countries in the area of domestic resource mobilisation and taxation. The track record is not poor but performance could be improved, not least to keep up with the rapidly evolving policy environment, changing needs and new players.

The principles presented here are meant to enable developing countries to benefit from the G20-inspired era of transparency in international tax matters. They are anchored in the 2005 Paris Declaration on Aid Effectiveness (OECD, 2005) - with its commitments to ownership, harmonisation, alignment, results and mutual accountability - but they focus specifically on revenue matters. Based on the experience of different countries and recent research, the purpose of the principles is two-fold: 1) to offer guidance for international assistance providers - donor agencies, 
revenue authorities and finance departments - on how to approach revenue matters within developing countries; and 2) to provide a tool for developing countries in engaging with international partners to maximise the effectiveness of assistance for revenue issues. They can inform the design of new projects and activities, and over time be used to measure the changing behaviour of the main assistance providers and help them reflect on, and improve, their collective efforts to support domestic resource mobilisation in developing countries.

\section{The principles for international engagement in revenue matters}

- Follow the leadership of government and co-ordinate at the country level. Governments in developing countries are responsible for deciding their policy and administration needs for mobilising domestic resources for development. For their part, international assistance providers should operate according to the Paris Declaration commitments of ownership and alignment, and follow the lead of partner country governments. International partners should collaborate to ensure that their support including advice on tax policy, capacity development and training for revenue authorities and customs - is co-ordinated, delivered at the right time, appropriately sequenced and covers the various sources of revenue. International partners have the responsibility to organise their assistance in a harmonised way, with an agreed division of labour, using appropriate co-ordination and dialogue mechanisms in partner countries.

- Do no harm. International partners are responsible for ensuring that their actions do not damage the revenue prospects of developing countries. Fundamentally, this involves supporting the independence of revenue authorities to operate in accordance with their country's legal framework. It also involves being sensitive to local conditions when providing support, particularly in situations where there is a notable imbalance between the revenue collected from taxpayers and the public services citizens expect. Most donors acknowledge political will as the essential determinant of revenue system reform and of whether outsiders can help. In practice, a smarter approach is needed to ensure that support for reformers is in line with political realities. Political economy analysis can help determine opportunities for change. For instance, when a country confronts a fiscal crisis or political transition, such analysis can help to understand whether public and/or political support for reform might crystallise or fragment. In extreme cases, there is a risk that aid may dampen the tax effort in highly aid-dependent countries and distort accountability between governments and their citizens. 
- Take a whole-of-government approach to maximise policy coherence and aid effectiveness. Countries providing international assistance have a responsibility to ensure a coherent and co-ordinated national support approach to developing countries on revenue matters. This whole-ofgovernment approach should involve regular co-ordination among development, revenue and finance officials to maximise policy coherence. The various ministries can co-ordinate efforts on a broad range of issues, from helping to deliver technical assistance for capacity building in developing countries (in revenue authorities, tax policy and data analysis for example) through to assessing changes to their own policy (trade agreements for example) in light of the possible negative implications for developing countries, including any undue trade advantage. Ministries of finance in particular can require nationally-registered multinational enterprises operating in developing countries to improve transparency and fully comply with applicable tax laws, to contribute to the debate on the impact of non-co-operative jurisdictions on developing countries and to agree to spontaneous information sharing in international tax fraud cases. In addition, to maximise aid effectiveness, donor agencies should avoid taking a supply-driven approach and respond with a flexible and complementary mix of short and longer-term support (including technical assistance, policy dialogue, basket funds and general budget support) appropriate to each case. Regardless of the type of funding used, exit strategies should be in place and regularly reviewed.

- Take account of international aspects of taxation. Globalisation is creating new and complex international cross-border revenue challenges to which developing countries must respond. These include the taxation of multinational enterprises, international tax evasion, illicit financial flows, and facilitating cross-border flows while managing the associated risks. At the country level, international assistance providers can build on a reasonably strong track record of supporting domestic tax policy and revenue administration in developing countries to help build capacity in international tax policy, transfer pricing and exchange of information. Supporting North-South and South-South co-operation through regional organisations of revenue administrations such as the African Tax Administration Forum (ATAF) and the Inter-American Center of Tax Administrations (CIAT), can play a critical role in promoting the exchange of experience. At the international level, aid providers should work with developing countries to enhance their participation in fora where international revenue matters, norms and standards are debated and agreed. In particular, they can support developing countries' efforts to consider or join new instruments such as the Multilateral Convention on Mutual Administrative Assistance in Tax Matters which allows for exchange of tax information between countries. More broadly they can 
help them to prepare for the adjustments that accompany accession to the World Trade Organization and entering into free trade agreements.

- Balance revenue collection imperatives with fairness, equity and governance considerations. How revenue is collected matters as much as how much is collected. International support should aim to encourage compliance but avoid unwarranted coercion and an over targeting of the most easily taxed corporate entities based in capital cities. More broadly, international support should encourage consideration of the trade-offs between revenue imperatives, effective enforcement mechanisms and social and governance objectives. For example, taxation of the informal sector may be labour intensive but could drive broader governance objectives by linking more people and traders to the state. Equally, extending the geographical coverage of the state may be costly but could promote state legitimacy by furthering the reach of the state. International partners can also promote fairness and equity in revenue systems (through progressive taxation, or the mix of direct and indirect taxes, for example). Although taxation is not the panacea for reducing inequalities in income and wealth, perceptions of fairness mean that taxation is a key instrument for addressing this issue.

- Encourage transparency in revenue matters. Transparency in revenue matters can improve accountability and answerability in several key ways. At the country level, the public disclosure of revenue statistics and budgets can help to build accountability for taxes paid and public services delivered, strengthening the legitimacy of the state and the revenue authority. Encouraging transparency in granting and administering investment-related tax incentives (for example, tax holidays for multinational enterprises) is consistent with encouraging debate on tax simplification objectives and efforts to reduce discretionary decision making. At the international level, greater transparency can help to address issues such as misuse of transfer pricing. Transparent financial reporting by multinational enterprises can also help to improve tax compliance. For the sake of coherence, donor governments should be transparent in the technical assistance they provide to developing countries and move to make the exemptions they claim on aid-funded goods and services fully transparent, in line with the 2011 Busan Partnership for Effective Development Co-operation.

- Strengthen revenue and expenditure linkages. International assistance providers can reinforce the linkages between the revenue and expenditure sides of the public finance equation, strengthening accountability and policy dialogue. While the primary purpose of revenue collection is to fund the activities of government, especially economic and social 
development, the revenue and expenditure sides of the public finance equation are often treated separately. International assistance providers can promote linkages between the two by, for example, challenging corrupt practices, linking support in the revenue area with other public financial management reforms, reinforcing the role of audit institutions, bolstering parliamentary scrutiny over both revenue and expenditures and supporting non-state actors to monitor the effective use of public revenues. Given the increasing decentralisation in many countries, recognising the respective responsibilities and revenue sources available to national and sub-national governments is important. In addition, international assistance missions can analyse the distributional effects of tax and spending reforms, highlight how they achieve multiple objectives (including fiscal and poverty reduction), and encourage the communication of the impacts of such reforms.

- Promote sustainability in revenue collection systems. International support can play an important role in building sustainable national revenue systems in developing countries. Efforts to ensure sustainability start with careful consideration of the main sources of revenue available (natural resources, personal income tax and customs revenue, for example) and their respective weights in order to help strike a sustainable balance between revenue collection and public expenditures. In countries where revenue largely depends on taxation of personal income, factors that build taxpayer confidence and compliance, such as the quality of service delivery and governance, are particularly important. In countries with significant natural resources, international partners can encourage the sustainable tax treatment of such resources while encouraging good governance and social investments that build a relationship with citizens. In general, diversified, broad-based revenue systems linked to countercyclical fiscal policy better adapt to the volatility of revenue. International partners can also help make the links between taxation and broader issues of sustainability by considering environmental issues in national revenue systems for example.

- Encourage broad-based dialogue on revenue matters that includes civil society, business and other stakeholders. Combined local, national and global actions are critical to progress on revenue matters. Most international partner interventions focus, sometimes exclusively, on capacity-building efforts in revenue administrations in developing countries. This is important work, but some donors are also well-placed to engage other stakeholders in their efforts to participate in tax dialogue, to monitor the operations of revenue authorities, and to hold governments to account for their revenue and expenditure policies. Actions to support parliaments, civil society, labour unions, media, and business associations 
at the national and - in a context of increasing decentralisation - subnational levels can complement the efforts made to build revenue capacity. Such actions can strengthen the policy dialogue on national resource mobilisation and build broad coalitions for reform.

- Measure progress and build the knowledge base for revenue matters. Measuring progress on revenue matters is in the interest of all stakeholders. It can assess the effectiveness of developing country efforts and investments, and help international assistance providers to demonstrate the results of their assistance. Developing countries should lead the development of country-specific indicators for measuring progress, but with the support of development partners, including regional organisations. Although tax/GDP ratio is a valuable indicator for measuring overall progress over time, other indicators are also important. These include indicators on the tax effort, compliance, progressivity, ease of doing business, poverty reduction and perceptions of ordinary tax players. These all measure different aspects of revenue progress and permit both developing countries and international partners to move beyond narrow revenue collection targets to include other governance and social objectives. The development and use of harmonised diagnostic and monitoring tools should be encouraged. In addition, international providers should build on existing efforts to ensure that externally-funded interventions are evaluated and lessons are shared for use at both the country and international levels.

Note

1. A report by the international organisations mandated by the $\mathrm{G} 20$ to support the development of more effective tax systems.

\section{References}

Fourth High Level Forum on Aid Effectiveness (2011), The Busan Partnership for Effective Development Co-operation, outcome document of the Fourth High Level Forum on Aid Effectiveness, Busan, Korea, 29 Nov-1 Dec, available at www.aideffectiveness.org/busanhlf4/images/stories/hlf4/OUTCOME_D OCUMENT_-_FINAL_EN.pdf

OECD (2005), Paris Declaration on Aid Effectiveness, OECD Publishing, Paris.

OECD (2010), African Economic Outlook 2010, OECD Publishing, Paris. 
UN (United Nations) (2009), Doha Declaration on Financing for Development, The final text of agreements and commitments adopted at the Follow-up International Conference on Financing for Development to Review the Implementation of the Monterrey Consensus, Doha, Qatar, 29 November-2 December 2008, available at www.un.org/esa/ffd/doha/documents/Doha_Declaration_FFD.pdf 


\section{Annex $A$ \\ Recommendations from case studies in Mali, Mozambique, Peru and Uganda}

This annex summarises key conclusions and recommendations drawn from each case study (Mali, Mozambique, Peru and Uganda). These will help provide practical ideas to guide future programming and in-country implementation to accountability.

\section{Insights from Mali: Improving accountability support to education and decentralisation}

The Mali case study focused on aid and accountability in the budget cycle, decentralisation process and the delivery of education services. The study found that for the most part, many opportunities for linking accountability institutions have been overlooked. Donors continue to provide targeted support to specific institutions, rather than grouping accountability actors to strengthen "communities" of accountability. There is a lack of understanding about what accountability means, and of the different roles and responsibilities of state and non-state actors in the accountability landscape. As a result, the impact is still unclear and monitoring of accountability is difficult to grasp. This is particularly poignant in Mali, where informal accountability actors and traditional norms are particularly strong, silently shaping power structures and behaviour.

Nevertheless, the Mali case offers innovative and important lessons in how development partners can foster co-ordination and partnership among different accountability actors. Key recommendations include:

- Build citizen demand in the decentralisation process by taking a long-term transformational view, bringing together civil society, communal authorities, local state services and Regional Assemblies. Empowering citizens to be heard in the decision-making process requires a long-term, context-sensitive approach and consideration 
of the traditional, cultural environment that inevitably shapes Mali's governance system.

- Mix top-down and bottom-up approaches: donors should continue to use a bottom-up approach to develop capacity and foster trust between citizens and elected officials at the local level. At the same time, it is important for donors to work at the centre and national level where ministries develop policies and where the legal framework can be influenced to create a more enabling environment for accountability.

- Link and mix aid approaches: there is a clear role for budget support in Mali, but this should be structured using disbursement indicators of accountability practices. However, budget support is not enough for building capacity and institutional change - these are better served by project aid and technical assistance.

- Work with national financial systems rather than around them: the introduction by donors of special procedures to ensure adequate financial management of the Agence nationale d'investissement des collectivités territoriales (ANICT) has weakened internal accountability. Instead of asking government to use exceptional budget procedures, donors should look to strengthen those financial systems and institutions believed to be the weak points in the programming and expenditure chains.

- Integrate accountability measures into monitoring and evaluation systems: Public perception surveys can be one important source of information to measure the demand side of accountability and the responsiveness of public services. Another useful tool is the PGP's local governance capacity index: a participatory score card with which citizens and local councillors can assess local government performance against a clear set of criteria with concrete indicators. The results help develop a common vision of success, inform capacity development needs and set steps for action.

- Clarify the institutional accountability framework: Mali has numerous external accountability institutions, but their roles, responsibilities and linkages are at times unclear. This makes it difficult to enforce anti-corruption measures and address accountability concerns, despite efforts from the government to make information publicly available. 
- Assess and take stock of legal accountability mechanisms in order to better use them: Spaces of accountability do exist, such as city hall audit sessions in the collectivités territoriales. However, CSOs and others rarely attend, partly due to a lack of understanding of the legal recourse available to them. Taking stock of all legal texts would allow CSOs to better target their advocacy for and control of public action.

\section{Insights from Mozambique: Improving accountability support in budgeting and health}

The research in this case study was dedicated to accountability in the budget cycle and health sector. Like many countries with a high dependence on foreign aid, there are concerns that the government's accountability to its donors trumps its responsibility to domestic stakeholders. Trust, political pluralism and inclusiveness are gradually eroding, with past elections giving rise to violent conflict. In addition, the distinction between state and political party is not always clear, raising perceptions of political discrimination within the civil service. Analysts are concerned that the space for political dialogue is usurped by donors' increasing role in sector-based working groups and general budget support (GBS) reviews. Donors need to recognise the impact of GBS on the country's political economy and work towards transforming the aid dialogue into a unique platform to bring civil society and parliamentarians to challenge policies and hold government to account. Key recommendations include:

- Balance performance assessment frameworks (PAFs) between donors and governments, and extend them beyond PAPs to include vertical funds and non-DAC donors. This requires changes in the behaviour and practices of international partners and increased confidence and capacity within government to use PAFs and to take the lead in co-ordinating aid.

- Empower parliament and civil society to participate in the aid dialogue and play more important roles in calling both government and donors to account. For example, donors should provide civil society organisations with types of aid and grants that enable them to fulfil their accountability roles and optimise their place and specific functions in Mozambican society.

- Recognise the power and political dimensions of each type of aid. GBS has a significant impact on the state's ability to respond to citizen needs, but is not the only aid modality available. Understanding patronage systems within the state structure could 
help donors shape their country programmes and balance the accountability impacts of each aid modality.

- Do more to strengthen how information is provided, analysed and acted upon. Local councils are an important mechanism for transparency in Mozambique, but they require more support to be able to provide citizens with accessible and understandable information on local services, plans and budgets. By working with local councils and assemblies, CSOs could help citizens access more information and improve the flow of questions and answers between them and the government.

- Strengthen Mozambique's numerous dialogue and consultation platforms so they become accountability mechanisms for building trust and common understanding among state representatives, local government officials, parliamentarians and citizens. The Development Observatories, for example, could become accountability structures with clear rules for engagement between state and non-state actors so that government not only consults, but also responds to citizens.

- Increase political dialogue and programmes to support political parties to create a more level playing field for political parties. In addition, the separation of party and state is an important part of an accountability system. The African Peer Review Mechanism review notes that recruitment in the public sector needs to be more meritbased and apolitical (APRM, 2009).

- Ensure civil society organisations engage with government and stop working in isolation on discrete projects. This increases the risk of duplication. By developing better co-operation and more aligned action plans, CSOs could increase their impact as accountability actors and promote a more critical and constructive dialogue.

\section{Insights from Peru: Improving accountability support in budgeting and child nutrition}

The Peru case study examined the role of donors in promoting domestic accountability through the budget cycle and the health sector. Peru benefits from strong laws and mechanisms to support accountability, including its transparency and access to information (TAI) laws, participatory spaces and a strong Defensoría (ombudsperson). But these institutions have had limited success in practice, particularly at the local level. The majority of donor support focuses on activities like helping public agencies publish more 
information on their websites (to comply with the TAI), but do little to combat local-level realities. Donors have had success in using reporting and procurement mechanisms to generate a culture of accountability and in supporting domestic reform movements and reform-minded state actors. Future challenges include respecting the decentralisation process in the selection of partners and working through country systems. Key recommendations include:

- Move beyond one-actor support and increase the systems-wide approaches some donors are already implementing. Use leverage with state actors to encourage a better engagement by the state with its citizens. In particular, improve support to how state entities respond to recommendations made by the two control entities, the Defensoría and the Contraloría.

- Expand support for missing actors as part of a systemic approach. Support to Congress should be increased, especially as part of a greater focus on horizontal accountability. Civil society and the media are also under-supported. Overall a greater emphasis on the demand-side of accountability is needed. This means developing citizenship and combating political apathy as important foundations upon which later accountability work can build.

- See "harmonisation" as not only about co-ordination among donors, but also about co-ordination among donors and other state and civil society actors. Identify domestic actors already engaged in change practices and use donor leveraging, capacity and resources to increase their success.

- Focus energies not only on how laws are written but also on how laws are implemented, especially at the decentralised level. This includes recognising the great diversity in terms of language, culture, and access that exists between one community and another, and encouraging state actors to do the same. Overall, focus more on "enforceability".

- Respect the decentralisation process and the areas of responsibility of different government levels when choosing partnerships with state actors. Continue to co-ordinate with the national level but enter into direct relationships with regional and local actors, recognising the areas in which they have autonomy to operate and the control they should exercise over decision making within their locality. 
- Improve donor co-ordination in the specific area of accountability. The Peru case shows relatively high donor co-ordination within sectors, but little co-ordination around the specific issue of accountability. Donors seem to treat accountability as a cross-cutting issue, but this requires more donor co-ordination mechanisms and strategic impetus if it is to have a real impact.

- Promote the continued use of other types of aid, such as basket funding and direct budget support. Basket funding in Peru and the donor co-ordination it promotes is improving the impact of work to strengthen a key accountability institution. Direct budget support has involved establishing specific accountability mechanisms, such as regulations for the transfer of funds. These seem to be responsible for the ability of this type of aid to promote accountability. The funding is also widely seen as providing an "extra" to reform-minded state actors who are pushing for accountability on their own.

- Recognise the growing role of private firms as development actors and include them in co-ordination mechanisms. Expanding the use of donor-private sector partnerships is one harmonisation option. Similarly, NGOs receiving private foundation funding are also very prevalent in Peru and should also be included in harmonisation efforts.

\section{Insights from Uganda: Improving accountability support in budget processes and service delivery}

This study explored aid and accountability in Uganda's health sector and budget process. Findings suggest that accountability does work as a system around budget processes and service delivery. For budget processes and the health sector alike, there have been significant improvements made to the capacities and capabilities of some key actors - including the Office of the Auditor General (OAG), the Ministry of Finance, Planning and Economic Development (MoFPED), the Public Accounts Committee in Parliament, and CSOs. However, donors supporting accountability in Uganda have tended to work in isolation and focus on specific accountability areas (such as public financial management, citizens' voice, elections) and particular actors (state or non-state). This approach does not always take account of the wider system, or facilitate links between actors or the sharing of information. Adopting a systems-approach does not, however, necessarily mean providing support in a single, unified programme - instead it means ensuring a systems-wide analysis and then supporting links between actors and areas of support, where feasible. Transparency and access to 
information continue to lie at the heart of aid and accountability issues. Key recommendations include:

- Conduct a "systems-wide analysis" to gain a more realistic understanding of the "reform space" for key aspects of accountability, including the role of donors and aid flows. Looking at the dynamics and links among accountability actors would improve engagement with the local reality and the incentives at work, instead of approaching reform with fixed, ideal models. Understanding how aid flows and modalities can shape and weaken citizen-states relationships, notably by excluding to some extent a strong fiscal contract, is crucial.

- Foster collaboration and co-ordination among donors, governmental institutions, and accountability actors (political parties, the media and CSOs) as well as professional associations to identify entry points for reform and strengthen reporting processes, availability and sharing of information, especially budget information with the Parliamentary Budget Office.

- Understand the diversity of budget aid and its implications for accountability. There is an increasing diversity in the types of both on-budget and off-budget aid. Particular challenges, especially in the health sector, are posed by high levels of off-budget aid. One possible solution is to require support for recurrent expenditures on service delivery inputs (which are particularly problematic if provided intermittently) to be funded through either general budget support or sector budget support. Project support would then be channelled towards one-off expenditures such as constructing infrastructure (though not recurrent maintenance). This would ease some of the constraints posed by volatile aid flows, in a context where project aid is likely to continue to be an important part of the aid landscape.

- Refocus support so that it does not encourage the "projectisation of accountability", but instead treats it as a process in which multiple actors need to interact. To aid in this process, donor support could be tailored to encourage collaboration and reduce competition among actors, in particular among CSOs. This could involve changes to funding modalities and support to develop common standards and approaches to monitoring. 


\section{References}

African Peer Review Mechanism (APRM) (2009), Country Review ReportRepublic of Mozambique, APR Secretariat, South Africa. 




\section{ORGANISATION FOR ECONOMIC CO-OPERATION AND DEVELOPMENT}

The OECD is a unique forum where governments work together to address the economic, social and environmental challenges of globalisation. The OECD is also at the forefront of efforts to understand and to help governments respond to new developments and concerns, such as corporate governance, the information economy and the challenges of an ageing population. The Organisation provides a setting where governments can compare policy experiences, seek answers to common problems, identify good practice and work to co-ordinate domestic and international policies.

The OECD member countries are: Australia, Austria, Belgium, Canada, Chile, the Czech Republic, Denmark, Estonia, Finland, France, Germany, Greece, Hungary, Iceland, Ireland, Israel, Italy, Japan, Korea, Luxembourg, Mexico, the Netherlands, New Zealand, Norway, Poland, Portugal, the Slovak Republic, Slovenia, Spain, Sweden, Switzerland, Turkey, the United Kingdom and the United States. The European Union takes part in the work of the OECD.

OECD Publishing disseminates widely the results of the Organisation's statistics gathering and research on economic, social and environmental issues, as well as the conventions, guidelines and standards agreed by its members.

\section{DEVELOPMENT ASSISTANCE COMMITTEE}

To achieve its aims, the OECD has set up a number of specialised committees. One of these is the Development Assistance Committee (DAC), whose mandate is to promote development co-operation and other policies so as to contribute to sustainable development -including pro poor economic growth, poverty reduction and the improvement of living standards in developing countries - and to a future in which no country will depend on aid. To this end, the DAC has grouped the world's main donors, defining and monitoring global standards in key areas of development.

The members of the DAC are Australia, Austria, Belgium, Canada, the Czech Republic, Denmark, the European Union, Finland, France, Germany, Greece, Iceland, Ireland, Italy, Japan, Korea, Luxembourg, the Netherlands, New Zealand, Norway, Poland, Portugal, the Slovak Republic, Slovenia, Spain, Sweden, Switzerland, the United Kingdom and the United States.

The DAC issues guidelines and reference documents in the DAC Guidelines and Reference Series to inform and assist members in the conduct of their development co-operation programmes. 


\section{DAC Guidelines and Reference Series}

\section{Accountability and Democratic Governance ORIENTATIONS AND PRINCIPLES FOR DEVELOPMENT}

Contents

Executive summary

Part I Orientations on development co-operation, accountability and democratic governance

Chapter 1. The role of accountability in promoting good governance

Chapter 2. Considering the political dimension, getting traction and achieving results

Chapter 3. Taking a systems-wide approach to accountability in developing countries

Chapter 4. Ensuring development co-operation helps rather than hinders accountability

Chapter 5. Conclusions and strategic orientations to improve support to accountability

Part II Principles for assistance to accountability actors and institutions:

Elections, political parties, the media, parliament and revenue matters

Chapter 6. Introduction to principles for assistance to accountability

Chapter 7. Principles for international electoral assistance

Chapter 8. Principles for political party assistance

Chapter 9. Principles for media assistance

Chapter 10. Principles for parliamentary assistance

Chapter 11. Principles for supporting developing countries in revenue matters

Annex A. Recommendations from case studies in Mali, Mozambique, Peru and Uganda

Consult this publication on line at $\boldsymbol{h t t p : / / d x . d o i . o r g / 1 0 . 1 7 8 7 / 9 7 8 9 2 6 4 1 8 3 6 3 6 - e n .}$

This work is published on the OECD iLibrary, which gathers all OECD books, periodicals and statistical databases.

Visit www.oecd-ilibrary.org for more information.

OECDpublishing

www.oecd.org/publishing
ISBN 978-92-64-18362-9

$432012181 \mathrm{P}$

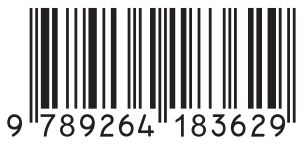

